\title{
Herpetofauna da Serra do Brigadeiro, um remanescente de Mata Atlântica em Minas Gerais, Sudeste do Brasil
}

\author{
Mário Ribeiro Moura ${ }^{1,2,3}$, Ana Paula Motta ${ }^{2}$, Vitor Dias Fernandes ${ }^{2}$ \& Renato Neves Feio ${ }^{2}$ \\ ${ }^{1}$ Ecos Biota Consultoria Ambiental, Rua Senador Vaz de Melo, 64/40, CEP 36570-000, Viçosa, MG, Brasil \\ ${ }^{2}$ Museu de Zoologia João Moojen, Departamento de Biologia Animal, \\ Universidade Federal de Viçosa - UFV, Vila Gianetti, 32, CEP 36570-000, Viçosa, MG, Brasil \\ ${ }^{3}$ Autor para correspondência: Mário Ribeiro Moura, e-mail: mario.moura@ecosbiota.com.br
}

\begin{abstract}
MOURA, M.R., MOTTA, A.P., FERNANDES, V.D. \& FEIO, R.N. Herpetofauna from Serra do Brigadeiro, an Atlantic Forest remain in the state of Minas Gerais, Southeastern Brazil. Biota Neotrop. 12(1): http:// www.biotaneotropica.org.br/v12n1/en/abstract?inventory+bn01012012012
\end{abstract}

\begin{abstract}
We present a list of amphibians and reptiles from northern region of the Serra da Mantiqueira mountain range, under local name Serra do Brigadeiro mountain. This region comprehends an Atlantic Forest remain with emphasis at the Serra do Brigadeiro State Park, a conservation unit with approximately 15,000 ha which the boundaries are included at the municipalities of Araponga, Divino, Ervália, Fervedouro, Miradouro, Muriaé, Pedra Bonita and Sericita, all in the state of Minas Gerais, southeastern Brazil. Throughout complementary methods as pitfall traps and local collectors, besides other conventional methods as visual and auditive surveys, occasional encounters and scientific collection records, the present list broaden the knowledge on herpetofauna on this region. We recorded 98 herpetofauna species, being 57 anurans, one gymnophiona, nine lizards, one amphisbenian, 29 snakes, and one turtle. Although amphibian species registered were not considered threatened of extinction in Minas Gerais, Brazil or by IUCN, 11 species (18.96\%) are considered Data Deficient. There is a high number of species endemic to Atlantic Forest (46.55\%) or with restricted distribution (20.68\%). Is worth noting the registers of the frogs Gastrotheca ernestoi and Megaelosia apuana, respectively the first and second registers of these genus for Minas Gerais. The caecilian Luetkenotyphlus brasiliensis is also rediscovered. Among reptiles, can be highlighted the presence of the freshwater turtle Hydromedusa maximiliani, which appears as vulnerable in the red lists of Minas Gerais and in IUCN. Sixty percent of the reptiles encountered are widely distributed in the Atlantic Forest, and the presence of the snakes Echinanthera melanostigma and E. undulata are important as, respectively, the second and third records for Minas Gerais.

Keywords: amphibian, reptiles, geographic distribution, Mantiqueira mountain range, Serra do Brigadeiro State Park.
\end{abstract}

MOURA, M.R., MOTTA, A.P., FERNANDES, V.D. \& FEIO, R.N. Herpetofauna da Serra do Brigadeiro, um remanescente de Mata Atlântica em Minas Gerais, Sudeste do Brasil. Biota Neotrop. 12(1): http://www. biotaneotropica.org.br/v12n1/pt/abstract?inventory+bn01012012012

Resumo: Apresentamos uma lista de anfíbios e répteis de uma região ao norte do complexo serrano da Mantiqueira, sob denominação local de Serra do Brigadeiro. Esta região compreende um remanescente de Mata Atlântica com destaque para o Parque Estadual da Serra do Brigadeiro, unidade de conservação com aproximadamente 15 mil ha nos municípios de Araponga, Divino, Ervália, Fervedouro, Miradouro, Muriaé, Pedra Bonita e Sericita, estado de Minas Gerais, sudeste do Brasil. Através da adoção de métodos complementares como o uso de armadilhas de interceptação e queda e postos de coleta, além de métodos convencionais de busca ativa, encontros ocasionais e registros em coleção científica, a presente lista amplia o conhecimento sobre a herpetofauna dessa região. Nós registramos 98 espécies da herpetofauna, sendo 57 de anuros, um gimnofiono, nove lagartos, uma anfisbênia, 29 serpentes e um quelônio. Embora nenhuma espécie de anfíbio encontrada seja considerada ameaçada de extinção em Minas Gerais, no Brasil ou pela IUCN, 11 espécies $(18,96 \%)$ são consideradas como Deficiente de Dados. Verifica-se um alto número de espécies exclusivas da Mata Atlântica (46,55\%) ou de distribuição restrita (20,68\%). Destaca-se o encontro da perereca Gastrotheca ernestoi e a rã Megaelosia apuana, respectivamente o primeiro e segundo registro desses gêneros para Minas Gerais. A cecília Luetkenotyphlus brasiliensis também é redescoberta. Entre os répteis, pode-se destacar a presença do cágado Hydromedusa maximiliani, que aparece como vulnerável nas listas vermelhas de Minas Gerais e da IUCN. Sessenta por cento das espécies de répteis apresentam ampla distribuição na Mata Atlântica, e a presença das serpentes Echinanthera melanostigma e E. undulata, são importantes como, respectivamente, o segundo e terceiro registro dessas espécies para Minas Gerais.

Palavras chave: anfíbios, répteis, distribuição geográfica, Serra da Mantiqueira, Parque Estadual da Serra do Brigadeiro. 


\section{Introdução}

Atualmente, são registradas no mundo mais de 6770 espécies de anfíbios e 9400 espécies de répteis (Frost 2011, Uetz et al. 2011). Estes grupos são responsáveis por importantes funções no equilíbrio e manutenção dos ecossistemas, ao atuarem como presas e predadores tanto de vertebrados como de invertebrados (Cadle \& Greene 1993, Pough et al. 2003, Eterovick \& Sazima 2004, Sabino \& Prado 2006). O Brasil destaca-se mundialmente pela alta diversidade de sua herpetofauna, possuindo mais de 870 espécies de anfíbios (Sociedade... 2010) e 730 espécies de répteis (Bérnils \& Costa 2011).

O domínio da Mata Atlântica é reconhecido mundialmente pela elevada riqueza de espécies, considerado um hotspot para conservação da biodiversidade (Myers et al. 2000, Mittermeier et al. 2004). Localizado em uma das regiões mais populosas do Brasil, este bioma sofreu intensa redução de sua cobertura original, resultante principalmente da perda de habitats naturais, proporcionada pela ação humana ao longo das últimas décadas. Hoje, restaram menos de $8 \%$ de sua cobertura original (Fundação... 2008), sendo que apenas $1 \%$ desta encontra-se inserida em áreas protegidas (Laurance 2009). Em geral, os estudos com anfíbios e répteis realizados na Mata Atlântica de Minas Gerais contemplam as regiões serranas dos complexos da Mantiqueira e do Espinhaço, acima de $1.000 \mathrm{~m}$ de altitude (Nascimento et al. 2005, 2009, Bérnils et al. 2009). Entre os estudos herpetofaunísticos realizados no complexo serrano do Espinhaço, destacam-se aqueles das regiões da Serra do Caraça (Canelas \& Bertoluci 2007, Baêta \& Silva 2009), Serra do Rola Moça (Nascimento et al. 1994), Serra do Cipó (Assis 1999, Eterovick \& Sazima 2004), região de Ouro Preto (Pedralli et al. 2001), Estação de Pesquisa e Desenvolvimento Ambiental de Peti, Santa Bárbara (Bertoluci et al. 2009), Serra do Ouro Branco (São-Pedro \& Pires 2009, São-Pedro \& Feio 2010, 2011) e região de Ouro Preto (Silveira et al. 2010). Para o complexo serrano da Mantiqueira podemos citar os trabalhos realizados nas regiões da Serra do Ibitipoca (Cruz et al. 2009), Serra do Caparaó (Rodrigues et al. 2009), Serra do Papagaio (Santos et al. 2009, Tolledo et al. 2009), Serra Negra (Oliveira et al. 2009) e Serra do Brigadeiro (Santos 2003, Eterovick \& Ferreira 2008, Feio et al. 2008a, Assis 2009, Lacerda et al. 2009a). Contudo, estudos básicos de inventário ainda são escassos, mesmo para regiões localizadas próximas aos principais núcleos de pesquisas herpetológicas do estado (Nascimento et al. 2009). A situação é menos favorável ainda para o grupo dos répteis, uma vez que a maioria dos estudos publicados aborda principalmente as comunidades de anfíbios, com pouca ou nenhuma informação sobre a composição de répteis dessas regiões. Em sua maioria, os trabalhos com répteis em Minas Gerais constituem-se em notas isoladas de história natural ou distribuição geográfica (e.g. Cassimiro 2003, Costa et al. 2008, 2009b, Evers-Junior. et al. 2006, Silveira 2004, 2008, Silveira et al. 2004a,b,c, Moura et al. 2010, Costa 2011). Desta forma, diversas áreas em Minas Gerais ainda carecem de dados básicos de inventários faunísticos para anfíbios ou répteis (Bérnils et al. 2009, Nascimento et al. 2009), e muitas das localidades já investigadas foram subamostradas, sendo necessários trabalhos mais completos para caracterização da fauna encontrada (Rodrigues 2005, Silvano \& Segalla 2005).

Embora a diversidade existente no estado seja muito elevada, o conhecimento atualmente disponível atualmente contempla apenas uma parcela desse patrimônio (Drummond et al. 2009). Com o objetivo de ampliar o conhecimento sobre a diversidade da herpetofauna da Mata Atlântica na região norte do complexo serrano da Mantiqueira, apresentamos aqui a lista das espécies de anfíbios e répteis registradas para a região da Serra do Brigadeiro, Minas Gerais, sudeste do Brasil.

\section{Material e Métodos}

\section{1. Área de estudo}

A Serra do Brigadeiro configura-se como um remanescente de Mata Atlântica inserido na porção norte do conjunto serrano da Mantiqueira. Encontra-se inserida em uma área prioritária para conservação da biodiversidade, definida como de "importância especial" para conservação de anfíbios e répteis no estado de Minas Gerais (Drummond et al. 2005). Com elevações que chegam a 1985 m de altitude, a Serra do Brigadeiro constitui-se em divisor de águas entre as bacias dos rios Doce e Paraíba do Sul. A região se destaca como um dos maiores fragmento de Mata Atlântica do estado, sendo o Parque Estadual da Serra do Brigadeiro (PESB) $\left(20^{\circ} 43^{\prime} \mathrm{S}\right.$ e $\left.42^{\circ} 29^{\prime} \mathrm{O}\right)$ importante unidade de conservação com 14.984 ha que abrange porções dos municípios de Araponga, Divino, Ervália, Fervedouro, Miradouro, Muriaé, Pedra Bonita e Sericita. A vegetação do PESB é composta por floresta estacional semidecidual, de formação altomontana, com campos de altitude ocupando os platôs e as escarpas isoladas em algumas áreas acima da cota de $1600 \mathrm{~m}$ (Veloso et al. 1991). O clima da região pode ser classificado como do tipo mesotérmico médio (Cwb) (Köppen 1948), com precipitação média anual de $1300 \mathrm{~mm}$ e temperatura média anual de $18{ }^{\circ} \mathrm{C}$ (Engevix 1995).

Devido a sua grande extensão latitudinal, optamos pela definição de três principais setores amostrais ao longo da Serra do Brigadeiro, nas áreas norte, central e sul da serra (Tabela 1, Figura 1). No setor norte seis ambientes foram amostrados, sendo trilhas no interior de matas, brejos e poças temporárias, riachos, afloramentos rochosos e formações de campos de altitude. No setor amostral central foram amostradas 12 localidades, entre elas áreas com presença de vários corpos d'água lênticos (temporários e permanentes) e com diversos riachos e córregos em áreas abertas e no interior de mata. É nesse setor que se encontra a sede administrativa do PESB (20 $43^{\prime} \mathrm{S}$ e $\left.42^{\circ} 29^{\prime} \mathrm{O}\right)$, com os melhores acessos, e consequentemente, maior amostragem. Por fim, no setor sul foram amostrados cinco localidades, sendo estas uma poça temporária localizada no interior da mata e riachos no interior de mata e áreas abertas. Outros ambientes aquáticos lênticos e lóticos também foram amostrados em expedições não padronizadas em todos os setores amostrais.

\section{Amostragem da herpetofauna}

Devido a questões logísticas, os esforços de amostragem nos três principais setores não foram padronizados. A amostragem da herpetofauna se deu por métodos usuais de busca ativa (BA), encontro ocasional (EO), armadilhas de interceptação e queda (AIQ), postos de coleta (PC), registro visual (RV), e levantamentos em coleções científicas (CC). Espécies não encontradas no presente estudo, mas presentes em trabalhos anteriores também são apresentadas no intuito de compilar a literatura disponível sobre a herpetofauna da Serra do Brigadeiro (e.g. Feio et al. 1999, 2000, 2008a, Santos 2003, Assis 2009).

Para a amostragem da herpetofauna no setor central do PESB foram utilizadas armadilhas de interceptação e queda com uso de cercas guias (cf. Cechin \& Martins 2000). Foram selecionadas quatro localidades situadas próximas a lagoas e poças temporárias para instalação das armadilhas. Em cada uma delas, foram instaladas cinco linhas de armadilhas, cada uma das trilhas composta por quatro baldes de $35 \mathrm{~L}$, conectados por $12 \mathrm{~m}$ de cerca-guia com $50 \mathrm{~cm}$ de altura, totalizando 80 baldes. A coleta de dados em armadilhas de queda foi realizada mensalmente durante quatro dias consecutivos, entre setembro de 2009 e agosto de 2011, com exceção para o mês de dezembro de 2009 no qual foram realizados 10 dias de coleta, 
Tabela 1. Pontos de amostragem no Parque Estadual da Serra do Brigadeiro e entorno.

Table 1. Sampling stations in the Serra do Brigadeiro State Park and surroundings.

\begin{tabular}{|c|c|c|}
\hline Ponto de amostragem & Características & Coordenadas \\
\hline Brejo da Vaca Morta ${ }^{N}$ & $\begin{array}{l}\text { Ambiente brejoso antropizado, com vegetação } \\
\text { arbustiva e arbórea no entorno }\end{array}$ & $20^{\circ} 36^{\prime} 22^{\prime \prime} \mathrm{S} ; 42^{\circ} 24^{\prime} 34^{\prime \prime} \mathrm{O}$ \\
\hline Trilha do Córrego do Ouro ${ }^{N}$ & $\begin{array}{l}\text { Transecção através de um longo trecho de mata } \\
\text { com serapilheira abundante }\end{array}$ & $20^{\circ} 38^{\prime} 05^{\prime \prime} \mathrm{S} ; 42^{\circ} 24^{\prime} 54^{\prime \prime} \mathrm{O}$ \\
\hline Laje do Ouro ${ }^{\mathrm{N}}$ & $\begin{array}{c}\text { Ambientes formados por cachoeiras em afloramentos } \\
\text { rochosos de campos rupestres }\end{array}$ & $20^{\circ} 38^{\prime} 40^{\prime \prime} \mathrm{S} ; 42^{\circ} 25^{\prime} 01^{\prime \prime} \mathrm{O}$ \\
\hline Riacho norte $^{\mathrm{N}}$ & Ambiente lótico no interior de mata & $20^{\circ} 38^{\prime} 48^{\prime \prime} \mathrm{S} ; 42^{\circ} 24^{\prime} 57^{\prime \prime} \mathrm{O}$ \\
\hline Pico do Soares ${ }^{N}$ & $\begin{array}{l}\text { Formações de campos de altitude, o ponto mais } \\
\text { alto do PESB com elevação máxima de } 1985 \mathrm{~m}\end{array}$ & $20^{\circ} 39^{\prime} 20^{\prime \prime} \mathrm{S} ; 42^{\circ} 25^{\prime} 00^{\prime \prime} \mathrm{O}$ \\
\hline Brejo norte $\mathrm{N}^{\mathrm{N}}$ & Ambiente brejoso no interior de mata & $20^{\circ} 38^{\prime} 04^{\prime \prime} \mathrm{S} ; 42^{\circ} 24^{\prime} 52^{\prime \prime} \mathrm{O}$ \\
\hline Brejo central $01^{\mathrm{C}}$ & Ambiente brejoso no interior de mata & $20^{\circ} 42^{\prime} 47^{\prime \prime} \mathrm{S} ; 42^{\circ} 29^{\prime} 16^{\prime \prime} \mathrm{O}$ \\
\hline Brejo central $02^{\mathrm{C}}$ & Ambiente brejoso na borda de mata & $20^{\circ} 43^{\prime} 22^{\prime \prime} \mathrm{S} ; 42^{\circ} 28^{\prime} 40^{\prime \prime} \mathrm{O}$ \\
\hline Brejo central $03^{\mathrm{C}}$ & Ambiente brejoso em área aberta & $20^{\circ} 43^{\prime} 33^{\prime \prime} \mathrm{S} ; 42^{\circ} 26^{\prime} 04^{\prime \prime} \mathrm{O}$ \\
\hline Lagoa do Cruzeiro $^{\mathrm{C}}$ & Poça temporária no interior de mata & $20^{\circ} 43^{\prime} 18^{\prime \prime} \mathrm{S} ; 42^{\circ} 28^{\prime} 43^{\prime \prime} \mathrm{O}$ \\
\hline Lagoa do Baiano $^{\mathrm{C}}$ & Poça temporária em área aberta & $20^{\circ} 43^{\prime} 14 ” \mathrm{~S} ; 42^{\circ} 28^{\prime} 47^{\prime \prime} \mathrm{O}$ \\
\hline Lagoa de Hóspedes ${ }^{\mathrm{C}}$ & Poça temporária na borda de mata & $20^{\circ} 43^{\prime} 01 ” \mathrm{~S} ; 42^{\circ} 28^{\prime} 46^{\prime \prime} \mathrm{O}$ \\
\hline Lagoa Seca ${ }^{\mathrm{C}}$ & Poça temporária na borda de mata & $20^{\circ} 42^{\prime} 55^{\prime \prime} \mathrm{S} ; 42^{\circ} 29^{\prime} 10^{\prime \prime} \mathrm{O}$ \\
\hline Riacho do Moinho $^{\mathrm{C}}$ & Ambiente lótico no interior de mata & $20^{\circ} 43^{\prime} 13^{\prime \prime} \mathrm{S} ; 42^{\circ} 28^{\prime} 43^{\prime \prime} \mathrm{O}$ \\
\hline Riacho da Serraria $^{\mathrm{C}}$ & Ambiente lótico no interior de mata & $20^{\circ} 44^{\prime} 07^{\prime \prime} \mathrm{S} ; 42^{\circ} 29^{\prime} 28^{\prime \prime} \mathrm{O}$ \\
\hline Riacho da Casa de Hóspedes ${ }^{\mathrm{C}}$ & Ambiente lótico no interior de mata & $20^{\circ} 43^{\prime} 01^{\prime \prime} \mathrm{S} ; 42^{\circ} 28^{\prime} 50^{\prime \prime} \mathrm{O}$ \\
\hline Afloramento rochoso ${ }^{C}$ & Afloramento rochoso com presença de várias bromélias terrestres & $20^{\circ} 43^{\prime} 23^{\prime \prime} \mathrm{S} ; 42^{\circ} 29^{\prime} 05^{\prime \prime} \mathrm{O}$ \\
\hline Mata do Pai Inácio ${ }^{C}$ & Mata de altitude preservada, com densa camada de serapilheira & $20^{\circ} 46^{\prime} 46^{\prime \prime} \mathrm{S} ; 42^{\circ} 29^{\prime} 02^{\prime \prime} \mathrm{O}$ \\
\hline Fazenda Água Limpas & $\begin{array}{c}\text { Ambiente antropizado, com presença de riachos } \\
\text { no interior de mata secundária }\end{array}$ & $20^{\circ} 51^{\prime} 58^{\prime \prime} \mathrm{S} ; 42^{\circ} 31^{\prime} 25^{\prime \prime} \mathrm{O}$ \\
\hline Lagoa do Careço ${ }^{\mathrm{S}}$ & $\begin{array}{l}\text { Poça temporária no interior de mata com a presença } \\
\text { de muitas bromélias e epífitas às suas margens }\end{array}$ & $21^{\circ} 42^{\prime} 39^{\prime \prime} \mathrm{S} ; 43^{\circ} 54^{\prime} 41^{\prime \prime} \mathrm{O}$ \\
\hline Riacho sul $01^{\mathrm{s}}$ & Ambiente lótico no interior de mata & $20^{\circ} 53 ’ 17^{\prime \prime} \mathrm{S} ; 42^{\circ} 31^{\prime} 43^{\prime \prime} \mathrm{O}$ \\
\hline Riacho sul $02^{\mathrm{S}}$ & Ambiente lótico no interior de mata & $21^{\circ} 53^{\prime} 02^{\prime \prime} \mathrm{S} ; 42^{\circ} 32^{\prime} 09^{\prime \prime} \mathrm{O}$ \\
\hline Riacho sul $03^{\mathrm{s}}$ & Ambiente lótico no interior de mata & $21^{\circ} 52^{\prime} 48^{\prime \prime} \mathrm{S} ; 42^{\circ} 32^{\prime} 14^{\prime \prime} \mathrm{O}$ \\
\hline
\end{tabular}

Índices: $\mathrm{C}=$ setor amostral central, $\mathrm{N}=$ setor amostral norte, e $\mathrm{S}=$ setor amostral sul.

Index: $\mathrm{C}=$ central sampling sector, $\mathrm{N}=$ north sampling sector, and $\mathrm{S}=$ south sampling sector.

totalizando 102 dias de amostragem, resultando em um esforço amostral de 408 dias-balde em cada uma das linhas amostradas e 8160 dias-balde no total. Entre agosto de 2009 a julho de 2011, ainda no setor amostral central do PESB, foram realizadas incursões diurnas e noturnas ao longo de trilhas no interior de mata e ambientes aquáticos, que foram utilizados principalmente pelos anfíbios como sítios reprodutivos. As incursões noturnas, realizadas com no mínimo de duas pessoas, ocorreram por três a quatro noites consecutivas, e foram desempenhadas principalmente nos ambientes aquáticos lênticos, totalizando 90 dias de campo. De agosto de 2009 a junho de 2010, também foram realizadas incursões mensais no setor amostral sul com duração de uma ou duas noites cada, totalizando 13 dias de campo. Expedições não padronizadas foram realizadas a ambientes semelhantes situados nos setores amostrais norte, central e sul da Serra do Brigadeiro, distribuídas entre as estações chuvosas de 2008/2009, 2009/2010, 2010/2011, e 2011/2012.

Em especial para animais serpentiformes (cecílias, anfisbênias, serpentes e alguns lagartos) foi adotada a utilização de postos de coleta, método baseado na coleta de espécimes por moradores locais (cf. Lema \& Araújo 1985, Hartmann et al. 2009a) em regiões onde o registro de ocorrência dos mesmos é mais frequente, sobretudo em áreas rurais. Foram implementados seis postos de coleta na região do entorno do PESB e um posto na sua sede administrativa (setor amostral central), os quais foram vistoriados mensalmente no período de janeiro de 2008 a março de 2010, totalizando 189 vistorias-mês. A lista de espécies obtida foi ainda complementada com registros de répteis depositados nas seguintes coleções herpetológicas: Museu de Zoologia João Moojen da Universidade Federal de Viçosa (MZUFV), Viçosa, Minas Gerais; Museu de Ciências Naturais da Pontifícia Universidade Católica de Minas Gerais (MCNR) e Universidade Federal de Minas Gerais (UFMG), Belo Horizonte, Minas Gerais; Museu de Zoologia da Universidade de São Paulo (MZUSP), São Paulo, São Paulo (Apêndice 1). Também foi consultada a coleção herpetológica do Laboratório de Zoologia dos Vertebrados (LZV), Universidade Federal de Ouro Preto, Ouro Preto, Minas Gerais, onde nenhum espécime com registros nos oito municípios abrangidos pelo PESB foi encontrado.

Em virtude de estudos anteriores realizados no PESB (e.g. Feio et al. 1999, 2000, 2008a, Santos 2003, Cruz et al. 2007, Caramaschi et al. 2008, Assis 2009, Lacerda et al. 2009a, Motta et al. 2010), optou-se por coletarem apenas exemplares das espécies que constituíram novos registros para a região, assim como aquelas de difícil identificação ou com problemas taxonômicos. Os animais coletados foram acondicionados e transportados para o laboratório 

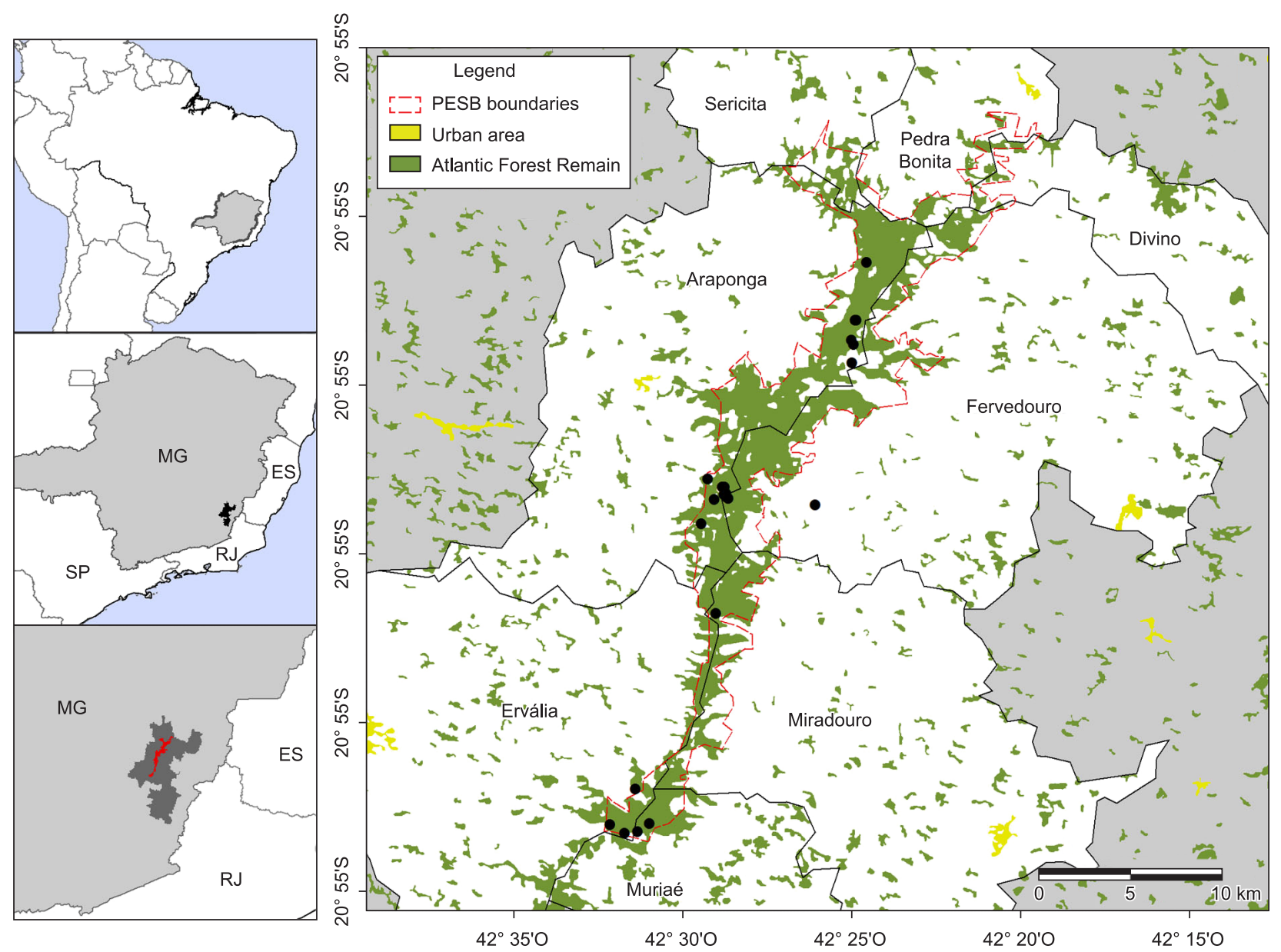

Figura 1. Localidades amostradas no Parque Estadual da Serra do Brigadeiro e entorno, nos municípios de Araponga, Divino, Ervália, Miradouro, Muriaé, Pedra Bonita, Sericita, estado de Minas Gerais, sudeste do Brasil.

Figure 1. Sampled localities at the Serra do Brigadeiro State Park and surroundings, at the municipalities of Araponga, Divino, Ervália, Miradouro, Muriaé, Pedra Bonita, Sericita, state of Minas Gerais, southeastern Brazil.

em sacos plásticos umedecidos (autorização de coleta nº 14208-1, 14208-2, 19655-1, 20857-1 e 20857-2 cedidas pelo Instituto Brasileiro do Meio Ambiente e dos Recursos Naturais Renováveis e licenças $n^{\circ}$ 071/08, 071/08ii, 056/09, 071/09, 071/09i e 071/09ii cedidas pelo Instituto Estadual de Florestas). Posteriormente, os exemplares foram fotografados e mortos com Xilocaína ${ }^{\circledR}$ a $5 \%$ (sapos) ou Tiopental ${ }^{\circledR}$ (lagartos e serpentes), fixados em formaldeído a $10 \%$ e conservados em álcool 70\%. Todo o material coletado encontra-se depositado na coleção herpetológica do Museu de Zoologia João Moojen (MZUFV) (Apêndice 1).

Todos os registros das espécies levantadas foram conferidos de acordo com a distribuição prévia das espécies por meio de consulta a literatura e bases de dados disponíveis na internet Amphibian Species of the World (Frost 2011), Global Amphibian Assessment (International... 2011) e Embl Reptile Database (Uetz et al. 2011). Os espécimes foram identificados com o auxílio de chaves taxonômicas, consultas aos especialistas dos grupos e a coleções de referência em diferentes instituições de pesquisa. A nomenclatura taxonômica adotada para os anfíbios segue Frost (2011), complementada por Faivovich et al. (2005), Frost et al. (2006), Hedges et al. (2008), Guayasamin et al. (2009) e Wilkinson et al. (2011), e para os répteis, segue Uetz et al. (2011), complementada por Adalsteinsson et al.
(2009), Curcio et al. (2009), Fenwick et al. (2009), e Pyron et al. (2011).

As espécies registradas foram classificadas em quatro categorias segundo sua distribuição geográfica. Espécies distribuídas em diversas localidades dentro do domínio morfoclimático da Mata Atlântica (sensu Ab'Saber 1977), em um espaço geográfico maior do que 50 mil km² foram consideradas como de "ampla distribuição na Mata Atlântica". Espécies com registros de ocorrência pontuais, ou quando as localidades de ocorrência interligadas resultam em espaço geográfico menor do que $50 \mathrm{mil} \mathrm{km}^{2}$ foram classificadas como de "distribuição restrita na Mata Atlântica" (cf. Eken et al. 2004). Espécies que ocorrem em outros biomas, além da Mata Atlântica foram classificadas como de "distribuição em mais de um bioma". A classificação "distribuição geográfica desconhecida" foi utilizada para espécies não descritas (quando ausentes maiores informações sobre sua distribuição) ou para aquelas sem identidade taxonômica confirmada.

Observou-se também o status de conservação de cada táxon, através da consulta às listas de espécies da fauna ameaçadas de extinção para o estado de Minas Gerais (Fundação... 2007, Drummond et al. 2008, Conselho...2010), à lista das espécies da fauna brasileira ameaçadas de extinção (Machado et al. 2005, 2008) 
e à lista vermelha de espécies ameaçadas da União Internacional para a Conservação da Natureza (International... 2011). Considerando a localização da área de estudo, próxima às fronteiras com os estados do Rio de Janeiro e Espírito Santo, e o intuito de caracterizar o status de conservação das espécies no sudeste do Brasil, listas vermelhas disponíveis para estados vizinhos também foram consultadas, entre elas as listas das espécies da fauna ameaçadas de extinção no estado de Espírito Santo (Passamani \& Mendes 2007), da fauna ameaçada de extinção do estado do Rio de Janeiro (Bergallo et al. 2000). Em virtude das diferenças de métodos e de esforço amostral empregado nos três setores amostrais, os resultados referentes ao método de amostragem e ao tipo de ambiente onde ocorreram as espécies são apenas informativos. As informações referentes ao tipo de método são fornecidas somente para espécies registradas durante o presente trabalho.

\section{Resultados e Discussão}

\section{Anfíbios}

Os estudos herpetofaunísticos na região da Serra do Brigadeiro iniciaram-se na década de 1990 por meio de incursões esporádicas durante estações chuvosas. Entre 1992 e 2003, 37 espécies de anfíbios foram registradas para o PESB (Feio et al. 2000, Santos 2003), com destaque para uma nova espécie, Physalaemus maximus (Feio et al. 1999). A continuidade dos estudos na Serra do Brigadeiro possibilitou a descrição de outras duas espécies, Chiasmocleis mantiqueira (Cruz et al. 2007) e Leptodactylus cupreus (Caramaschi et al. 2008), além da efetuação de novos registros que elevaram para 44 o número de anfíbios conhecidos (Feio et al. 2008a). Posteriormente, Assis (2009) aumentou para 45, e Motta et al. (2010) para 46 o número de espécies de anfíbios registradas para a Serra do Brigadeiro. No presente estudo reportamos 12 novos registros de anfíbios para a Serra do Brigadeiro, totalizando 58 espécies de anfíbios (Tabela 2, Figuras 2 a 6 ).

A maioria das espécies, 46,55\% (27 espécies), apresenta distribuição ampla no domínio da Mata Atlântica, 12 (20,68\%) possuem distribuição restrita a alguma(s) localidade(s) da Mata Atlântica, 10 (17,24\%) possuem distribuição em mais de um bioma e as outras nove $(15,51 \%)$ possuem distribuição geográfica desconhecida. O método mais eficiente foi o de busca ativa (BA), que possibilitou o registro de $50(86,20 \%)$ espécies de anfíbios, seguido pelo uso de armadilhas de queda (AIQ) e o encontro ocasional (EO) que permitiram o registro de $14(24,13 \%)$ e oito $(13,79 \%)$ espécies, respectivamente. Seis espécies $(10,34 \%)$ não foram registradas no presente estudo, não sendo informado tipo de registro para as mesmas.

Nenhuma das espécies de anfíbios registradas está incluída nas listas vermelhas de espécies ameaçadas de extinção da IUCN (International... 2011), do Brasil (Machado et al. 2008) ou do estado de Minas Gerais (Fundação... 2007, Feio et al. 2008b, Conselho...2010). As duas espécies de Centrolenidae registradas, Vitreorana eurygnatha e $V$. unanoscopa são presumivelmente consideradas ameaçadas no estado de Rio de Janeiro. Segundo Caramaschi et al. (2000) suas populações eram abundantes no passado, mas se tornaram muito raras nos locais onde eram anteriormente encontradas. $\mathrm{O}$ status de ameaça de Megaelosia apuana e Vitreorana unanoscopa é ainda considerado "Vulnerável" (VU) no estado do Espírito Santo (Gasparini et al. 2007). Situação semelhante é observada para Ceratophrys aurita, espécie que chegou a ser considerada como "Em Perigo" (EN) na lista anterior de espécies da fauna ameaçadas de extinção para o estado de Minas Gerais (Machado et al. 1998), quando o conhecimento sobre sua distribuição ainda era escasso. Com relação às espécies consideradas como "Deficiente de Dados" (DD), nove $(15,51 \%)$ estão presentes na lista da IUCN (Bokermannohyla ibitipoca, Chiasmocleis mantiqueira, Gastrotheca ernestoi, Hylodes babax, Ischnocnema verrucosa, Luetkenotyphlus brasiliensis, Megaelosia apuana, Physalaemus maximus e Zachaenus carvalhoi). Com exceção de C. Mantiqueira, M. apuana e G. ernestoi, não listadas em Feio et al. (2008b) e Ischnocnema verrucosa, as demais espécies também são listadas como "DD" na lista de espécies da fauna ameaçadas de extinção para o estado de Minas Gerais (Fundação...2007), incluindo ainda Bokermannohyla caramaschii, Brachycephalus ephippium e Proceratophrys melanopogon $(\mathrm{n}=8$; 13,79\%). Além disso, tem-se Ceratophrys aurita, H. babax e Z. carvalhoi consideradas como "DD" na lista da fauna ameaçadas de extinção no estado de Espírito Santo (Gasparini et al. 2007).

Algumas das espécies encontradas na Serra do Brigadeiro constituem-se em importantes registros zoogeográficos. A seguir, apresentamos para algumas espécies, considerações sobre a distribuição geográfica e comentários sobre alterações na identificação adotada com relação a estudos anteriores.

A presença Brachycephalus ephippium na área amostral central do PESB consiste no primeiro e único registro da espécie para Minas Gerais, assim como no limite continental de sua distribuição (Dayrell et al. 2006b) (Figura 10a). Dentro deste gênero, merece destaque também o encontro de Brachycephalus cf. didactylus, reportado através de um indivíduo capturado no setor amostral central da Serra do Brigadeiro por Assis (2009). A ausência de novos espécimes coletados de $B$. cf. didactylus dificulta a melhor caracterização taxonômica dessa população, embora a coloração negra e a presença de apenas dois dedos nas mãos distingam o exemplar coletado de sua congênre na área de estudo.

O encontro de Ischnocnema verrucosa corresponde ao segundo registro da espécie para o estado de Minas Gerais, conhecida anteriormente para Juiz de Fora (localidade tipo) (Figura 10b). A presença de Proceratophrys melanopogon para a Serra do Brigadeiro corresponde ao limite continental e norte de distribuição (Feio et al. 2003a) (Figura 10c), embora os espécimes provenientes desta localidade não tenham sido examinados na revisão sistemática efetuada por Prado \& Pombal-Junior (2008). Zachaenus carvalhoi teve na Serra do Brigadeiro o segundo registro de sua ocorrência no estado (Motta et al. 2010), recentemente encontrado em Juiz de Fora, atual limite sudoeste de sua distribuição (Salles \& Maciel 2010), (Figura 10d). A captura da espécie em AIQ no setor amostral central corresponde também à maior cota altimétrica (1360 m de elevação) na qual esta foi registrada.

A presença de Gastrotheca ernestoi configura o registro mais continental e norte de sua distribuição, localizado a $160 \mathrm{~km}$ a noroeste do município de Nova Friburgo, a localidade mais próxima conhecida (Siqueira et al. 2011) e a $200 \mathrm{~km}$ de Macaé (localidade tipo), Rio de Janeiro (Figura 10e). Na Serra do Brigadeiro, a espécie foi observada em campos de altitude entre 1800 e 1980 m, nos setores amostrais central e norte, sendo o primeiro registro do gênero para o estado de Minas Gerais.

A ocorrência de Bokermannohyla caramaschii no setor amostral sul, município de Ervália, consiste no limite meridional de sua distribuição, a aproximadamente $230 \mathrm{~km}$ da localidade tipo em Santa Teresa, Espírito Santo (Figura 10f). Trabalhos anteriores na Serra do Brigadeiro (e.g. Feio et al. 2008a, Assis 2009, Lacerda et al. 2009a) trataram essa espécie como Bokermannohyla circumdata, devido à semelhança desta última com B. caramaschii (ver Napoli et al. 2011). Dentro do gênero, também merece menção o encontro de Bokermannohyla ibitipoca, considerado o primeiro registro da espécie fora da localidade tipo (Feio et al. 2003b), posteriormente essa espécie também foi registrada para os Picos de Pedra Azul (Moura et al. 2008) e Forno Grande (Montesinos et al. 2012), ambos no Espírito Santo 
Tabela 2. Lista de espécies de anfíbios registradas para o Parque Estadual da Serra do Brigadeiro e entorno, Minas Gerais, sudeste do Brasil.

Table 2. Species list of amphibians recorded at the Serra do Brigadeiro State Park and surroundings, state of Minas Gerais, southeastern Brazil.

\begin{tabular}{|c|c|c|c|}
\hline Família/espécie & Tipo de registro & Setor amostral & Área de registro \\
\hline \multicolumn{4}{|l|}{ ANURA } \\
\hline \multicolumn{4}{|l|}{ Brachycephalidae } \\
\hline 1. Brachycephalus ephippium (Spix, 1824) ${ }^{a}$ & - & $\mathrm{C}$ & $\mathrm{P}$ \\
\hline 2. Brachycephalus cf. didactylus ${ }^{d}$ & - & $\mathrm{C}, \mathrm{N}$ & $\mathrm{P}$ \\
\hline 3. *Ischnocnema parva $(\text { Girard, } 1853)^{a}$ & $\mathrm{AQ}, \mathrm{BA}, \mathrm{EO}$ & $\mathrm{C}, \mathrm{S}$ & $\mathrm{P}, \mathrm{E}$ \\
\hline 4.*Ischnocnema verrucosa (Reinhardt \& Lütken, 1862) ${ }^{b}$ & AQ & $\mathrm{C}$ & $\mathrm{P}$ \\
\hline 5. Ischnocnema cf. izecksohni ${ }^{a}$ & $\mathrm{BA}, \mathrm{EO}$ & $\mathrm{C}, \mathrm{N}, \mathrm{S}$ & $\mathrm{P}, \mathrm{E}$ \\
\hline 6. Ischnocnema sp. (aff. guentheri) ${ }^{d}$ & $\mathrm{BA}, \mathrm{EO}$ & $\mathrm{C}, \mathrm{N}, \mathrm{S}$ & $\mathrm{P}, \mathrm{E}$ \\
\hline \multicolumn{4}{|l|}{ Bufonidae } \\
\hline 1. Rhinella pombali (Baldissera-Jr, Caramaschi \& Haddad, 2004) ${ }^{a}$ & $\mathrm{AQ}, \mathrm{BA}, \mathrm{EO}$ & $\mathrm{C}, \mathrm{N}, \mathrm{S}$ & $\mathrm{P}, \mathrm{E}$ \\
\hline \multicolumn{4}{|l|}{ Centrolenidae } \\
\hline 1. Vitreorana eurygnatha (A. Lutz, 1925) ${ }^{a}$ & BA & $\mathrm{C}, \mathrm{N}$ & $\mathrm{P}$ \\
\hline 2. Vitreorana uranoscopa (Müller, 1924) ${ }^{a}$ & BA & $\mathrm{C}, \mathrm{N}$ & $\mathrm{P}$ \\
\hline \multicolumn{4}{|l|}{ Ceratophryidae } \\
\hline 1. Ceratophrys aurita $(\text { Raddi, } 1823)^{a}$ & - & $\mathrm{C}$ & $\mathrm{P}$ \\
\hline \multicolumn{4}{|l|}{ Craugastoridae } \\
\hline 1. Haddadus binotatus $\left(\right.$ Spix, 1824) ${ }^{a}$ & $\mathrm{BA}, \mathrm{EO}$ & $\mathrm{C}, \mathrm{N}, \mathrm{S}$ & $\mathrm{P}, \mathrm{E}$ \\
\hline \multicolumn{4}{|l|}{ Cycloramphidae } \\
\hline 1. Odontophrynus cultripes Reinhardt \& Lütken, $1862^{a}$ & BA & $\mathrm{C}$ & $\mathrm{P}, \mathrm{E}$ \\
\hline 2. Proceratophrys boiei (Wied-Neuwied, 1825$)^{a}$ & $\mathrm{AQ}, \mathrm{BA}$ & $\mathrm{C}, \mathrm{N}, \mathrm{S}$ & $\mathrm{P}, \mathrm{E}$ \\
\hline 3. Proceratophrys melanopogon (Miranda-Ribeiro, 1926) ${ }^{b}$ & $\mathrm{AQ}, \mathrm{BA}$ & $\mathrm{C}, \mathrm{N}, \mathrm{S}$ & $\mathrm{P}$ \\
\hline 4. Thoropa miliaris (Spix, 1824) ${ }^{a}$ & $\mathrm{BA}, \mathrm{EO}$ & $\mathrm{C}, \mathrm{N}, \mathrm{S}$ & $\mathrm{P}$ \\
\hline 5. Zachaenus carvalhoi Izecksohn, $1983^{b}$ & $\mathrm{AQ}, \mathrm{BA}$ & $\mathrm{C}, \mathrm{S}$ & $\mathrm{P}$ \\
\hline \multicolumn{4}{|l|}{ Hemiphractidae } \\
\hline 1. *Gastrotheca ernestoi Miranda Ribeiro, $1920^{b}$ & BA & $\mathrm{C}, \mathrm{N}$ & $\mathrm{P}$ \\
\hline \multicolumn{4}{|l|}{ Hylidae } \\
\hline 1. Aplastodiscus arildae (Cruz \& Peixoto, 1987) ${ }^{a}$ & BA & $\mathrm{C}, \mathrm{N}, \mathrm{S}$ & $\mathrm{P}$ \\
\hline 2. Aplastodiscus leucopygius (Cruz \& Peixoto, 1985) ${ }^{a}$ & $\mathrm{AQ}, \mathrm{BA}$ & $\mathrm{C}, \mathrm{N}, \mathrm{S}$ & $\mathrm{P}$ \\
\hline 3. Bokermannohyla caramaschii (Napoli, 2005) $)^{b}$ & $\mathrm{AQ}, \mathrm{BA}$ & $\mathrm{C}, \mathrm{N}, \mathrm{S}$ & $\mathrm{P}$ \\
\hline 4. Bokermannohyla ibitipoca (Caramaschi \& Feio, 1990) ${ }^{b}$ & BA & $\mathrm{N}$ & $\mathrm{P}$ \\
\hline 5. Dendropsophus decipiens (A. Lutz, 1925) ${ }^{a}$ & BA & $\mathrm{C}, \mathrm{N}, \mathrm{S}$ & $\mathrm{P}, \mathrm{E}$ \\
\hline 6. Dendropsophus elegans (Wied-Neuwied, 1824) ${ }^{a}$ & BA & $\mathrm{C}$ & $\mathrm{P}, \mathrm{E}$ \\
\hline 7. Dendropsophus minutus (Peters, 1872) ${ }^{c}$ & BA & $\mathrm{C}, \mathrm{N}, \mathrm{S}$ & $\mathrm{P}, \mathrm{E}$ \\
\hline 8. ${ }^{* H y p s i b o a s ~ a l b o m a r g i n a t u s ~(S p i x, ~ 1824) ~}{ }^{a}$ & BA & $\mathrm{C}, \mathrm{S}$ & $\mathrm{P}, \mathrm{E}$ \\
\hline 9. Hypsiboas albopunctatus (Spix, 1824) ${ }^{c}$ & BA & $\mathrm{C}$ & $\mathrm{P}, \mathrm{E}$ \\
\hline 10 Hypsiboas faber (Wied-Neuwied, 1821) ${ }^{a}$ & BA & $\mathrm{C}, \mathrm{N}, \mathrm{S}$ & $\mathrm{P}, \mathrm{E}$ \\
\hline 11. Hypsiboas pardalis $\left(\right.$ Spix, 1824) ${ }^{a}$ & BA & $\mathrm{C}, \mathrm{S}$ & $\mathrm{P}, \mathrm{E}$ \\
\hline 12. Hypsiboas polytaenius (Cope, 1870$)^{a}$ & BA & $\mathrm{C}, \mathrm{N}$, & $\mathrm{P}$ \\
\hline 13. *Hypsiboas semilineatus (Spix, 1824) ${ }^{a}$ & BA & $\mathrm{C}$ & $\mathrm{E}$ \\
\hline 14. Phasmahyla $\mathrm{sp}^{d}$ & - & $\mathrm{N}$ & $\mathrm{P}$ \\
\hline 15. Phyllomedusa burmeisteri Boulenger, $1882^{a}$ & $\mathrm{AQ}, \mathrm{BA}$ & $\mathrm{C}, \mathrm{N}, \mathrm{S}$ & $\mathrm{P}$ \\
\hline 16. $*$ Scinax alter $(\text { B. Lutz, 1973) })^{d}$ & BA & $\mathrm{C}$ & $\mathrm{E}$ \\
\hline 17. ${ }^{*}$ Scinax crospedospilus (A. Lutz, 1925) ${ }^{a}$ & $\mathrm{BA}$ & $\mathrm{C}$ & $\mathrm{E}$ \\
\hline 18. Scinax eurydice (Bokermann, 1968) ${ }^{a}$ & BA & $\mathrm{C}$ & $\mathrm{P}, \mathrm{E}$ \\
\hline 19. ${ }^{*}$ Scinax flavoguttaus (Lutz \& Lutz, 1939) ${ }^{a}$ & BA & $\mathrm{S}$ & $\mathrm{P}$ \\
\hline
\end{tabular}

Método de amostragem: BA = busca ativa, EO = encontro ocasional, AIQ = armadilha de interceptação e queda. Setor amostral: C = central, $\mathrm{N}=$ norte, $\mathrm{S}=$ sul. Área de registro: $\mathrm{P}=$ interior do Parque, $\mathrm{E}=$ entorno do Parque. Índices: $\mathrm{a}=$ espécie com distribuição geográfica ampla na Mata Atlântica, b = espécie com distribuição restrita a algumas localidades da Mata Atlântica, $\mathrm{c}=$ espécie com distribuição em mais de um bioma, $\mathrm{d}=$ espécie com distribuição geográfica desconhecida. *novos registros de espécies não encontradas em estudos anteriores. Sampling method: $\mathrm{BA}=$ active search, $\mathrm{EO}=$ occasional encounter, $\mathrm{AIQ}=$ pitfall traps. Sampling sites: $\mathrm{C}=$ central, $\mathrm{N}=$ north, $\mathrm{S}=$ south. Area of register: $\mathrm{P}=$ inside the Park, $\mathrm{E}=$ outside the Park. Index: $\mathrm{a}=$ widespread species in the Atlantic Forest; $\mathrm{b}=$ species restricted to few localities at Atlantic Forest; $\mathrm{c}=$ species distributed in more than one biome; $\mathrm{d}=$ species with unknown distribution. *new records of species not registered in previous studies. 
Tabela 2. Continuação...

\begin{tabular}{|c|c|c|c|}
\hline Família/espécie & Tipo de registro & Setor amostral & Área de registro \\
\hline 20. Scinax fuscovarius (A. Lutz, 1925) ${ }^{c}$ & - & $\mathrm{C}$ & $\mathrm{P}, \mathrm{E}$ \\
\hline 21 Scinax luizotavioi (Caramaschi \& Kisteumacher, 1989) ${ }^{a}$ & BA & $\mathrm{C}, \mathrm{N}, \mathrm{S}$ & $\mathrm{P}$ \\
\hline 22. Scinax cf. tripui $^{d}$ & BA & $\mathrm{C}, \mathrm{S}$ & $\mathrm{P}$ \\
\hline 23. Scinax sp. (aff. perereca) ${ }^{d}$ & $\mathrm{AQ}, \mathrm{BA}$ & $\mathrm{C}, \mathrm{N}, \mathrm{S}$ & $\mathrm{P}$ \\
\hline 24. Scinax sp. (aff. perpusillus) ${ }^{d}$ & BA & $\mathrm{C}, \mathrm{S}$ & $\mathrm{P}$ \\
\hline 25. Scinax sp. (aff. rizibilis) ${ }^{d}$ & BA & S & $\mathrm{P}$ \\
\hline \multicolumn{4}{|l|}{ Hylodidae } \\
\hline 1. Crossodactylus gr. gaudichaudii ${ }^{d}$ & - & - & - \\
\hline 2. Hylodes babax Heyer, $1982^{b}$ & BA & $\mathrm{C}$ & $\mathrm{P}$ \\
\hline 3. *Hylodes lateristrigatus (Baumann, 1912) ${ }^{b}$ & BA & S & $\mathrm{P}$ \\
\hline 4. *Megaelosia apuana Pombal, Prado \& Canedo, $2003^{b}$ & BA & S & $\mathrm{E}$ \\
\hline \multicolumn{4}{|l|}{ Leiuperidae } \\
\hline 1. Physalaemus cuvieri Fitzinger, $1826^{c}$ & BA & $\mathrm{C}, \mathrm{N}, \mathrm{S}$ & $\mathrm{E}$ \\
\hline 2. Physalaemus feioi Cassini, Cruz \& Caramaschi, $2010^{a}$ & $\mathrm{AQ}, \mathrm{BA}$ & $\mathrm{C}, \mathrm{N}, \mathrm{S}$ & $\mathrm{P}, \mathrm{E}$ \\
\hline 3. Physalaemus maximus Feio, Pombal \& Caramaschi, $1999^{b}$ & $\mathrm{AQ}, \mathrm{BA}$ & $\mathrm{C}$ & $\mathrm{P}$ \\
\hline \multicolumn{4}{|l|}{ Leptodactylidae } \\
\hline 1. Leptodactylus cupreus Caramaschi, Feio \& São-Pedro, $2008^{b}$ & BA & S & $\mathrm{P}$ \\
\hline 2. Leptodactylus fuscus (Schneider, 1799) ${ }^{c}$ & BA & $\mathrm{C}, \mathrm{N}, \mathrm{S}$ & $\mathrm{P}, \mathrm{E}$ \\
\hline 3. Leptodactylus labyrinthicus (Spix, 1824) ${ }^{c}$ & BA & $\mathrm{C}, \mathrm{S}$ & $\mathrm{E}$ \\
\hline 4. Leptodactylus latrans $(\text { Steffen, } 1815)^{c}$ & BA & $\mathrm{C}, \mathrm{S}$ & $\mathrm{E}$ \\
\hline 5. Leptodactylus mystacinus (Burmeister, 1861) ${ }^{c}$ & BA & $\mathrm{C}$ & $\mathrm{P}, \mathrm{E}$ \\
\hline 6. * Leptodactylus sp. (aff. mystaceus) ${ }^{d}$ & $\mathrm{AQ}, \mathrm{BA}$ & $\mathrm{C}, \mathrm{S}$ & $\mathrm{P}, \mathrm{E}$ \\
\hline \multicolumn{4}{|l|}{ Microhylidae } \\
\hline 1. Chiasmocleis mantiqueira Cruz, Feio \& Cassini, $2007^{b}$ & $\mathrm{BA}, \mathrm{EO}$ & $\mathrm{C}, \mathrm{S}$ & $\mathrm{P}$ \\
\hline 2. Elachistocleis cesarii Miranda Ribeiro, $1920^{c}$ & BA & $\mathrm{C}$ & $\mathrm{P}, \mathrm{E}$ \\
\hline \multicolumn{4}{|l|}{ GYMNOPHIONA } \\
\hline \multicolumn{4}{|l|}{ Siphonopidae } \\
\hline 1. *Luetkenotyphlus brasiliensis (Lütken, 1852) ${ }^{c}$ & $\mathrm{AQ}, \mathrm{EO}$ & $\mathrm{C}$ & $\mathrm{P}$ \\
\hline
\end{tabular}

Método de amostragem: BA = busca ativa, EO = encontro ocasional, AIQ = armadilha de interceptação e queda. Setor amostral: $\mathrm{C}=$ central, $\mathrm{N}=$ norte, $\mathrm{S}=$ sul. Área de registro: $\mathrm{P}=$ interior do Parque, $\mathrm{E}=$ entorno do Parque. Índices: $\mathrm{a}=$ espécie com distribuição geográfica ampla na Mata Atlântica, b = espécie com distribuição restrita a algumas localidades da Mata Atlântica, $\mathrm{c}=$ espécie com distribuição em mais de um bioma, $\mathrm{d}$ = espécie com distribuição geográfica desconhecida. *novos registros de espécies não encontradas em estudos anteriores.

Sampling method: $\mathrm{BA}=$ active search, $\mathrm{EO}=$ occasional encounter, AIQ = pitfall traps. Sampling sites: $\mathrm{C}=$ central, $\mathrm{N}=$ north, $\mathrm{S}=$ south. Area of register: $\mathrm{P}=$ inside the Park, $\mathrm{E}=$ outside the Park. Index: $\mathrm{a}=$ widespread species in the Atlantic Forest; $\mathrm{b}=$ species restricted to few localities at Atlantic Forest; $\mathrm{c}=$ species distributed in more than one biome; $\mathrm{d}=$ species with unknown distribution. *new records of species not registered in previous studies.

(Figura 11a). O encontro de Hypsiboas albomarginatus no setor amostral central, a aproximadamente $1350 \mathrm{~m}$ de altitude, configura a maior cota altimétrica para a qual a espécie é conhecida, usualmente encontrada em áreas de baixada no entorno da serra.

Três espécies de Scinax têm sua identificação atualizada em relação a estudos anteriores. Scinax luizotavioi, anteriormente denominada como Scinax sp. 2 em Feio et al. (2008a). Estudos taxonômicos posteriores não apresentaram diferenças morfológicas e citogenéticas que permitissem a separação da população da Serra do Brigadeiro (L.H.R. Lima \& R.N. Feio, dados não publicados) das populações da Serra do Espinhaço. Ademais, a espécie tem sido reportada para fora do complexo serrano do Espinhaço, em áreas ao sul (Cruz et al. 2009, Lourenço et al. 2009a) e ao norte da Serra da Mantiqueira (Carvalho-Junior et al. 2010). Scinax cf. tripui foi tratada como Scinax sp. 1 por Feio et al. (2008a). A população desta espécie na Serra do Brigadeiro apresenta semelhanças morfológicas a Scinax tripui, descrita recentemente para o sul da Cadeia do Espinhaço, na região de Ouro Preto (Lourenço et al. 2009b). Estudos comparativos de vocalização e características dos girinos podem auxiliar na confirmação desta identidade. Scinax sp. (aff. perpusillus), identificada inicialmente como Scinax gr. perpusillus em Feio et al. (2008a) e Lacerda et al. (2009a). Trata-se de uma espécie nova, a população encontrada na Serra do Brigadeiro encontra-se em processo de descrição (Lacerda et al., no prelo).

O registro de Crossodactylus gr. gaudichaudii é baseado em um exemplar tombado na coleção científica do MZUFV coletado em 1984 na "Serra do Araponga" (maiores informações são ausentes). Segundo a Biblioteca do IBGE (Biblioteca... 2010), supõe-se que o topônimo Araponga (nome do principal município de acesso ao PESB), originouse de Serra do Araponga. Com base nesta informação, é provável que o referido exemplar configure em um registro adicional para o município de Araponga, região centro-sul do PESB. Destaca-se ainda o encontro de Hylodes babax como o primeiro registro fora da localidade tipo e o limite sul da distribuição da espécie (Assis 2009, Pirani et al. 2010). Tratada como Hylodes sp. em Feio et al. (2008a), o seu registro na Serra do Brigadeiro representa uma extensão de distribuição de 80 km 

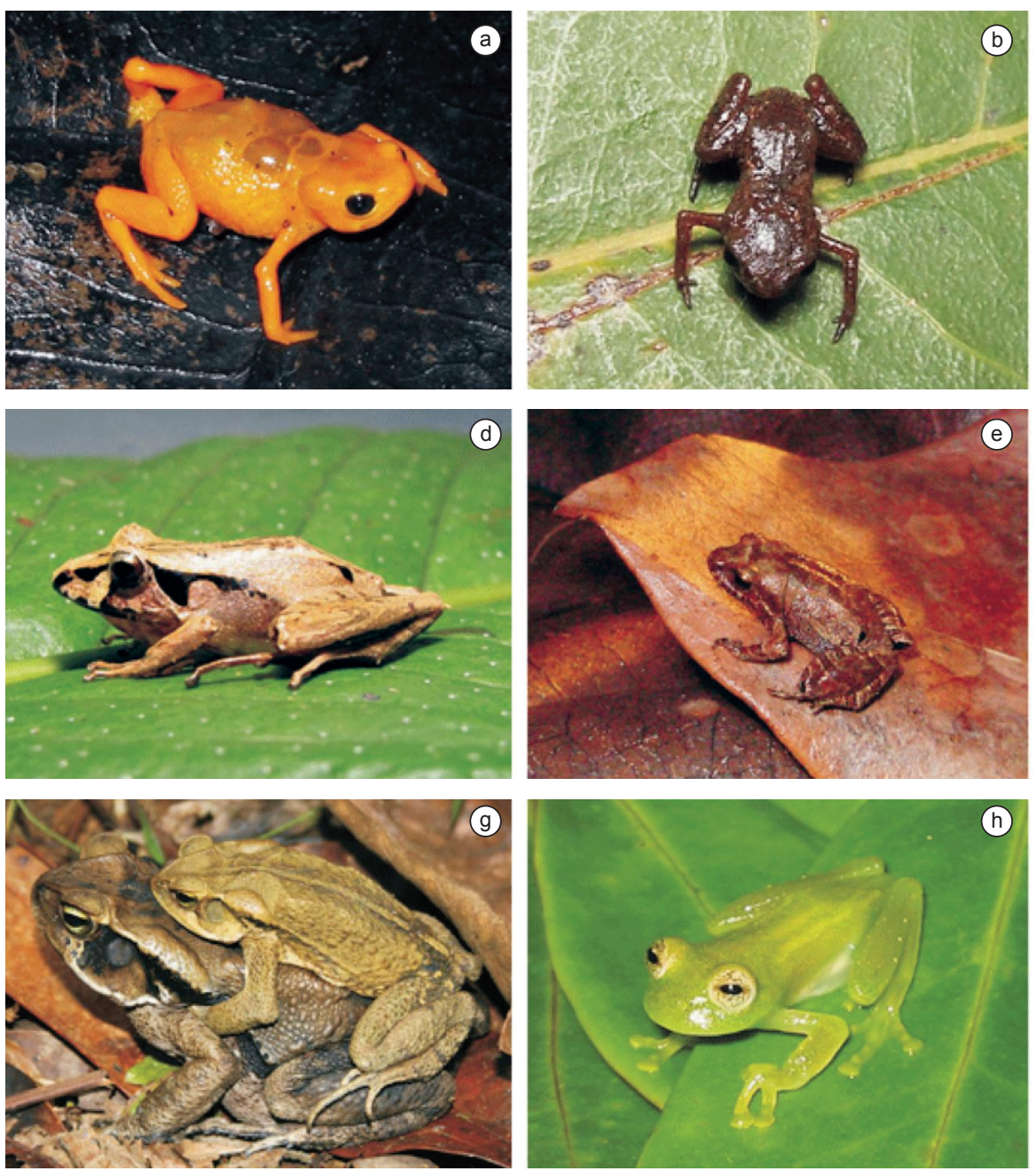

(h)
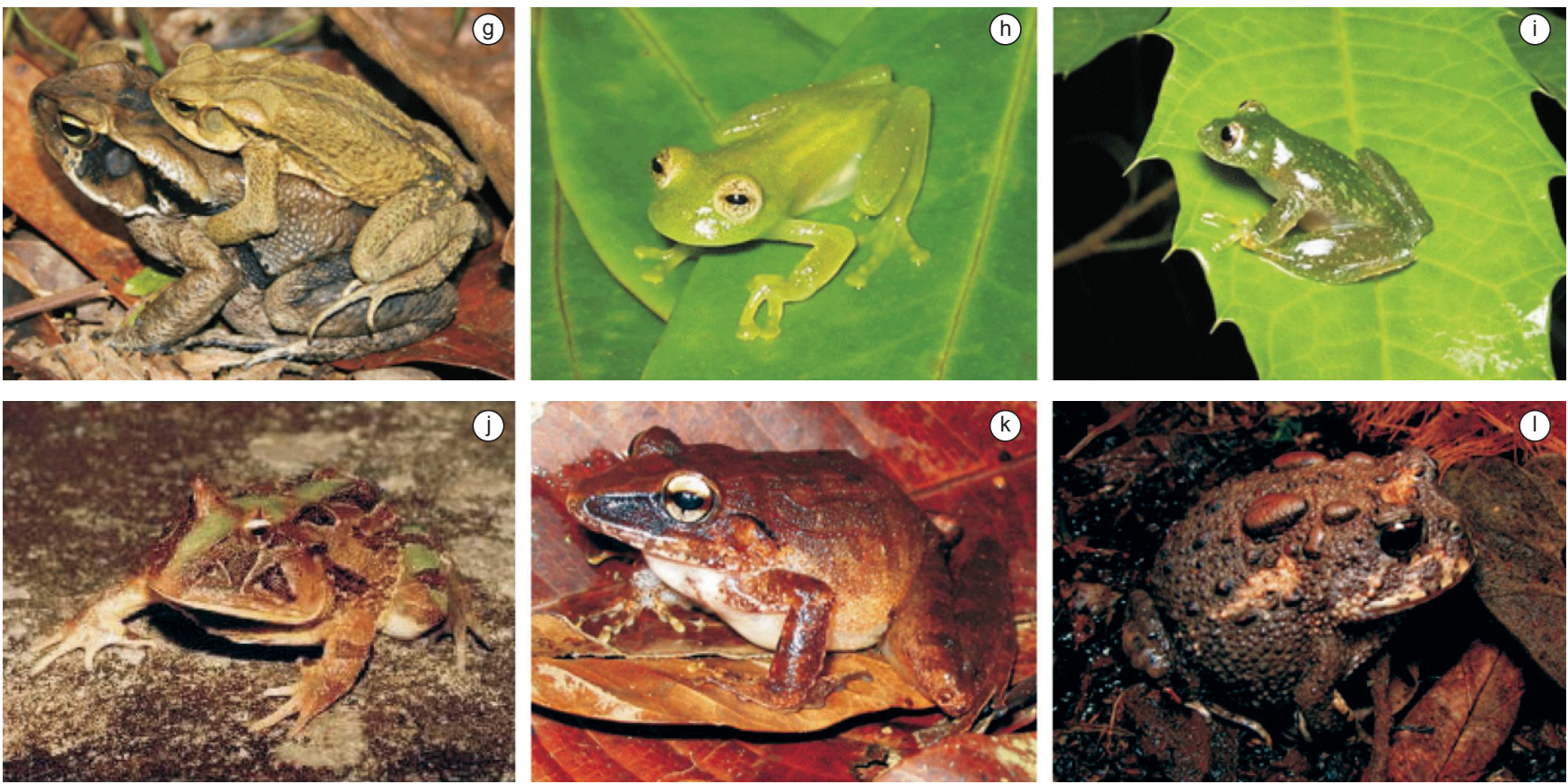

Figura 2. Anfíbios registrados no Parque Estadual da Serra do Brigadeiro e entorno, estado de Minas Gerais, sudeste do Brasil: a) Brachycephalus ephippium, b) Brachycephalus cf. didactylus, c) Ischnocnema cf. nasuta, d) Ischnocnema sp. (aff. guentheri), e) Ischnocnema parva, f) Ischnocnema verrucosa, g) Rhinella pombali, h) Vitreorana eurygnatha, i) Vitreorana uranoscopa, j) Ceratophrys aurita, k) Haddadus binotatus, 1) Odontophrynus cultripes. Crédito das fotos: C.C.A. Silva (g), D.J. Santana (b, i), H.C. Costa (1), M.R. Moura (e, f), P.S. Santos (d), R.N. Feio (a, c, h, i, j, k).

Figure 2. Amphibians from Serra do Brigadeiro State Park and surroundings, state of Minas Gerais, southeastern Brazil: a) Brachycephalus ephippium, b) Brachycephalus cf. didactylus, c) Ischnocnema cf. nasuta, d) Ischnocnema sp. (aff. guentheri), e) Ischnocnema parva, f) Ischnocnema verrucosa, g) Rhinella pombali, h) Vitreorana eurygnatha, i) Vitreorana uranoscopa, j) Ceratophrys aurita, k) Haddadus binotatus, 1) Odontophrynus cultripes. Photo credits: C.C.A. Silva (g), D.J. Santana (b, i), H.C. Costa (1), M.R. Moura (e, f), P.S. Santos (d), R.N. Feio (a, c, h, i, j, k).

a sudoeste da localidade tipo (Figura 11b), além de uma extensão altitudinal de $1200 \mathrm{~m}$ (Heyer 1982) para $1350 \mathrm{~m}$ de altitude (Assis 2009). O encontro de Hylodes lateristrigatus na área amostral sul corresponde ao primeiro registro para Minas Gerais, a $175 \mathrm{~km}$ ao norte de Teresópolis (localidade tipo, segundo Bokermann 1966), e 155 km a noroeste da localidade mais próxima, em Nova Friburgo, Rio de Janeiro
(Figura 11c). O registro de Megaelosia apuana corresponde a segunda ocorrência da espécie para Minas Gerais (Figura 11d), recentemente registrada no município de Simonésia, $110 \mathrm{~km}$ a nordeste da Serra do Brigadeiro (Santos et al. 2011).

Anteriormente as populações de Physalaemus feioi encontradas na mesorregião da Zona da Mata eram referidas como $P$. cf. olfersii 

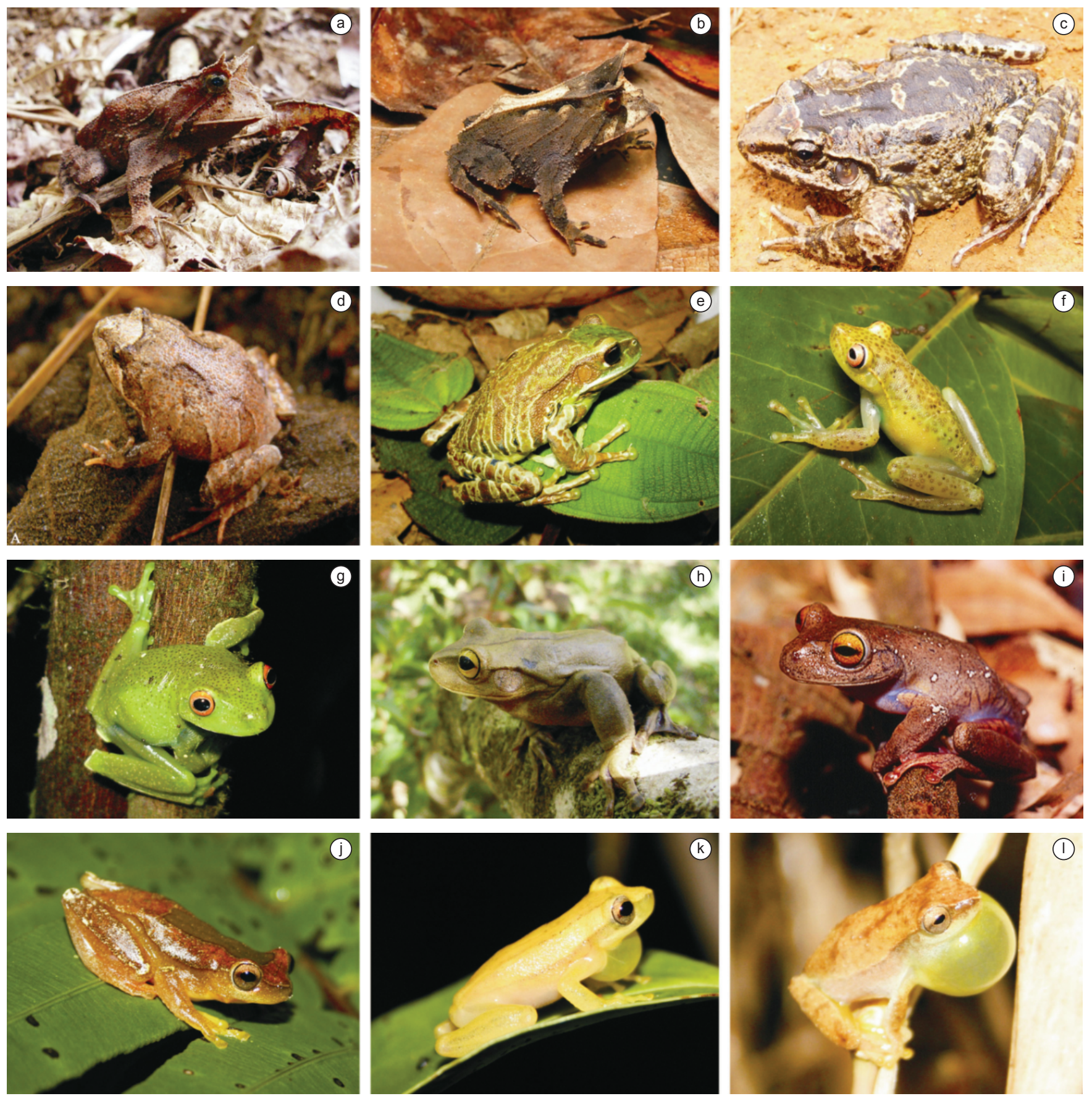

(1)

Figura 3. Anfíbios registrados no Parque Estadual da Serra do Brigadeiro e entorno, estado de Minas Gerais, sudeste do Brasil: a) Proceratophrys boiei, b) Proceratophrys melanopogon, c) Thoropa miliaris, d) Zachaenus carvalhoi, e) Gastrotheca ernestoi, f) Aplastodiscus arildae, g) Aplastodiscus leucopygius, h) Bokermannohyla caramaschii, i) Bokermannohyla ibitipoca, j) Dendropsophus elegans, k) Dendropsophus decipiens, 1) Dendropsophus minutus. Crédito das fotos: C. Coelho-Augusto (j, k, l), D.J. Santana (c, f), E.T. Silva (d), M.R. Moura (a, e, g, h), R.N. Feio (i), S. Mângia (b).

Figure 3. Amphibians from Serra do Brigadeiro State Park and surroundings, state of Minas Gerais, southeastern Brazil: a) Proceratophrys boiei, b) Proceratophrys melanopogon, c) Thoropa miliaris, d) Zachaenus carvalhoi, e) Gastrotheca ernestoi, f) Aplastodiscus arildae , g) Aplastodiscus leucopygius, h) Bokermannohyla caramaschii, i) Bokermannohyla ibitipoca, j) Dendropsophus elegans, k) Dendropsophus decipiens, 1) Dendropsophus minutus. Photo credits: C. Augusto-Coelho (j, k, 1), D.J. Santana (c, f), E.T. Silva (d), M.R. Moura (a, e, g, h), R.N. Feio (i), S. Mângia (b).

(e.g. Feio et al. 1999) ou P. aff. olfersii (e.g. Feio et al. 2008a, Assis 2009, Lacerda et al. 2009b). A Serra do Brigadeiro consistia no limite norte de sua distribuição, a qual foi recentemente expandida para áreas $110 \mathrm{~km}$ ao norte (Silva et al. 2011). Cassini et al. (2010) menciona espécimes de $P$. feioi para a região metrolopolitana de Belo Horizonte, nos municípios de Barão de Cocais e Caeté, ao norte das áreas relacionadas por Silva et al. (2011), entretanto, tais espécimes correspondem na realidade a P. orophilus (C.S. Cassini, com. pess.). Physalaemus maximus foi descrito a partir de exemplares coletados na Serra do Brigadeiro, além do PESB, sua distribuição é conhecida somente para a Serra do Ouro Branco, município de Ouro Preto (Baêta et al. 2005) (Figura 11e). 

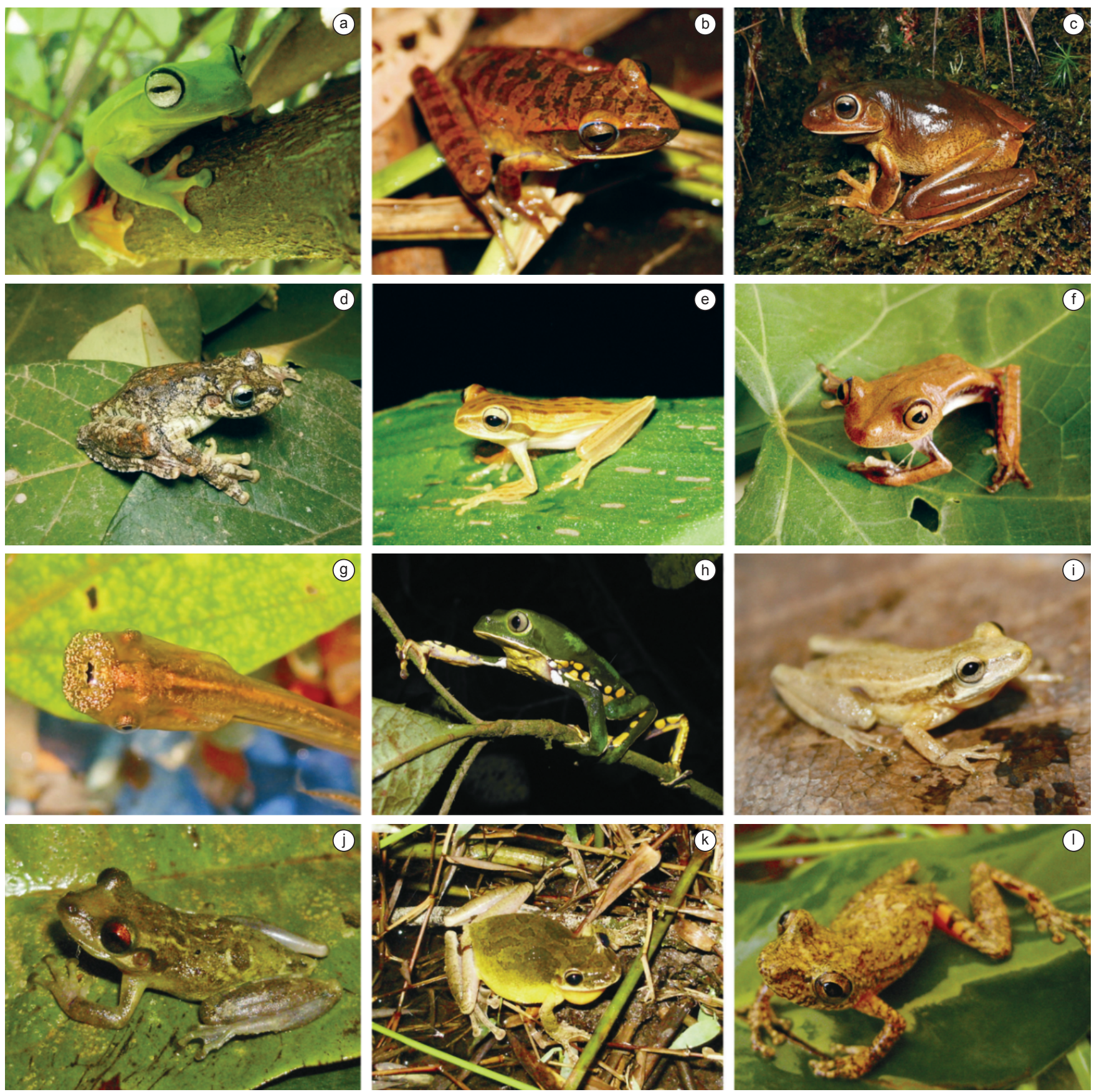

Figura 4. Anfíbios registrados no Parque Estadual da Serra do Brigadeiro e entorno, estado de Minas Gerais, sudeste do Brasil: a) Hypsiboas albomarginatus, b) Hypsiboas albopunctatus, c) Hypsiboas faber, d) Hypsiboas pardalis, e) Hypsiboas polytaenius, f) Hypsiboas semilineatus, g) Phasmahyla sp., h) Phyllomedusa burmeisteri, i) Scinax alter, j) Scinax crospedospilus, k) Scinax eurydice, 1) Scinax flavoguttatus. Crédito das fotos: A.P. Motta (h), C. CoelhoAugusto (b, i), D.J. Santana (d), M.R. Moura (a, e, f, j, k, l), R.F. Feio (g), S. Mângia (c).

Figure 4. Amphibians from Serra do Brigadeiro State Park and surroundings, state of Minas Gerais, southeastern Brazil: a) Hypsiboas albomarginatus, b) Hypsiboas albopunctatus, c) Hypsiboas faber, d) Hypsiboas pardalis, e) Hypsiboas polytaenius, f) Hypsiboas semilineatus, g) Phasmahyla sp., h) Phyllomedusa burmeisteri i) Scinax alter, j) Scinax crospedospilus, k) Scinax eurydice, 1) Scinax flavoguttatus. Photo credits: A.P. Motta (h), C. Coelho-Augusto (b, i), D.J. Santana (d), M.R. Moura (a, e, f, j, k, l), R.F. Feio (g), S. Mângia (c).

Leptodactylus cupreus, também descrito a partir de exemplares coletados no setor amostral sul da Serra do Brigadeiro, teve sua distribuição expandida para o município de Santa Teresa, Espírito Santo (Peres et al. 2010), e recentemente relatada para áreas ao norte deste estado, nos municípios de Linhares e Barra do São Francisco (Almeida et al. 2011). Atualmente, a Serra do Brigadeiro representa o limite continental de sua distribuição (Figura 11f). Outra espécie descrita do setor amostral sul é Chiasmocleis mantiqueira, coletada a 1220 m elevação (Cruz et al. 2007). Esta espécie também foi observada em poça temporária no setor amostral central, a $1380 \mathrm{~m}$, elevação que corresponde a maior cota altimétrica conhecida para o gênero Chiasmocleis, anteriormente com distribuição limitada a elevações de aproximadamente $800 \mathrm{~m}$ (Cruz et al. 2007). Araújo et al. (2009) reportaram a ocorrência de $C$. mantiqueira para áreas de Mata 

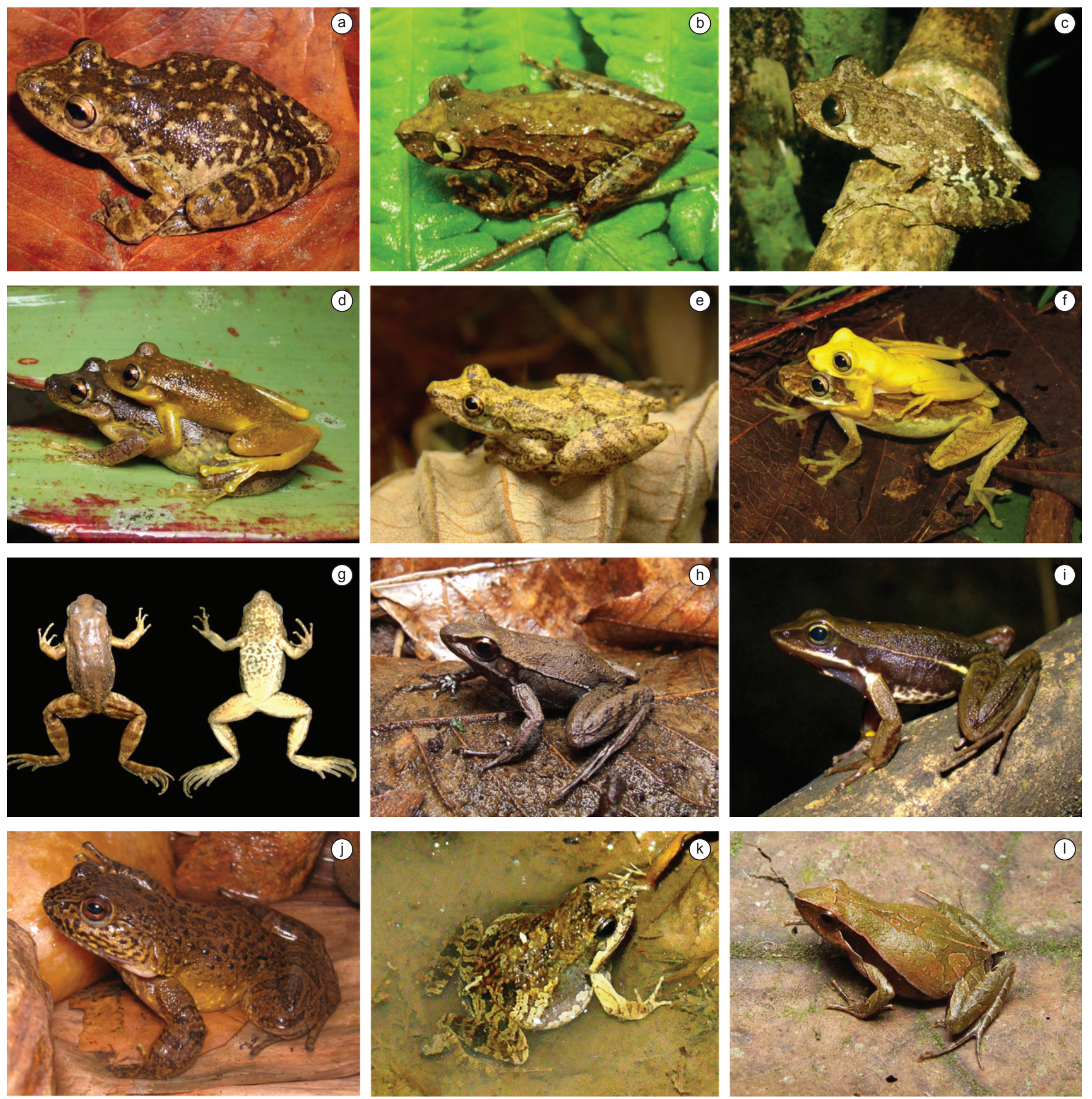

Figura 5. Anfíbios registrados no Parque Estadual da Serra do Brigadeiro e entorno, estado de Minas Gerais, sudeste do Brasil: a) Scinax fuscovarius, b) Scinax luizotavioi, c) Scinax cf. tripui, d) Scinax sp. (aff. perereca), e) Scinax sp. (aff. perpusillus), f) Scinax sp. (aff. rizibilis), g) Crossodactylus gr. gaudichaudii, h) Hylodes babax, i) Hylodes lateristrigatus, j) Megaelosia apuana, k) Physalaemus cuvieri, 1) Physalaemus feioi. Crédito das fotos: A.P. Motta (e), D.J. Santana (h, k, 1), E.T. Silva (f, i), M.R. Moura (b, c, g), R.N. Feio (a, j), S. Mângia (d).

Figure 5. Amphibians from Serra do Brigadeiro State Park and surroundings, state of Minas Gerais, southeastern Brazil: a) Scinax fuscovarius, b) Scinax luizotavioi, c) Scinax cf. tripui, d) Scinax sp. (aff. perereca), e) Scinax sp. (aff. perpusillus), f) Scinax sp. (aff. rizibilis), g) Crossodactylus gr. gaudichaudii, h) Hylodes babax, i) Hylodes lateristrigatus, j) Megaelosia apuana, k) Physalaemus cuvieri, 1) Physalaemus feioi. Photo credits: A.P. Motta (e), D.J. Santana (h, k, l), E.T. Silva (f, i), M.R. Moura (b, c, g), R.N. Feio (a, j), S. Mângia (d).

Atlântica no estado de São Paulo, embora a localidade específica do registro não tenha sido fornecida.

Outro registro importanteéo da cecília Luetkenotyphlus brasiliensis, correspondendo ao limite norte de sua distribuição (Mott et al. 2011). Esta cecília era conhecida anteriormente para áreas do litoral de São Paulo a Santa Catarina (Dunn 1942), atingindo a Argentina (Heer \& Lanari 1998) e Paraguai (Nussbaum 1986).

\section{Répteis}

Foram registradas 40 espécies de répteis para a região estudada, sendo nove lagartos, uma anfisbênia, um quelônio e 29 serpentes (Tabela 3, Figuras 6 a 9). Entre as espécies de répteis registradas, 24 (60\%) apresentam ampla distribuição no domínio da Mata Atlântica, sendo cinco espécies de lagartos (55,55\% destes) e 19 serpentes 

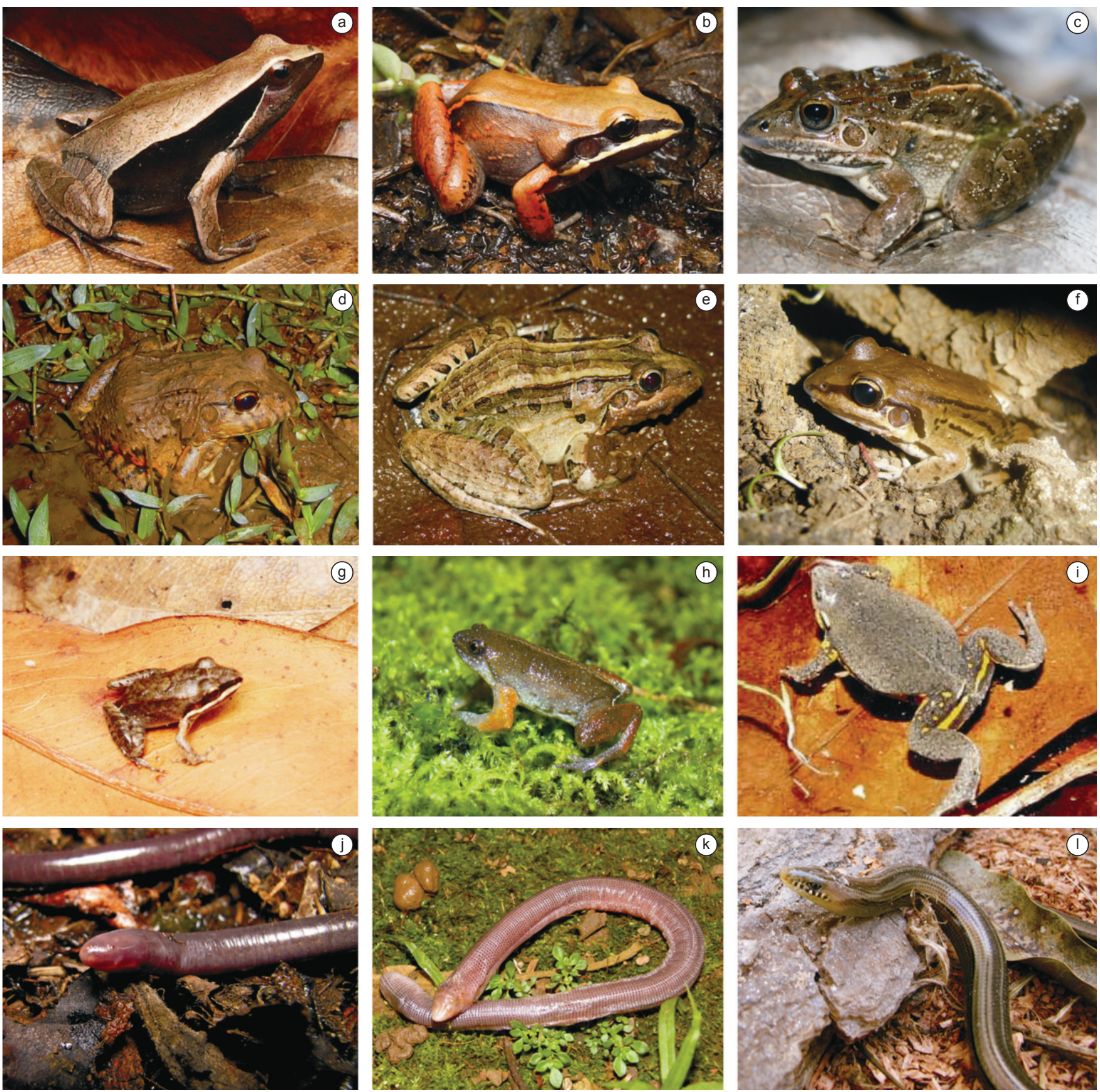

Figura 6. Anfíbios e répteis registrados no Parque Estadual da Serra do Brigadeiro e entorno, estado de Minas Gerais, sudeste do Brasil: a) Physalaemus maximus, b) Leptodactylus cupreus, c) Leptodactylus fuscus, d) Leptodactylus labirinthycus (espécime proveniente de Caratinga, $60 \mathrm{~km}$ ao norte da Serra do Brigadeiro), e) Leptodactylus latrans, f) Leptodactylus mystacinus (espécime proveniente de Viçosa, $30 \mathrm{~km}$ a oeste da Serra do Brigadeiro), g) Leptodactylus sp. (aff. mystaceus), h) Chiasmocleis mantiqueira, i) Elachistocleis cesarii), j) Luetkenotyphlus brasiliensis, k) Amphisbaena microcephala, l) Ophiodes striatus. Créditos das fotos: C. Coelho-Augusto (c,e), D.J. Santana (a, b, i), E.T. Silva (d, h), H.C. Costa (j), J.S. Dayrell (f), M.R. Moura (g), V.A. São-Pedro (k, 1).

Figure 6. Amphibians and reptiles from Serra do Brigadeiro State Park and surroundings, state of Minas Gerais, southeastern Brazil: a) Physalaemus maximus, b) Leptodactylus cupreus, c) Leptodactylus fuscus, d) Leptodactylus labirinthycus (espécime proveniente de Caratinga, $60 \mathrm{~km}$ ao norte da Serra do Brigadeiro), e) Leptodactylus latrans, f) Leptodactylus mystacinus (specimen from Viçosa, $30 \mathrm{~km}$ western from Serra do Brigadeiro), g) Leptodactylus sp. (aff. mystaceus), h) Chiasmocleis mantiqueira, i) Elachistocleis cesarii), j) Luetkenotyphlus brasiliensis, k) Amphisbaena microcephala, l) Ophiodes striatus. Photo credits: C. Coelho-Augusto (c,e), D.J. Santana (a, b, i), E.T. Silva (d, h), H.C. Costa (j), J.S. Dayrell (f), M.R. Moura (g), V.A. São-Pedro (k, 1).

(65,51\% destas). As demais espécies apresentam distribuição geográfica em mais de um bioma, correspondendo a $40 \%(\mathrm{~N}=16)$ das espécies registradas (Tabela 3 ). O método mais eficiente para o registro de répteis foi a adoção de postos de coleta (PC), que possibilitou o registro de 16 espécies (40\%), 14 delas serpentes. A consulta a coleções científicas (CC) e o método de encontro ocasional (EO) permitiram o registro de
$11(27,5 \%)$ e 14 (35\%) espécies respectivamente, seguidos pelo uso de armadilhas de interceptação e queda (AIQ) que registrou sete espécies $(17,5 \%)$ (Tabela 3). Somente uma espécie foi assinalada apenas por registro visual (RV), Tupinambis merianae.

O cágado Hydromedusa maximiliani foi uma espécie considerada como criticamente ameaçada (CR) no estado de Minas Gerais 
Tabela 3. Lista de espécies de répteis registradas para o Parque Estadual da Serra do Brigadeiro e entorno, Minas Gerais, sudeste do Brasil.

Table 3. Species list of reptiles recorded at the Serra do Brigadeiro State Park and surroundings, state of Minas Gerais, southeastern Brazil.

\begin{tabular}{|c|c|c|c|}
\hline Família/espécie & Tipo de registro & Setor amostral & Área de registro \\
\hline \multicolumn{4}{|l|}{ TESTUDINES } \\
\hline \multicolumn{4}{|l|}{ Chelidae } \\
\hline 1. Hydromedusa maximiliani (Mikan, 1820) ${ }^{a}$ & $\mathrm{EO}, \mathrm{RV}$ & $\mathrm{C}, \mathrm{S}$ & $\mathrm{P}, \mathrm{E}$ \\
\hline \multicolumn{4}{|l|}{ SQUAMATA - Amphisbaenia } \\
\hline \multicolumn{4}{|l|}{ Amphisbaenidae } \\
\hline 1. Amphisbaena microcephala (Wagler, 1824) ${ }^{c}$ & $\mathrm{PC}, \mathrm{EO}$ & $\mathrm{C}, \mathrm{S}$ & $\mathrm{P}, \mathrm{E}$ \\
\hline \multicolumn{4}{|l|}{ SQUAMATA - Lacertillia } \\
\hline \multicolumn{4}{|l|}{ Anguidae } \\
\hline 1. Ophiodes striatus $(\text { Spix, } 1825)^{c}$ & $\mathrm{PC}$ & $\mathrm{C}, \mathrm{S}$ & $\mathrm{P}, \mathrm{E}$ \\
\hline \multicolumn{4}{|l|}{ Gymnophtalmidae } \\
\hline 1. Ecpleopus gaudichaudii Duméril \& Bibron, $1839^{a}$ & $\mathrm{CC}$ & $\mathrm{C}$ & $\mathrm{E}$ \\
\hline 2. Heterodactylus imbricatus Spix, $1825^{a}$ & AQ & $\mathrm{C}, \mathrm{N}$ & $\mathrm{P}$ \\
\hline \multicolumn{4}{|l|}{ Leiosauridae } \\
\hline 1. Enyalius bilineatus Duméril \& Bibron, $1837^{a}$ & EO & $\mathrm{S}$ & $\mathrm{E}$ \\
\hline 2. Enyalius perditus Jackson, $1978^{a}$ & AQ & $\mathrm{C}, \mathrm{S}$ & $\mathrm{P}$ \\
\hline 3. Urostrophus vautieri Duméril \& Bibron, $1837^{c}$ & AQ & $\mathrm{C}, \mathrm{N}$ & $\mathrm{P}$ \\
\hline \multicolumn{4}{|l|}{ Scincidae } \\
\hline 1. Mabuya dorsivittata Cope, $1862^{c}$ & $\mathrm{EO}$ & $\mathrm{C}, \mathrm{N}, \mathrm{S}$ & $\mathrm{P}$ \\
\hline \multicolumn{4}{|l|}{ Teiidae } \\
\hline 1. Tupinambis merianae (Duméril \& Bibron, 1839) ${ }^{c}$ & RV & $\mathrm{C}, \mathrm{N}, \mathrm{S}$ & $\mathrm{P}, \mathrm{E}$ \\
\hline \multicolumn{4}{|l|}{ Tropiduridae } \\
\hline 1. Tropidurus torquatus $(\text { Wied, } 1820)^{a}$ & $\mathrm{AQ}, \mathrm{RV}$ & $\mathrm{C}, \mathrm{N}, \mathrm{S}$ & $\mathrm{P}, \mathrm{E}$ \\
\hline \multicolumn{4}{|l|}{ SQUAMATA - Serpentes } \\
\hline \multicolumn{4}{|l|}{ Boidae } \\
\hline 1 Epicrates sp. ${ }^{c}$ & $\mathrm{CC}$ & - & - \\
\hline \multicolumn{4}{|l|}{ Colubridae } \\
\hline 1. Chironius bicarinatus (Wied, 1820) ${ }^{a}$ & $\mathrm{PC}$ & $\mathrm{C}, \mathrm{S}$ & $\mathrm{P}$ \\
\hline 2. Chironius quadricarinatus $\left(\right.$ Boie, 1827) ${ }^{c}$ & EO & $\mathrm{S}$ & $\mathrm{P}$ \\
\hline 3. Echinanthera melanostigma (Wagler, 1824) ${ }^{a}$ & $\mathrm{PC}$ & $\mathrm{C}$ & $\mathrm{P}$ \\
\hline 4. Echinanthera undulata $(\text { Wied, } 1824)^{a}$ & AQ & $\mathrm{C}$ & $\mathrm{P}$ \\
\hline 5. Elapomorphus lepidus Reinhardt, $1861^{a}$ & AQ & $\mathrm{C}$ & $\mathrm{P}$ \\
\hline 6. Elapomorphus quinquelineatus (Raddi, 1820) ${ }^{a}$ & $\mathrm{CC}$ & $\mathrm{C}$ & $\mathrm{E}$ \\
\hline 7. Erythrolamprus aesculapii (Linnaeus, 1766) ${ }^{c}$ & EO & $\mathrm{S}$ & $\mathrm{E}$ \\
\hline 8. Liophis jaegeri (Günther, 1858) ${ }^{a}$ & $\mathrm{CC}$ & - & $\mathrm{E}$ \\
\hline 9. Liophis miliaris (Linnaeus, 1758) ${ }^{c}$ & $\mathrm{PC}$ & $\mathrm{C}$ & $\mathrm{E}$ \\
\hline 10. Liophis poecilogyrus $(\text { Wied, } 1825)^{a}$ & $\mathrm{PC}$ & $\mathrm{C}$ & $\mathrm{E}$ \\
\hline 11. Oxyrhopus clathratus Duméril, Bibron \& Duméril, $1854^{a}$ & $\mathrm{AQ}, \mathrm{PC}$ & $\mathrm{C}$ & $\mathrm{P}, \mathrm{E}$ \\
\hline 12. Oxyrhopus guibei Hoge \& Romano, $1978^{c}$ & $\mathrm{CC}$ & - & $\mathrm{E}$ \\
\hline 13. Oxyrhopus petola (Linnaeus, 1758) ${ }^{c}$ & $\mathrm{CC}$ & - & $\mathrm{E}$ \\
\hline 14. Oxyrhopus trigeminus Duméril, Bibron \& Duméril, $1854^{c}$ & $\mathrm{CC}$ & - & $\mathrm{E}$ \\
\hline 15. Philodryas olfersii (Lichtenstein, 1823) ${ }^{a}$ & $\mathrm{EO}, \mathrm{PC}$ & $\mathrm{C}, \mathrm{S}$ & $\mathrm{P}, \mathrm{E}$ \\
\hline 16. Sibynomorphus mikanii (Schlegel, 1837) ${ }^{c}$ & $\mathrm{CC}$ & - & $\mathrm{E}$ \\
\hline 17. Sibynomorphus neuwiedi (Ihering, 1911) ${ }^{a}$ & $\mathrm{PC}$ & $\mathrm{C}, \mathrm{S}$ & $\mathrm{E}$ \\
\hline 18. Spilotes pullatus (Linnaeus, 1758) ${ }^{a}$ & EO & $\mathrm{C}$ & $\mathrm{E}$ \\
\hline 19. Taeniophallus affinis (Günther, 1858) ${ }^{a}$ & $\mathrm{PC}$ & $\mathrm{C}$ & $\mathrm{P}, \mathrm{E}$ \\
\hline 20. Tropidodryas striaticeps (Cope, 1869) ${ }^{a}$ & $\mathrm{EO}, \mathrm{PC}$ & $\mathrm{C}$ & $\mathrm{P}, \mathrm{E}$ \\
\hline
\end{tabular}

Método de amostragem: AIQ = armadilha de interceptação e queda, $\mathrm{CC}=$ registro de coleção científica, $\mathrm{EO}=$ encontro ocasional, $\mathrm{PC}=$ postos de coleta, $\mathrm{RV}=$ registro visual. Setor amostral: $\mathrm{C}=$ central, $\mathrm{N}=$ norte, $\mathrm{S}=$ sul. Área de registro: $\mathrm{P}=$ interior do Parque, $\mathrm{E}=$ entorno do Parque. Índices: $\mathrm{a}=$ espécie com distribuição geográfica ampla na Mata Atlântica, $\mathrm{c}=$ espécie com distribuição em mais de um bioma.

Sampling method: $\mathrm{AIQ}=$ pitfall traps with drift fences, $\mathrm{CC}=$ record of scientific collection, $\mathrm{EO}=$ incidental encounter, $\mathrm{PC}=$ local collectors, $\mathrm{RV}=\mathrm{visual}$ record. Sampling sector: $\mathrm{C}=$ central, $\mathrm{N}=$ north $\mathrm{S}=$ south. Area of register: $\mathrm{P}=$ inside the Park, $\mathrm{E}=$ outside the Park. Index: $\mathrm{a}=$ widespread species in the Atlantic Forest, $\mathrm{c}=$ species distributed in more than one biome. 
Moura, M.R. et al.

Tabela 3. Continuação...

\begin{tabular}{|c|c|c|c|}
\hline Família/espécie & Tipo de registro & Setor amostral & Área de registro \\
\hline 21. Thamnodynastes $\mathrm{cf}$. nattereri ${ }^{a}$ & $\mathrm{EO}, \mathrm{PC}$ & $\mathrm{C}, \mathrm{N}$ & $\mathrm{P}$ \\
\hline 22. Xenodon merremii (Wagler, 1824) ${ }^{c}$ & $\mathrm{EO}, \mathrm{PC}$ & $\mathrm{C}$ & $\mathrm{E}$ \\
\hline 23. Xenodon neuwiedii Günther, $1863^{a}$ & $\mathrm{EO}, \mathrm{PC}$ & $\mathrm{C}, \mathrm{N}$ & $\mathrm{P}, \mathrm{E}$ \\
\hline \multicolumn{4}{|l|}{ Elapidae } \\
\hline 1. Micrurus corallinus (Merrem, 1820) ${ }^{a}$ & $\mathrm{CC}$ & - & $\mathrm{E}$ \\
\hline 2. Micrurus frontalis (Duméril, Bibron \& Duméril, 1854) ${ }^{c}$ & $\mathrm{EO}, \mathrm{PC}$ & $\mathrm{C}$ & $\mathrm{P}, \mathrm{E}$ \\
\hline 3. Micrurus lemniscatus (Linnaeus, 1758) ${ }^{c}$ & $\mathrm{CC}$ & $\mathrm{C}$ & $\mathrm{E}$ \\
\hline \multicolumn{4}{|l|}{ Leptotyphlopidae } \\
\hline 1. Tricheilostoma salgueiroi (Amaral, 1955) ${ }^{a}$ & $\mathrm{CC}$ & - & $\mathrm{E}$ \\
\hline \multicolumn{4}{|l|}{ Viperidae } \\
\hline 1. Bothropoides jararaca $\left(\right.$ Wied, 1824) ${ }^{a}$ & $\mathrm{EO}, \mathrm{PC}$ & $\mathrm{C}, \mathrm{S}$ & $\mathrm{P}, \mathrm{E}$ \\
\hline
\end{tabular}

Método de amostragem: $\mathrm{AIQ}=$ armadilha de interceptação e queda, $\mathrm{CC}=$ registro de coleção científica, $\mathrm{EO}=$ encontro ocasional, $\mathrm{PC}=$ postos de coleta, $\mathrm{RV}=$ registro visual. Setor amostral: $\mathrm{C}=$ central, $\mathrm{N}=$ norte, $\mathrm{S}=$ sul. Área de registro: $\mathrm{P}=$ interior do Parque, $\mathrm{E}=$ entorno do Parque. Índices: $\mathrm{a}=$ espécie com distribuição geográfica ampla na Mata Atlântica, c = espécie com distribuição em mais de um bioma.

Sampling method: AIQ = pitfall traps with drift fences, $\mathrm{CC}=$ record of scientific collection, $\mathrm{EO}=$ incidental encounter, $\mathrm{PC}=$ local collectors, $\mathrm{RV}=$ visual record. Sampling sector: $\mathrm{C}=$ central, $\mathrm{N}=$ north, $\mathrm{S}=$ south. Area of register: $\mathrm{P}=$ inside the Park, $\mathrm{E}=$ outside the Park. Index: $\mathrm{a}=$ widespread species in the Atlantic Forest, $\mathrm{c}=$ species distributed in more than one biome.

(Machado et al. 1998). Atualmente a espécie é listada como "VU" nas listas de espécies da fauna ameaçadas de extinção para o estado de Minas Gerais (Martins et al. 2008), do Espírito Santo (Almeida et al. 2007) e da IUCN (International... 2011). A mudança de categoria na atual lista de Minas Gerais deve-se principalmente ao encontro dessa espécie em outras localidades do estado (Fundação... 2007). O lagarto Enyalius perditus está entre as espécies consideradas como quase ameaçadas (NT) na lista da fauna ameaçada de extinção do estado do Rio de Janeiro, pouco é conhecido sobre a espécie, as populações são raras naquele estado e ela é mal representada em coleções (Rocha et al. 2000). As demais espécies de répteis registradas na Serra do Brigadeiro não figuram entre nenhuma das categorias de ameaça nas listas da fauna de espécies ameaçadas do Brasil (Machado et al. 2008), Minas Gerais (Fundação... 2007, Drummond et al. 2008, Conselho... 2010), Espírito Santo (Passamani \& Mendes 2007), Rio de Janeiro (Bergallo et al. 2000).

Jackson (1978), baseado em espécimes coletados por João Moojen de Oliveira, reporta a ocorrência de Enyalius brasiliensis Lesson, 1828 para o município de Araponga. Entretanto, a espécie não foi registrada neste estudo para a região da Serra do Brigadeiro. Segundo Jackon (1978), o nicho de Enyalius da Mata Atlântica (exceto E bilineatus, adaptado a áreas abertas) é similar, de forma que a especiação possa ter ocorrido de forma alopátrica, sendo que as únicas populações sintópicas conhecidas para o gênero são entre Enyalius iheringii Boulenger, 1885 e E. perditus, no leste de São Paulo e sudoeste do Rio de Janeiro. Jackson (1978) também sugere que uma expansão nordeste da distribuição de $E$. perditus tenha propiciado a simpatria desta com E. brasiliensis em algumas áreas, embora não haja referência a sintopia. Os espécimes de E. brasiliensis coletados estariam depositados no ICBUFV (atual coleção MZUFV), estes não foram encontrados, e provavelmente encontram-se perdidos. Dada a impossibilidade de se rastrear o material testemunho de Jackson (1978) e o frequente registro de E. perditus na Serra do Brigadeiro, optou-se por não considerar a inclusão de E. brasiliensis entre as espécies de répteis aqui listadas. Entretanto, trata-se de uma espécie comum em áreas de mata na região de Viçosa (Costa et al. 2009a), sendo possível que futuros estudos confirmem sua ocorrência na região da Serra do Brigadeiro.
Destaca-se a ocorrência de duas serpentes, Echinanthera melanostigma e E. undulata. A primeira tem na Serra do Brigadeiro o segundo registro para o estado de Minas Gerais (Costa et al. 2010), além do limite leste de sua distribuição (Figura 12a). Embora a localidade tipo desta espécie seja o estado da Bahia, a mesma é dada como incerta (Di-Bernardo 1992). Os espécimes citados por Argôlo (2004) para o sudeste da Bahia correspondem na realidade à E. cephalostriata (A.J.S. Argôlo, com. pess.). Deste modo, é provável que seu registro para a região de Ouro Preto, no sul da Cadeia do Espinhaço (Silveira et al. 2004b) seja atualmente o limite norte de sua distribuição. Com relação a E. undulata, a Serra do Brigadeiro representa o limite setentrional de sua distribuição, anteriormente conhecida em Minas Gerais para os municípios de Camanducaia e Machado (Di-Bernardo 1992). O registro para a Serra do Brigadeiro também representa a terceira ocorrência para Minas Gerais (Figura 12b).

A seguir são realizados alguns comentários sobre o material testemunho das espécies de serpentes registradas somente por meio de coleções científicas. Epicrates sp. teve seu registro efetuado com base na pele de espécime depositado na coleção científica do MZUFV, coletado em novembro de 1980 no município de Muriaé. O epíteto específico não pode ser confirmado pois o material foi perdido (MZUFV 1358). Embora a distribuição de ambas as espécies possa abranger a Serra do Brigadeiro e entorno (ver Passos \& Fernandes 2008), a ocorrência de E. cenchria é mais provável, dado o seu registro em localidades próximas (e.g. municípios de Rio Casca, Raul Soares e Caratinga, distantes aproximadamente $40 \mathrm{~km}$ dos limites do PESB), (Passos \& Fernandes 2008, Palmuti et al. 2009). Os registros de E. crassus indicados para Minas Gerais por Passos \& Fernandes (2008) correspondem principalmente à localidades no domínio do Cerrado, sendo ausentes na mesorregião da Zona da Mata, onde a Serra do Brigadeiro está inserida.

Costa et al. (2010, Figura 2d), reportam a foto do exemplar MZUFV 1757 em vida, proveniente da Serra do Brigadeiro. No referido trabalho a identidade aferida ao espécime é de $C$. exoletus, entretanto, trata-se de um exemplar C. quadricarinatus (Figura 7j). Embora C. exoletus ocorra na região de Viçosa, próximo à Serra do Brigadeiro, a mesma não foi detectada no presente estudo. 

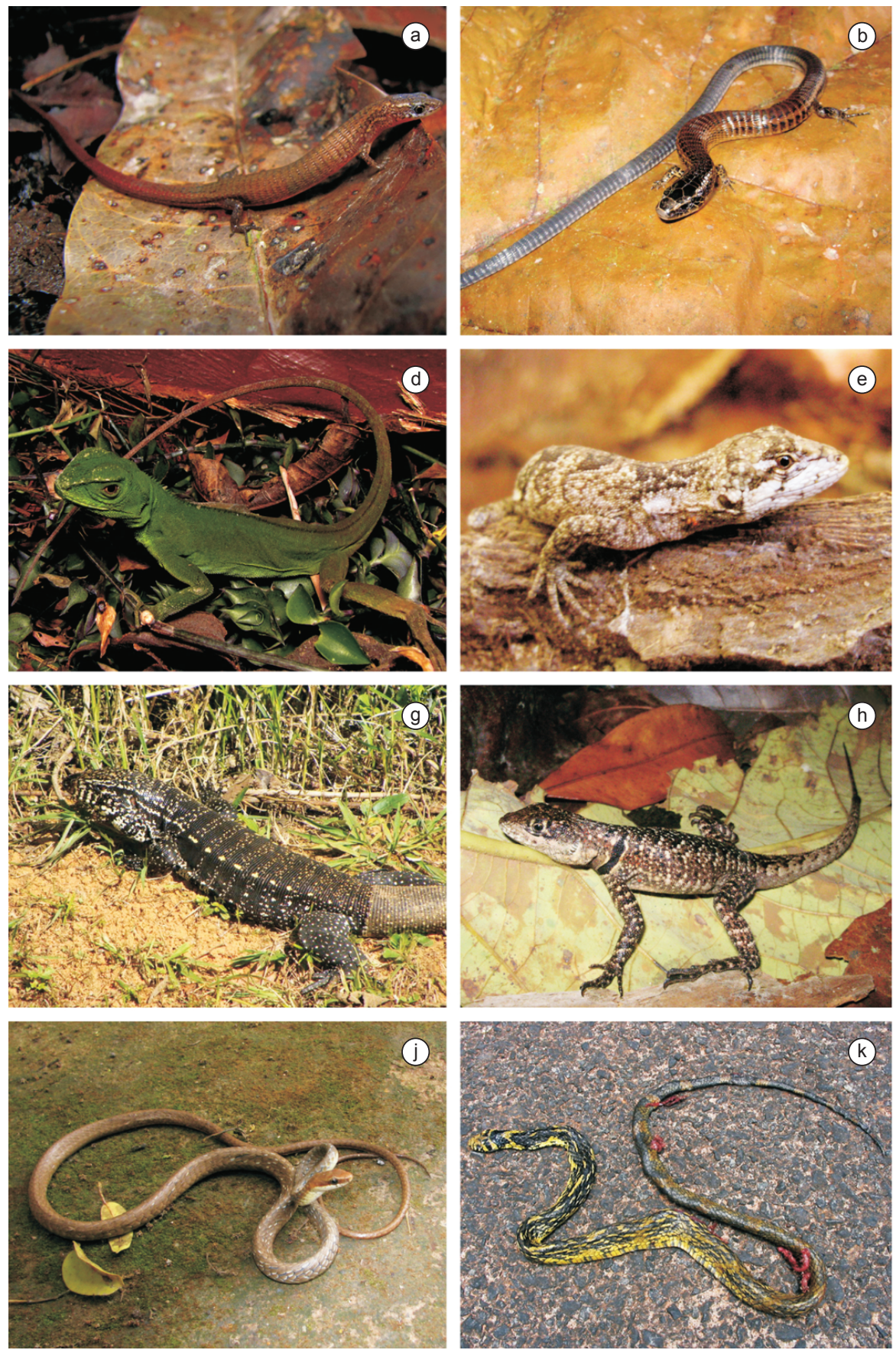
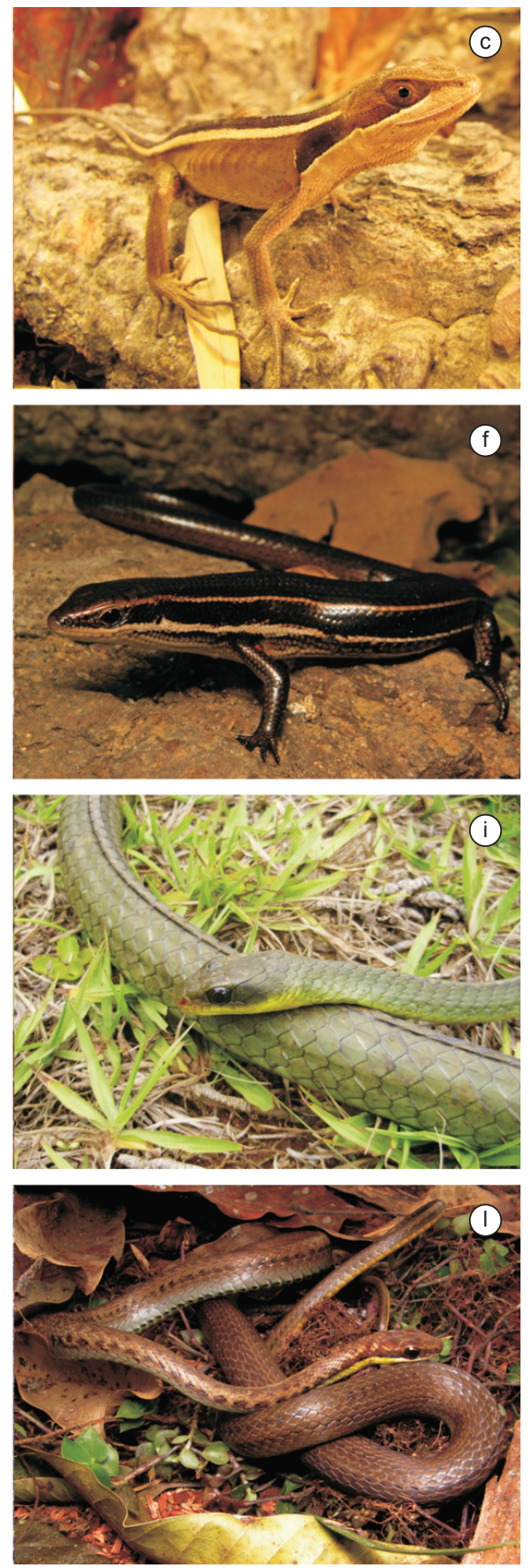

Figura 7. Répteis registrados no Parque Estadual da Serra do Brigadeiro e entorno, estado de Minas Gerais, sudeste do Brasil: a) Ecpleopus gaudichaudi (espécime proveniente de Viçosa, $30 \mathrm{~km}$ a oeste da Serra do Brigadeiro), b) Heterodactylus imbricatus, c) Enyalius bilineatus, d) Enyalius perditus, e) Urostrophus vautieri, f) Mabuya dorsivittata), g) Tupinambis merianae (espécime proveniente de Viçosa, $30 \mathrm{~km}$ a oeste da Serra do Brigadeiro), h) Tropidurus torquatus, i) Chironius bicarinatus, j) Chironius quadricarinatus, k) Spilotes pullatus, 1) Echinanthera melanostigma. Crédito das fotos: A. Rodrigues (g), H.C. Costa (a, d, j, l), M.R. Moura (b, c, e, f, h, i), R.N. Feio (k).

Figure 7. Reptiles from Serra do Brigadeiro State Park and surroundings, state of Minas Gerais, southeastern Brazil: a) Ecpleopus gaudichaudii (specimen from Viçosa, $30 \mathrm{~km}$ western from Serra do Brigadeiro), b) Heterodactylus imbricatus, c) Enyalius bilineatus, d) Enyalius perditus, e) Urostrophus vautieri, f) Mabuya dorsivittata), g) Tupinambis merianae (specimen from Viçosa, $30 \mathrm{~km}$ western from Serra do Brigadeiro), h) Tropidurus torquatus, i) Chironius bicarinatus, j) Chironius quadricarinatus, k) Spilotes pullatus, 1) Echinanthera melanostigma. Photo credits: A. Rodrigues (g), H.C. Costa (a, d, j, l), M.R. Moura (b, c, e, f, h, i), R.N. Feio (k).

O registro de Liophis jaegeri é efetuado com base em um espécime coletado em junho de 1986, proveniente do município de Muriaé (MZUSP 9064), região inserida no setor amostral sul da Serra do Brigadeiro. Oxyrhopus guibei (MCNR 037) e O. trigeminus (MCNR 083) são consideradas com base em espécimes capturados em maio e outubro de 1991, no município de Miradouro, região inserida no setor amostral central. Oxyrhopus petola (MZUFV 1389) é registrada com base em espécime proveniente do município de Muriaé, coletado em abril de 2007. Sibynomorphus mikanii tem seu registro efetuado com base em três espécimes provenientes dos municípios de Ervália 

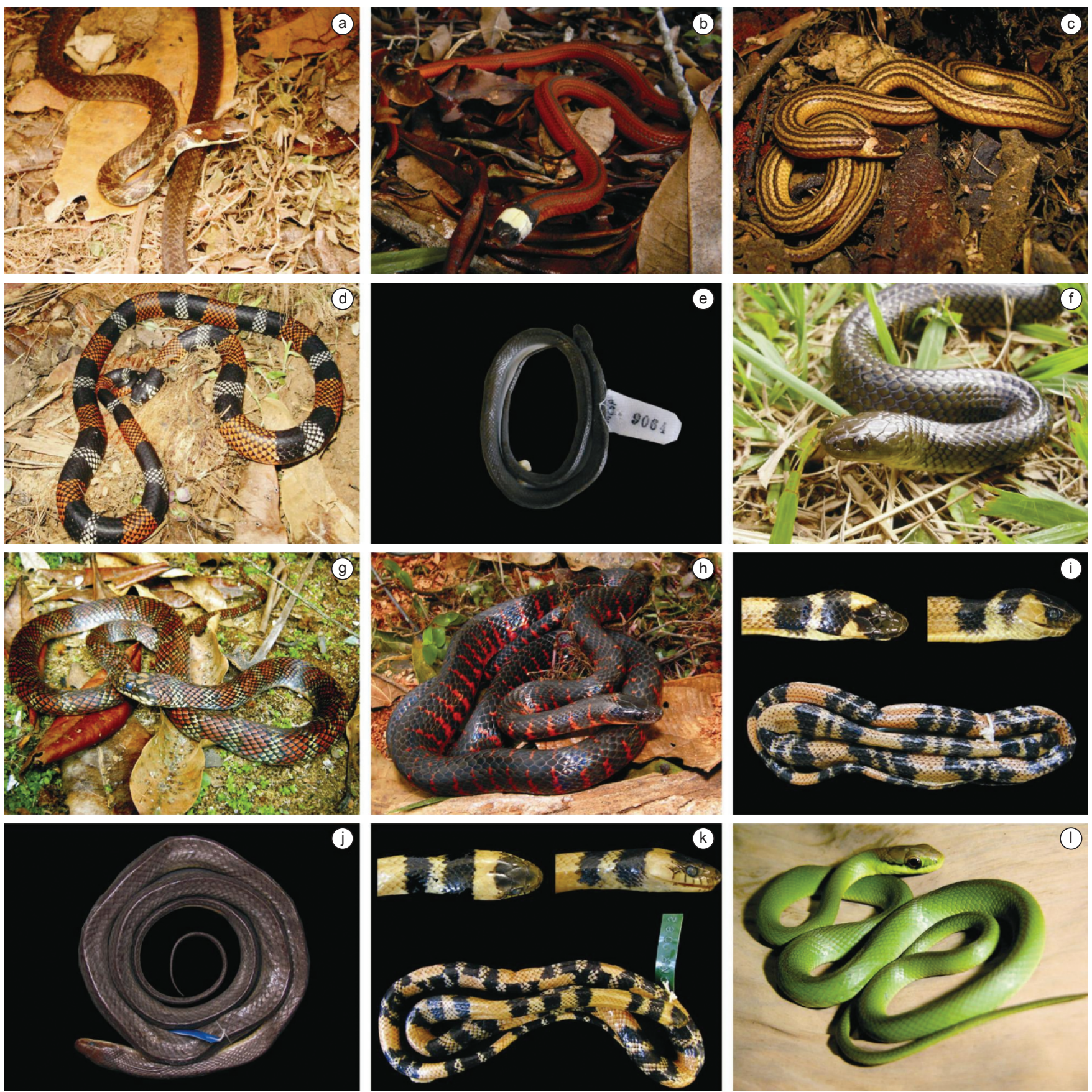

Figura 8. Répteis registrados no Parque Estadual da Serra do Brigadeiro e entorno, estado de Minas Gerais, sudeste do Brasil: a) Echinanthera undulata, b) Elapomorphus lepidus, c) Elapomorphus quinquelineatus (espécime proveniente de Viçosa, $30 \mathrm{~km}$ a oeste da Serra do Brigadeiro), d) Erythrolamprus aesculapii, e) Liophis jaegeri, f) Liophis miliaris, g) Liophis poecilogyrus, h) Oxyrhopus clathratus, i) Oxyrhopus guibei, j) Oxyrhopus petola, k) Oxyrhopus trigeminus, 1) Philodryas olfersii (espécime proveniente de Viçosa, $30 \mathrm{~km}$ a oeste da Serra do Brigadeiro). Crédito das fotos: C. Mello (e), D.J. Santana (g), H.C. Costa (c, h, l), M.R. Moura (a, b, d, f, i, j, l).

Figure 8. Reptiles from Serra do Brigadeiro State Park and surroundings, state of Minas Gerais, southeastern Brazil: a) Echinanthera melanostigma, b) Echinanthera undulata, c) Elapomorphus quinquelineatus (specimen from Viçosa, $30 \mathrm{~km}$ western from Serra do Brigadeiro), d) Erythrolamprus aesculapii, e) Liophis jaegeri, f) Liophis miliaris, g) Liophis poecilogyrus, h) Oxyrhopus clathratus, i) Oxyrhopus guibei, j) Oxyrhopus petola, k) Oxyrhopus trigeminus, 1) Philodryas olfersii (specimen from Viçosa, $30 \mathrm{~km}$ western from Serra do Brigadeiro). Photo credits: C. Mello (e), D.J. Santana (g), H.C. Costa (c, h, 1), M.R. Moura (a, b, d, f, i, j, l).

(MZUFV 1395, MZUFV 1723) e Muriaé (MZUFV 1681), ambos na região sul da Serra do Brigadeiro, coletados entre 2007 e 2009. Duas cobras-corais, Micrurus corallinus, registrada através do espécime MCNR 053 coletado em maio de 1991, proveniente do município de Miradouro e M. lemniscatus, registro obtido através do exame de um exemplar de coleção particular, espécime proveniente do entorno do parque, no município de Fervedouro, tendo sido coletado há mais de 15 anos. Tricheilostoma salgueiroi é considerada a partir de dois espécimes (MZUFV 1397, MZUFV 1519) coletados em 2007 e 2008 no município de Muriaé, localizado na porção meridional da Serra do Brigadeiro. 

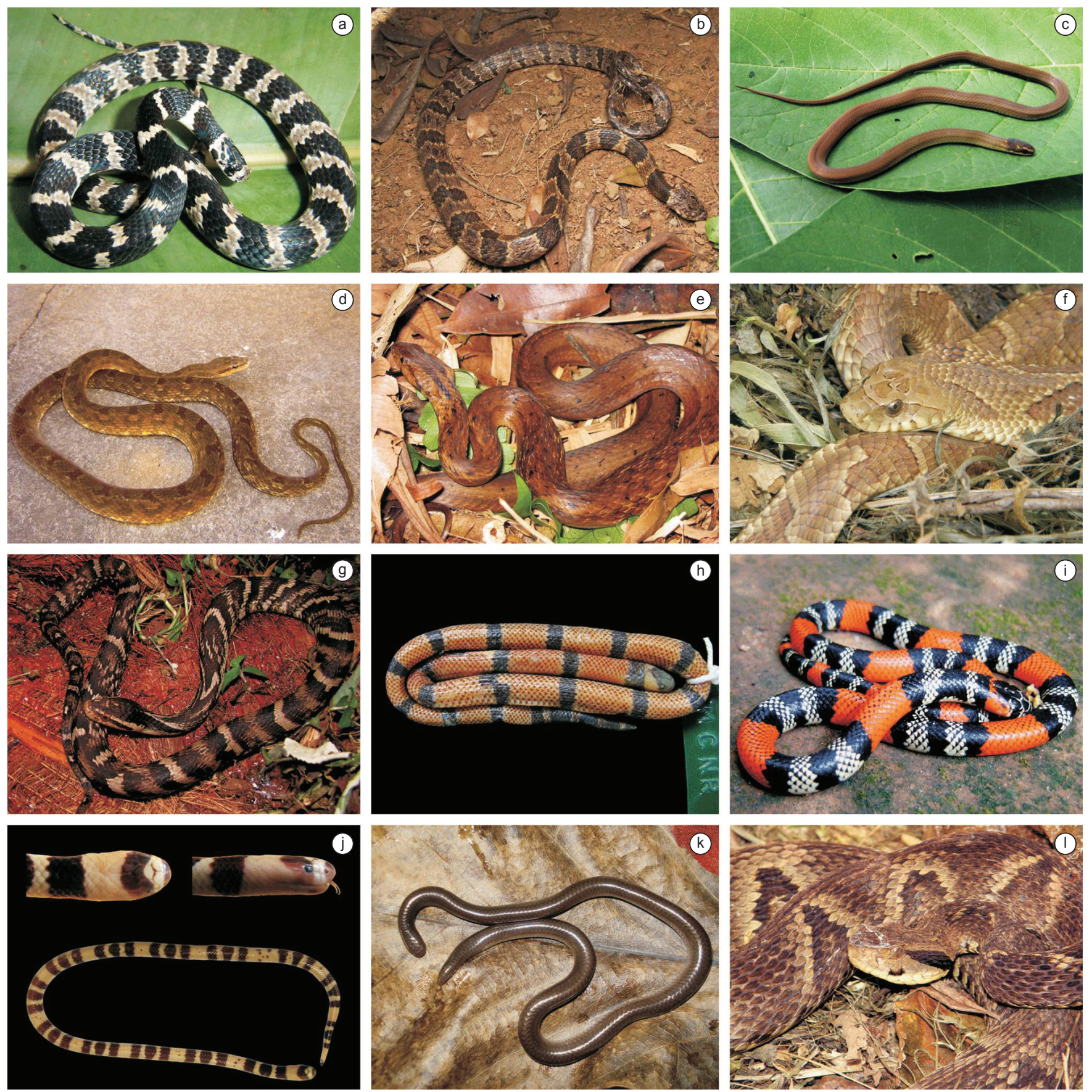

Figura 9. Répteis registrados no Parque Estadual da Serra do Brigadeiro e entorno, estado de Minas Gerais, sudeste do Brasil: a) Sibynomorphus mikanii, b) Sibynomorphus neuwiedi, c) Taeniophallus affinis (espécime proveniente de Viçosa, $30 \mathrm{~km}$ a oeste da Serra do Brigadeiro), d) Tropidodryas striaticeps (espécime proveniente de Porto Firme, $60 \mathrm{~km}$ a oeste da Serra do Brigadeiro), e) Thamnodynastes cf. nattereri, f) Xenodon merremii, g) Xenodon neuwiedii, h) Micrurus corallinus, i) Micrurus frontalis (espécime proveniente de Viçosa, $30 \mathrm{~km}$ a oeste da Serra do Brigadeiro), j) Micrurus lemniscatus, k) Tricheilostoma salgueiroi, 1) Bothropoides jararaca. Créditos das fotos: D.J. Santana (b), H.C. Costa (a, c, d, g, h, i, j, k), R.N. Feio (e), V.D. Fernandes (f, l).

Figure 9. Reptiles from Serra do Brigadeiro State Park and surroundings, state of Minas Gerais, southeastern Brazil: a) Sibynomorphus mikanii, b) Sibynomorphus neuwiedi, c) Taeniophallus affinis (specimen from Viçosa, $30 \mathrm{~km}$ western from Serra do Brigadeiro), d) Tropidodryas striaticeps (specimen from Porto Firme, $60 \mathrm{~km}$ western of Serra do Brigadeiro), e) Thamnodynastes cf. nattereri, f) Xenodon merremii, g) Xenodon neuwiedii, h) Micrurus corallinus, i) Micrurus frontalis (specimen from Viçosa, $30 \mathrm{~km}$ western from Serra do Brigadeiro), j) Micrurus lemniscatus, k) Tricheilostoma salgueiroi, 1) Bothropoides jararaca. Photo credits: D.J. Santana (b), H.C. Costa (a, c, d, g, h, i, k), R.N. Feio (e), V.D. Fernandes (f, 1).

\section{Considerações Finais}

Embora algumas espécies de anfíbios e répteis da Serra do Brigadeiro apresentem distribuição geográfica em mais de um bioma, a maioria dos registros de anfíbios e répteis para esta serra corresponde a espécies com distribuições conhecidas apenas para o domínio morfoclimático da Mata Atlântica, caracterizando a herpetofauna dessa região como típica desse bioma. Um número considerável de espécies apresentou distribuição restrita $(\mathrm{N}=11$; $11,22 \%)$ ou desconhecida $(\mathrm{N}=10 ; 10,20 \%)$. Entretanto, várias das espécies presentes na região constituem complexo de espécies (e.g. Ischnocnema parva, Leptodactylus latrans, Scinax alter, S. flavoguttatus, 

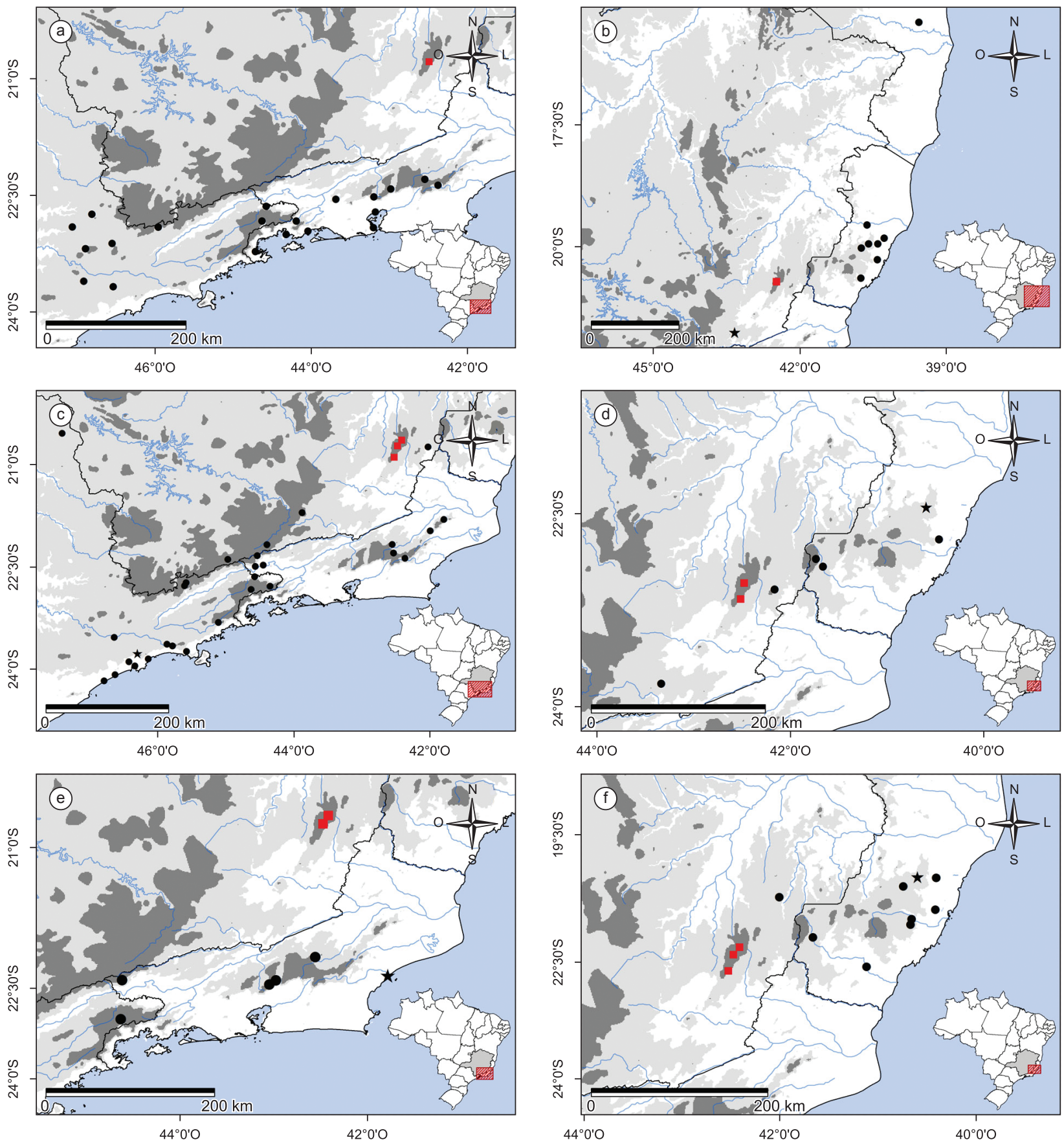

Figura 10. Distribuição geográfica de anfíbios com limites de ocorrência na Serra do Brigadeiro ou distribuição restrita no estado de Minas Gerais. a) Brachycephalus ephippium, b) Ischnocnema verrucosa, c) Proceratophrys melanopogon, d) Zachaenus carvalhoi, e) Gastrotheca ernestoi, f) Bokermannohyla caramaschii. Símbolos: círculo = registro de literatura (Apêndice 2), quadrado = registros nos setores amostrais da Serra do Brigadeiro, estrela $=$ localidade tipo da referida espécie. Áreas em branco = elevações de 0 a 600 m, área em cinza médio = elevações de 600 a $1000 \mathrm{~m}$, áreas em cinza escuro = elevações superiores a $1000 \mathrm{~m}$. Escala $=200 \mathrm{~km}$.

Figure 10. Geographic distribution of amphibians with extremes of it occurrence from Serra do Brigadeiro mountain or distribution restricted in the state of Minas Gerais. a) Brachycephalus ephippium, b) Ischnocnema verrucosa, c) Proceratophrys melanopogon, d) Zachaenus carvalhoi, e) Gastrotheca ernestoi, f) Bokermannohyla caramaschii. Symbols: circle $=$ literature records (Appendix 2), square $=$ records from sampling sectors of the Serra do Brigadeiro mountain, $\mathrm{star}=$ type-locality regarding on species distribution represented. Areas in white $=$ elevations below $600 \mathrm{~m}$, areas in medium gray $=$ elevations between 600 to $1000 \mathrm{~m}$, areas in dark gray $=$ elevations above $1000 \mathrm{~m}$. Scale $=200 \mathrm{~km}$.

S. fuscovarius, Ophiodes striatus, Liophis miliaris), de forma que o número de endemismos para a área pode aumentar, à medida que revisões taxonômicas sejam realizadas.

A Serra do Brigadeiro apresenta alta riqueza de espécies de anfíbios (58 espécies) em relação a outras localidades próximas.
Dentre os levantamentos de espécies para o estado de Minas Gerais presentes na literatura, destacam-se Cardoso \& Haddad (1992), que registraram 19 espécies para o planalto de Morro do Ferro em Poços de Caldas, Feio et al. (1998), com 38 espécies para o Parque Estadual do Rio Doce, Pedralli et al. (2001) com 32 espécies para a região de 

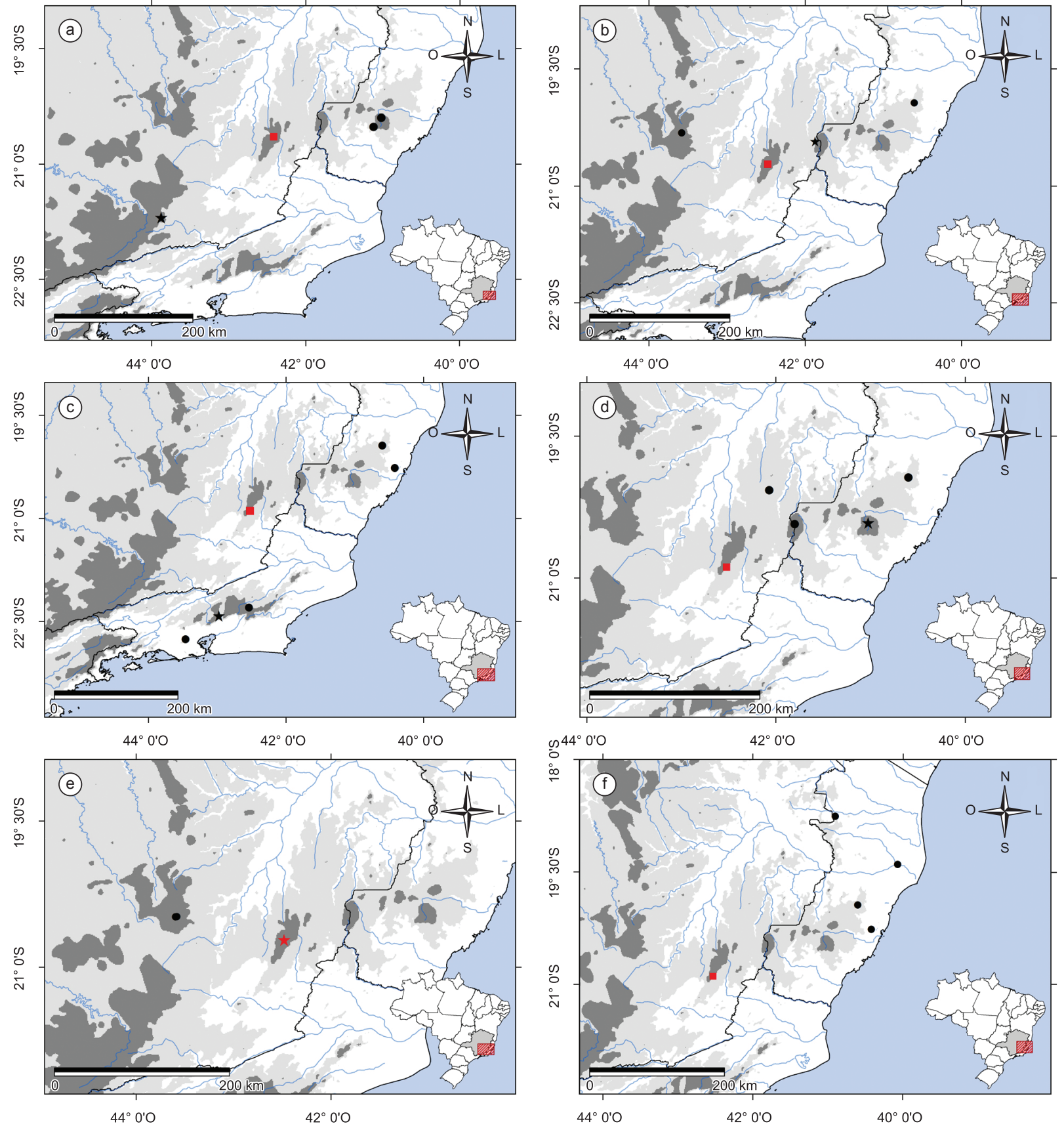

Figura 11. Distribuição geográfica de anfíbios com limites de ocorrência na Serra do Brigadeiro ou distribuição restrita no estado de Minas Gerais: a) Bokermannohyla ibitipoca, b) Hylodes babax, c) Hylodes lateristrigatus, d) Megaelosia apuana, e) Physalaemus maximus, f) Leptodactylus cupreus. Símbolos: círculo $=$ registro de literatura (Apêndice 2), quadrado = registros nos setores amostrais da Serra do Brigadeiro, estrela = localidade tipo da referida espécie. Áreas em branco = elevações de 0 a 600 m, área em cinza médio = elevações de 600 a $1000 \mathrm{~m}$, áreas em cinza escuro = elevações superiores a $1000 \mathrm{~m}$. Escala = $200 \mathrm{~km}$.

Figure 11. Geographic distribution of amphibians with extremes of it occurrence from Serra do Brigadeiro mountain or distribution restricted in the state of Minas Gerais. a) Bokermannohyla ibitipoca, b) Hylodes babax, c) Hylodes lateristrigatus, d) Megaelosia apuana, e) Physalaemus maximus, f) Leptodactylus cupreus. Symbols: circle $=$ literature records $($ Appendix 2$)$, square $=$ records from sampling sectors of the Serra do Brigadeiro mountain, star $=$ type-locality regarding on species distribution represented. Areas in white $=$ elevations below $600 \mathrm{~m}$, areas in medium gray = elevations between 600 to $1000 \mathrm{~m}$, areas in dark gray $=$ elevations above $1000 \mathrm{~m}$. Scale $=200 \mathrm{~km}$.

Ouro Preto, Eterovick \& Sazima (2004) com 43 espécies para a Serra do Cipó, Feio \& Ferreira (2005) com 20 espécies no município de Rio Novo, Canelas \& Bertoluci (2007) com 38 espécies de anuros na Serra do Caraça, Bertoluci et al. (2009) com 30 espécies para a Estação de Pesquisa e Desenvolvimento Ambiental de Peti, Cruz et al. (2009) com 41 espécies para a Serra do Ibitipoca, Santana et al. (2010) com
41 espécies para o município de Muriaé, e São-Pedro \& Feio (2011) com 47 espécies de anfíbios para a Serra do Ouro Branco. O estudo de Santana et al. (2010) ainda se destaca pois foi realizado em área limítrofe a Serra do Brigadeiro e do total de espécies registradas 11 não possuem ocorrência confirmada para a Serra do Brigadeiro, sugerindo que a intensificação de estudos na porção sul da Serra do 

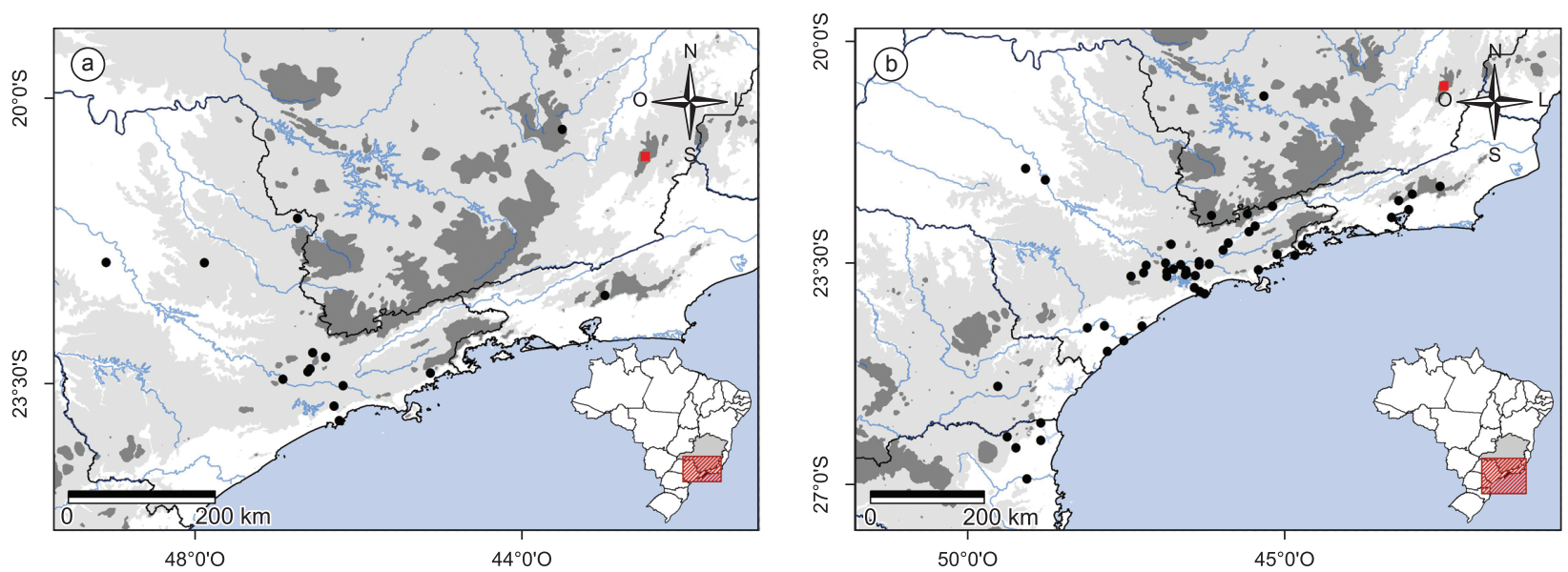

Figura 12. Distribuição geográfica de répteis com limites de ocorrência na Serra do Brigadeiro ou distribuição restrita no estado de Minas Gerais: a) Echinanthera melanostigma, b) Echinanthera undulata. Símbolos: círculo = registro de literatura (Apêndice 2), quadrado = registros nos setores amostrais da Serra do Brigadeiro. Áreas em branco = elevações de 0 a 600 m, área em cinza médio = elevações de 600 a $1000 \mathrm{~m}$, áreas em cinza escuro = elevações superiores a $1000 \mathrm{~m}$. Escala $=200 \mathrm{~km}$.

Figure 12. Geographic distribution of reptiles with extremes of it occurrence from Serra do Brigadeiro mountain or distribution restricted in the state of Minas Gerais. a) Echinanthera melanostigma, b) Echinanthera undulata. Symbols: circle = literature records (Appendix 2), square = records from sampling sectors of the Serra do Brigadeiro mountain. Areas in white $=$ elevations below $600 \mathrm{~m}$, areas in medium gray $=$ elevations between 600 to $1000 \mathrm{~m}$, areas in dark gray $=$ elevations above $1000 \mathrm{~m}$. Scale bar $=200 \mathrm{~km}$.

Brigadeiro permitirá o registro de novas espécies de anfíbios para essa região.

Com relação aos répteis, também se constatou elevada riqueza quando comparada a estudos realizados em localidades próximas. Assis (1999) registrou 29 espécies de serpentes para a Serra do Cipó, Bertoluci et al. (2009) registrou 18 espécies para a Estação de Pesquisa e Desenvolvimento Ambiental de Peti, Costa et al. (2009b) assinalaram14 espécies de lagartos e anfisbênias para o município de Viçosa, Palmuti et al. (2009) registraram 20 espécies de serpentes para a RPPN Miguel Feliciano Abdala no município de Caratinga, São-Pedro \& Pires (2009) registraram 28 espécies de serpentes para a Serra do Ouro Branco, Silveira et al. (2010) reportam 58 espécies de serpentes para a região de Ouro Preto, Mariana e Itabirito, e Costa et al. (2010) que registraram 34 espécies de serpentes para o município de Viçosa. Do total de espécies de serpentes registradas por Costa et al. (2010), 12 não foram registradas na Serra do Brigadeiro, localizada a aproximadamente $35 \mathrm{~km}$ do município de Viçosa.

Apesar da maioria das espécies de anfíbios e répteis registradas apresentarem ampla distribuição na Mata Atlântica, a ocorrência de espécies de distribuição restrita somada a presença de espécies incluídas em listas de fauna ameaçada de extinção reforça a necessidade de conservação da região da Serra do Brigadeiro. É importante ressaltar que embora estudos de médio a longo prazo já ocorram na região da Serra do Brigadeiro, o uso de métodos complementares de coleta como postos de coleta e armadilhas de interceptação e queda propiciaram aumento significativo do número de espécies conhecido para a região. Em particular para os répteis, verifica-se que a adoção simultânea de métodos diversos somada a esforços amostrais de médio a longo prazo são essenciais para uma amostragem eficiente.

\section{Agradecimentos}

Agradecemos aos três revisores anônimos, Marianna Dixo, Paulo C.A. Garcia e Rômulo Ribon pelas valiosas sugestões no manuscrito. À equipe do Museu de Zoologia João Moojen pelo apoio nas coletas; à Carlos A.G. da Cruz (MNRJ), Henrique C. Costa (MZUFV), Paulo. C. A. Garcia (UFMG) e Ulisses Caramaschi
(MNRJ) pelo auxílio na identificação de espécimes. Ao Departamento de Biologia Animal da Universidade Federal de Viçosa pelo apoio logístico e financeiro. À Fundação de Amparo à Pesquisa do Estado de Minas Gerais (FAPEMIG - CRA-APQ-02370-09), à Organização IDEA WILD, e ao Programa de Pós-Graduação em Biologia Animal da Universidade Federal de Viçosa pelo apoio financeiro. A Coordenação de Aperfeiçoamento de Pessoal de Nível Superior (CAPES) pela bolsa de Mestrado concedida a M.R.M. Ao Conselho Nacional de Desenvolvimento Científico e Tecnológico (CNPq) pela bolsa de Iniciação Científica concedida a A.P.M. A Fundação SOS Mata Atlântica pela autorização de uso de seus shapefiles. Agradecemos especialmente a todos os voluntários dos postos de coleta e funcionários do PESB que colaboraram de forma essencial para esse estudo.

\section{Referências Bibliográficas}

AB'SABER, A.N. 1977. Os domínios morfoclimáticos na América do Sul. Primeira aproximação. Geomorfológica. 52:1-21.

ADALSTEINSSON, S.A., BRANCH, W.R., TRAPE, S., VITT, L.J. \& HEDGES, S.B. 2009. Molecular phylogeny, classification, and biogeography of snakes of the Family Leptotyphlopidae (Reptilia, Squamata). Zootaxa. 2244:1-50.

ALMEIDA, A.P., GASPARINI, J.L, ABE, A.S., ARGÔLO, A.J.S., BAPTISTOTTE, C., FERNANDES, R., ROCHA, C.F.D. \& VAN-SLUYS, M. 2007. Os Répteis Ameaçados de Extinção no Estado do Espírito Santo. In Espécies da Fauna Ameaçadas de Extinção no Estado do Espírito Santo (M. Passamani\& S.L. Mendes). Instituto de Pesquisas da Mata Atlântica, Vitória, p.65-74.

ALMEIDA, A.P., GASPARINI, J.L. \& PELOSO, P.L.V. 2011. Frogs of the state of Espírito Santo, southeastern Brazil - The need for looking at the 'coldspots'. Check List. 7(4):542-560.

ARAÚJO, O.G.S., TOLEDO, L.F., GARCIA, P.C.A. \& HADDAD, C.F.B. 2009. The amphibians of São Paulo State. Biota Neotrop. 9(4): http://www.biotaneotropica.org.br/v9n4/en/abstract?inventory+ bn03109042009. (último acesso em 15/02/2010).

ARGÔLO, A.J.S. 2004. As Serpentes dos cacauais do sudeste da Bahia. Editora da UESC, Ilhéus. 
ASSIS, B. 2009. Riqueza, distribuição temporal e utilização de habitats por anfíbios anuros na Serra do Brigadeiro, Minas Gerais. Dissertação de Mestrado, Universidade Federal de Viçosa, Viçosa.

ASSIS, V.B. 1999 Introdução às serpentes da "Serra do Cipó" (municípios de Santana do Riacho e Jaboticatubas). BIOS 7:69-71.

BAÊTA, D. \& SILVA, D.H. 2009. Amphibia, Anura, Leiuperidae, Physalaemus erythros Caramaschi, Feio and Guimarães-Neto, 2003: Distribution extension. Check List 5(4):812-814.

BAÊTA, D., BERNARDO, P.H., ASSIS, B., SÃO-PEDRO, V.A., DRUMMOND, L. O. \& PIRES, M.R.S. 2005. Geographic distribution: Physalaemus maximus. Herpetol. Rev. 36(2):200.

BERGALLO, H.G., ROCHA, C.F.D., ALVES, M.A.S. \& VAN-SLUYS, M. 2000.A fauna ameaçada de extinção do Estado do Rio de Janeiro. Editora da UERJ, Rio de Janeiro.

BÉRNILS, R.S. \& COSTA, H.C. 2011. Brazilian Reptiles - List of Species. Sociedade Brasileira de Herpetologia. http://www.sbherpetologia.org.br/ checklist/repteis.htm (último acesso em 05/01/2012).

BÉRNILS, R.S., NOGUEIRA, C.C. \& XAVIER-DA-SILVA, V. 2009 Répteis. In Biota Minas: Diagnóstico do Conhecimento sobre a Biodiversidade no Estado de Minas Gerais - Subsídio ao Programa BIOTA MINAS (G.M. Drummond, C.S. Martins, M.B. Greco \& F. Vieira, org.). Fundação Biodiversitas, Belo Horizonte, p.251-278.

BERTOLUCI, J., CANELAS, M.A.S., EISEMBERG, C.C., PALMUTI, C.F.S \& MONTINGELLI, G.G. 2009. Herpetofauna da Estação Ambiental de Peti, um fragmento de Mata Atlântica do estado de Minas Gerais, sudeste do Brasil. Biota Neotrop. 9(1): http://www.biotaneotropica.org.br/v9n1/ en/abstract?inventory+bn01409012009 (último acesso em 15/02/2010).

BIBLIOTECA DO INSTITUTO BRASILEIRO DE GEOGRAFIA E ESTATÍSTICA - IBGE. 2010. Documentação Territorial do Brasil: Araponga, Minas Gerais. http://biblioteca.ibge.gov.br (último acesso em 18/05/2010).

BOKERMANN, W.C.A. 1966. Lista anotada das localidades tipo de anfíbios brasileiros. Serviço de Documentação RUSP, São Paulo.

CADLE, J.E. \& GREENE, H.W. 1993. Phylogenetic patterns biogeography, and the ecological structure of Neotropical snake assemblages. In Species Diversity in Ecological Communities - Historical and geographical perspectives (R.E. Ricklefs \& D. Schutler, eds.), The University of Chicago Press, Chicago, p.281-293.

CANEDO, C.C. 2008. Revisão taxonômica de Hylodes Fitzinger, 1826 (Anura, Hylodidae). Tese de Doutorado, Universidade Federal do Rio de Janeiro.

CANELAS, M.A.S. \& BERTOLUCI, J. 2007. Anurans of the Serra do Caraça, southeastern Brazil: species composition and phenological patterns of calling activity. Iheringia, Sér. Zool. 97(1):21-26.

CARAMASCHI, U. \& CANEDO, C. 2006. Reassessment of the taxonomic status of the genera Ischnocnema Reinhardt and Lütken, 1862 and Oreobates Jiménez-de-la-Espada, 1872, with notes on the synonymy of Leiuperus verrucosus Reinhardt and Lütken, 1862 (Anura: Leptodactylidae). Zootaxa 1116:43-54.

CARAMASCHI, U. \& FEIO, R.N. 1990. A new species of Hyla (Anura, Hylidae) from Southern Minas Gerais, Brazil. Copeia1990(2):524-546.

CARAMASCHI, U., FEIO, R.N. \& SÃO-PEDRO, V.D. 2008. A new species of Leptodactylus Fitzinger (Anura, Leptodactylidae) from Serra do Brigadeiro, State of Minas Gerais, Southeastern Brazil. Zootaxa 1861:44-54.

CARAMASCHI, U. \& RODRIGUES, M.T. 2007. Taxonomic status of the species of Gastrotheca Fitzinger, 1843 (Amphibia, Anura, Amphignathodontidae) of the Atlantic Rain Forest of eastern Brazil, with description of a new species. Bol. Mus. Nac, N.S., Zool. 525:1-19.

CARAMASCHI, U., SILVA, A.M.P.T.C., SILVA, S.P., GOUVÊA, E., IZECKSOHN, E., PEIXOTO, O.L. \& POMBAL, J.P. 2000. Anfíbios. In A fauna ameaçada de extinção do Estado do Rio de Janeiro. Rio de Janeiro (H.G. Bergallo, C.F.D Rocha, M.A.S. Alves \& M. Van-Sluys, eds.). p.75-86
CARDOSO, A.J. \& HADDAD, C.F.B. 1992. Diversidade e turno de vocalização de anuros em comunidade neotropical. Acta Zool. Lilloana 41:93-105.

CARVALHO-JUNIOR, R.R., GRANDINETTI, L., ROCHA, M.D., CALIXTO, V.A.F. \& MACHADO, L.L. 2010. Geographic distribution: Scinax luizotavioi (Santa Barbara Snouted Treefrog). Herpetol. Rev. 41(1):104-105.

CASSIMIRO, J. 2003. Geographic distribution: Tantilla boipiranga (NCN). Herpetol. Rev. 34(3):390.

CASSINI, C.S., CRUZ, C.A.G. \& CARAMASCHI, U. 2010. Taxonomic review of Physalaemus olfersii (Lichtenstein \& Martens, 1856) with revalidation of Physalaemus lateristriga (Steindachner, 1864) and description of two new related species (Anura: Leiuperidae). Zootaxa 2491:1-33.

CECHIN, S.Z. \& MARTINS, M. 2000. Eficiência de armadilhas de queda (pitfall straps) em amostragens de anfíbios e répteis no Brasil. Rev. Bras. Zool. 17(3):729-740. http://dx.doi.org/10.1590/S010181752000000300017

CICCHI, P.J.P., SENA, M.A. PECCININI-SEALE, D.M. \& DUARTE, M.R. 2007. Snakes from coastal islands of State of São Paulo, Southeastern Brazil. Biota Neotrop. 7(2): http://www.biotaneotropica.org.br/v7n2/pt/ abstract?inventory+bn03907012007.

CLEMENTE-CARVALHO, R.B.G., MONTEIRO, L.R., BONATO, V., ROCHA, H.S., PEREIRA, G.R., OLIVEIRA, D.F., LOPES, R.T., HADDAD, C.F.B., MARTINS, E.G. \& REIS, S.F. 2008. Geographic Variation in Cranial Shape in the Pumpkin Toadlet (Brachycephalus ephippium): A Geometric Analysis. J. Herpet. 42(1):176-185. http:// dx.doi.org/10.1670/07-141R1.1

CONSELHO DE POLÍTICA AMBIENTAL - COPAM. 2010. Deliberação Normativa COPAM n ${ }^{\circ}$ 147, de 30 de abril de 2010. Aprova a Lista de Espécies Ameaçadas de Extinção da Fauna do Estado de Minas Gerais. Diário do Executivo do Estado de Minas Gerais, Belo Horizonte, 04 maio 2010.

COSTA, H.C. 2011. Geographic Distribution: Strobilurus torquatus. Herpet. Ver. 42(4):570.

COSTA, H.C., FERNANDES, V.D., VRCIBRADIC, D. \& FEIO, R.N. 2008 Reptilia, Scincidae, Mabuya frenata: Distribution extension. Check List. 4(1):86-88

COSTA, H.C., FERNANDES, V.D., RODRIGUES, A.D. \& FEIO, R.N. 2009a. Lizards and Amphisbaenians, municipality of Viçosa, state of Minas Gerais, southeastern Brazil. Check List. 5(3):732-745.

COSTA, H.C., PINTO, R.R. \& SANTANA, D.J. 2009b. Reptilia, Leptotyphlopidae, Leptotyphlops salgueiroi Amaral, 1954: Distribution extension and geographic variation. Check List. 5(4):783-786.

COSTA, H.C., PANTOJA, D.L., PONTES, J.L. \& FEIO, R.N. 2010. Serpentes do município de Viçosa, Mata Attântica do sudeste do Brasil. Biota Neotrop. 10(3): http://www.biotaneotropica.org.br/v10n3/en/abstract? nventory+bn03610032010.

CRUZ, C.A.G., FEIO, R.N. \& CASSINI, C.S. 2007. Nova espécie de Chiasmocleis Mehely, 1904 (Amphibia, Anura, Microhylidae) da Serra da Mantiqueira, Estado de Minas Gerais, Brasil. Arq. Mus. Nac. 65(1):33-38.

CRUZ, C.A.G., FEIO, R.N. \& CARAMASCHI, U. 2009. Amphibians of Ibitipoca. Editora Bicho do Mato, Belo Horizonte.

CURCIO, F.F., PIACENTINI, V.Q. \& FERNANDES, D. 2009. On the status of the snake genera Erythrolamprus Boie, Liophis Wagler and Lygophis Fitzinger (Serpentes, Xenodontinae). Zootaxa 2173:66-68.

DAYRELL, J.S., NEVES, C.P., CASSINI, C.S. \& FEIO, R.N. 2006 a. Geographic distribution: Zachaenus carvalhoi (Carvalho's Bug-eyed Frog). Herpetol. Rev. 37(3):360.

DAYRELL, J.S., OLIVEIRA, E.F., CASSINI, C.S. \& FEIO, R.N. 2006 b. Geographic distribution: Brachycephalus ephippium. Herpetol. Rev. 37(1):357.

DI-BERNARDO, M. 1992. Revalidation of the genus Echinanthera Cope, 1894 and its conceptual amplification (Serpentes, Colubridae). Comun. Mus. Cienc. Tecnol. PUCRS, Ser. Zool.5(13):225-256. 
DRUMMOND, G.M., MARTINS, C.S., MACHADO, A.B.M., SEBAIO, F.A., ANTONINI, Y. 2005. Biodiversidade em Minas Gerais: um atlas para a conservação. Fundação Biodiversitas, Belo Horizonte.

DRUMMOND, G.M., MACHADO, A.B.M., MARTINS, C.S., MENDONÇA, M.P. \& STEHMANN, J.R. 2008. Listas vermelhas das espécies de fauna e flora ameaçadas de extinção em Minas Gerais. 2nd ed. Fundação Biodiversitas, Belo Horizonte.

DRUMMOND, G.M., MARTINS, C.S., GRECO, M.B. \& VIEIRA, F. 2009. Biota Minas: Diagnóstico do Conhecimento sobre a Biodiversidade no Estado de Minas Gerais - Subsídio ao Programa BIOTA MINAS. Fundação Biodiversitas, Belo Horizonte.

DUNN, E.R. 1942. The American Cacecilians. Bull. Mus. Comp. Zool. 91(6):439-540.

EKEN, G., BENNUN, L., BROOKS, T.M., DARWALL, W., FISHPOOL, L.D.C., FOSTER, M., KNOX, D., LANGHAMMER, P., MATIKU, P., RADFORD, E., SALAMAN, P., SECHREST, W., SMITH, M.L., SPECTOR, S. \& TORDOFF, A. 2004. Key biodiversity areas as site conservation targets. BioScience. 54(12):1110-1118. http://dx.doi. org/10.1641/0006-3568(2004)054[1110:KBAASC]2.0.CO;2

ENGEVIX. 1995. Caracterização do Meio Físico da Área Autorizada para Criação do Parque Estadual da Serra do Brigadeiro: Relatório Técnico Final dos Estudos - 8296- RE-H4-003/94. Instituto Estadual de Florestas, Belo Horizonte.

ETEROVICK, P.C. \& FERREIRA, A.D.M. 2008. Breeding habitat and microhabitat choices by male and female frogs: are there differences between sexes and seasons? Herpetologica, 64(4):397-405. http://dx.doi. org/10.1655/08-025R1.1

ETEROVICK, P.C. \& SAZIMA, I. 2004. Anfíbios da Serra do Cipó, Minas Gerais, Brasil. Editora PUC Minas, Belo Horizonte.

EVERS-JUNIOR, P.R., SILVEIRA, A.L. \& LIMA-FILHO, D.S.. 2006. Geographic distribution: Amphisbaena dubia. Herpetol. Rev. 37(2):240.

FAIVOVICH, J., HADDAD, C.F.B., GARCIA, P.A., FROST, D.R., CAMPBELL, J.A. \& WHEELER, W.C. 2005. Systematic review of the frog family Hylidae, with special reference to Hylinae: phylogenetic analysis and taxonomic revision. B. Am. Mus. Nat. Hist. 294:1-240. http://dx.doi.org/10.1206/0003-0090(2005)294[0001:SROTFF]2.0.CO;2

FEIO, R.N. \& FERREIRA, P.L. 2005. Anfíbios de dois fragmentos de Mata Atlântica do município de Rio Novo, Minas Gerais. Rev. Bras. Zooc. 7(1):121-128.

FEIO, R.N., BRAGA, U.M.L., WIEDERHECKER, H. \& SANTOS, P.S. 1998. Anfíbios do Parque Estadual do Rio Doce (Minas Gerais). Imprensa Universitária UFV, Viçosa.

FEIO, R.N., POMBAL, J.P. \& CARAMASCHI, U. 1999. A new Physalaemus (Anura: Leptodactylidae) from the Atlantic Forest of Minas Gerais, Brazil. Copeia 1999(1):141-145. http://dx.doi.org/10.2307/1447394

FEIO, R.N., RIBON, R. \& COSENZA, B. 2000. Estudos de Fauna na Serra do Brigadeiro, Minas Gerais. In Anais do Simpósio: Contribuições para Elaboração do Plano de Manejo Integrado e Participativo do PESB e Entorno (L.E.F. Fontes, J.C.L. Oliveira, J.B. Gomide, W.A. Barbosa \& P.S.F Neto, coord.), Universidade Federal de Viçosa, Viçosa.

FEIO, R.N., CRUZ, C.A.G. \& IZECKSOHN, E. 2003a. Geographic distribution: Proceratophrys melanopogon. Herpetol. Rev. 32(2):125.

FEIO, R.N., FERREIRA, P.L. \& PANTOJA, D.L. 2003b. Geographic distribution: Bokermannohyla ibitipoca. Herpetol. Rev.34(3):258.

FEIO, R.N., SANTOS, P.S., CASSINI, C.S., DAYRELL, J.S. \& OLIVEIRA, E.F. 2008a. Anfíbios da Serra do Brigadeiro. MG.Biota 1(1):1-32.

FEIO, R.N., SILVANO, D.L., NASCIMENTO, L.B., LEITE, F.S.F., ETEROVICK, P.C., PIRES, M.R.S., GIARETTA, A.A., CRUZ, C.A.G., NETO, A.S. \& SEGALLA, M.V. 2008b. Anfíbios Ameaçados de Extinção em Minas Gerais. In Listas Vermelhas das Espécies de Fauna e Flora Ameaçadas de Extinção em Minas Gerais (G.M. Drummond, A.B.M. Machado, C.S. Martins \& J.R. Stehmann, eds.), 2nd ed. Fundação Biodiversitas, Belo Horizonte, CD-ROM.
FENWICK, A.M., GUTBERLET-JUNIOR, R.L., EVANS, J.A. \& PARKINSON, C.L. 2009. Morphological and molecular evidence for phylogeny and classification of South American pitvipers, genera Bothrops, Bothriopsis, and Bothrocophias (Serpentes: Viperidae). Zool. J. Linnean Soc. 156(3):617-640.

FROST, D.R. 2011. Amphibian Species of the World: an Online reference. Version 5.5. http://research.amnh.org/herpetology/amphibia/index.php (último acesso em 28/04/2011).

FROST, D.R., GRANT, T., FAIVOVICH, J., BAIN, R.H., HAAS, A., HADDAD, C.F.B., DE SÁ, R.O., HANNING, A., WILKINSON, M., DONNELLAN, S.C., RAXWORTHY, C.J., CAMPBELL, J.A., BLOTTO, B.L., MOLER, P., DREWES, R.C., NUSSBAUM, R.A., LYNCH, J.D., GREEN, D.M. \& WHEELER, W.C. 2006. The amphibian tree of life. B. Am. Mus. Nat. Hist. 297:1-370. http://dx.doi. org/10.1206/0003-0090(2006)297[0001:TATOL]2.0.CO;2

FUNDAÇÃO BIODIVERSITAS. 2007. Revisão das Listas das Espécies da Flora e da Fauna Ameaçadas de Extinção do Estado de Minas Gerais: Relatório Final. Fundação Biodiversitas, Belo Horizonte.

FUNDAÇÃO SOS MATA ATLÂNTICA. 2008. Atlas dos remanescentes florestais de Mata Atlântica. Período 2000 a 2005. SOS Mata Atlântica e INPE, São Paulo.

GASPARINI, J.L., ALMEIDA, A.P., CRUZ, C.A.G., FEIO, R.N. 2007. Os Anfíbios Ameaçados de Extinção no Estado do Espírito Santo. In Espécies da Fauna Ameaçadas de Extinção no Estado do Espírito Santo (M. Passamani \& S.L. Mendes, eds.), Instituto de Pesquisas da Mata Atlântica, Vitória, p.75-86.

GUAYASAMIN, J.M., CASTROVIEJO-FISHER, S., TRUEB, L., AYARZAGUENA, J., RADA, M. \& VILÀ, C. 2009. Phylogenetic systematics of Glassfrogs (Amphibia: Centrolenidae) and their sister taxon Allophryne ruthveni. Zootaxa 2100:1-97.

HARTMANN, P.F., HARTMANN, M.T. \& MARTINS, M. 2009a. Ecologia e história natural de uma taxocenose de serpentes no Núcleo Santa Virgínia do Parque Estadual da Serra do Mar, no sudeste do Brasil. Biota Neotrop. 9(3): www.biotaneotropica.org.br/v9n3/en/ abstract?article+bn03609032009 (último acesso em 20/02/2010).

HARTMANN, P.A., HARTMANN, M.T. \& MARTINS, M. 2009b. Ecology of a snake assemblage in the Atlantic Forest of Southeastern Brazil. Pap. Avul. Zool. 49(27):343-360.

HEDGES, S.B., DUELLMAN, W.E. \& HEINICKE, M.P. 2008. New World direct-developing frogs (Anura: Terrarana): Molecular phylogeny, classification, biogeography, and conservation. Zootaxa. 1737(45):1-182.

HEER, T. \& LANARI, L. 1998. Geographic distribution: Lutkenotyphlus brasiliensis (São Paulo Caecilian). Herpetol. Rev. 29(4):244.

HEYER, W.R. 1982. Two New Species of the Frog Genus Hylodes from Caparaó, Minas Gerais, Brasil (Amphibia: Leptodactylidae). Proc. Biol. Soc. Washington. 95(2):377-385.

INTERNATIONAL UNION FOR CONSERVATION OF NATURE- IUCN. 2011. IUCN Red List of Threatened Species. Version 2010.1. Electronic Database. Disponível em: http://www.iucnredlist.org (último acesso em 05/05/2010).

IZECKSOHN, E. 1983. Uma nova especie de Zachaenus Cope, do Estado do Espírito Santo, Brasil (Amphibia, Anura, Leptodactylidae). Arq. Univ. Fed. Rur. Rio J. 5:7-11.

IZECKSOHN, E. \& CARVALHO-E-SILVA, S.P. 2008. As espécies de Gastrotheca Fitzinger na Serra dos Órgãos, Estado do Rio de Janeiro, Brasil (Amphibia, Anura, Amphignathodontidae). Rev. Bras. Zool 25:100110. http://dx.doi.org/10.1590/S0101-81752008000100014

JACKSON, J.F. 1978. Differentiation in the genera Enyalius and Strobilurus (Iguanidae): implications for pleistocene climatic changes in eastern Brazil. Arq. Zool. 30(1):1-79.

KÖPPEN, W. 1948. Climatologia: conunestudio de los climas de latierra. Fondo de Cultura Econômica, México.

LACERDA, J.V.A., ASSIS, B., SANTANA, D.J. \& FEIO. R.N. 2009a. Anurans in bromeliads, Parque Estadual da Serra do Brigadeiro, state of Minas Gerais, southeastern Brazil. Check List. 5(4):800-806. 
LACERDA, J.V.A., ASSIS, B., TOLLEDO, J., LIMA, L.H.R. \& FEIO, R.N. 2009b. Registro de ninho comunal em Physalaemus aff. olfersii (Anura, Leiuperidae), Viçosa, Minas Gerais, Brasil. Rev. Bras. Zoocienc. 11(2):167-170

LACERDA, J.V.A., PEIXOTO, O.L. \& FEIO, R.N. (No prelo). A new species of the bromeligenous Scinax perpusillus group (Anura; Hylidae) from Serra do Brigadeiro, State of Minas Gerais, Southeastern Brazil. Zootaxa.

LAURANCE, W.F. 2009. Conserving the hottest of the hotspots. Biol. Conserv. 142:1137. http://dx.doi.org/10.1016/j.biocon.2008.10.011

LEMA, T. \& ARAUJO, M.L. 1985. Manual de Técnicas de Preparação de Coleções Zoológicas n. 38 - Répteis. Sociedade Brasileira de Zoologia, São Paulo.

LOURENÇO, A.C.C., BAÊTA, D., MONTEIRO, V.S. \& PIRES, M.R.S. 2009a. O canto de anúncio de Scinax luizotavioi (Caramashci \& Kisteumacher, 1989) (Anura, Hylidae). Arq. Mus. Nac. 67(1-2):73-79.

LOURENÇO, A.C.C., NASCIMENTO, L.B. \& PIRES, M.R.S. 2009b. A new species of the Scinax catharinae species group (Anura: Hylidae) from Minas Gerais, Southeastern Brazil. Herpetologica 65(4):468-479. http://dx.doi.org/10.1655/07-088.1

MACHADO, A.B.M., FONSECA, G.A.B., MACHADO, R.B., AGUIAR, L.M.S. \& LINS, L.V. 1998. Livro Vermelho das Espécies Ameaçadas de Extinção da Fauna de Minas Gerais. Fundação Biodiversitas, Belo Horizonte.

MACHADO, A.B.M., MARTINS, C.S. \& DRUMMOND, G.M. 2005. Lista da Fauna Brasileira Ameaça de Extinção - Incluindo as Listas das Espécies Quase Ameaçadas e Deficientes em Dados. Fundação Biodiversitas, Belo Horizonte.

MACHADO, A.B.M., DRUMMOND, G.M. \& PAGLIA, A.P. 2008. Livro Vermelho da Fauna Brasileira Ameaçada de Extinção. Fundação Biodiversitas, Belo Horizonte.

MARTINS, M., BÉRNILS, R., SILVEIRA, A.L., SOUSA, B.M., DRUMMOND, G.M., COUTINHO, M.E., COTTA, G.A., BARBOSA, V., FERNANDES, R., MARQUES, O.A.V. \& MELLO, H.E.S. 2008. Répteis Ameaçados de Extinção em Minas Gerais. In Lista Vermelha das Espécies de Fauna e Flora Ameaçadas de Extinção em Minas Gerais (G.M. Drummond, A.B.M. Machado, C.S. Martins, M.P.

MENDONÇA \& J.R. STEHMANN. 2nd ed. Fundação Biodiversitas, Belo Horizonte. CD-ROM.

MOURA, M.R., GASPARINI, J.L. \& FEIO, R.N. 2008. Amphibia, Anura, Hylidae, Bokermannohyla ibitipoca: Distribution extension, new state record and Geographic distribution map. Check List. 4(4):389-391.

MOURA, M.R., DAYRELL, J.S. \& SÃO-PEDRO, V.A. 2010. Reptilia, Gymnophthalmidae, Micrablepharus maximiliani (Reinhardt and Lutken, 1861): Distribution extension, new state record and geographic distribution map. Check List. 6(3):419-426.

MITTERMEIER, R.A., GIL, P.R., HOFFMANN, M., PILGRIM, J., BROOKS, T., MITTERMEIER, C.G., LAMOREUX, J. \& FONSECA, G.A.B. 2004. Hotspots Revisited. Cemex, México City.

MONTESINOS, R., PELOSO, P.L.V., KOSKI, D.A., VALADARES, A.P. \& GASPARINI, J.L. 2012. Frogs and toads of the Pedra Azul - Forno Grande Biodiversity Corridor, southeastern Brazil. Check List. 8(1):102-111.

MOTT, T., MOURA, M.R., MACIEL, A.O. \& FEIO, R.N. 2011. Morphological variation and geographical distribution of Luetkenotyphlus brasiliensis (Gymnophiona: Siphonopidae). Phyllomedusa. 10(2):153-163.

MOTTA, A.P.; PIRANI, R.M., SILVA, E.T., SANTANA, D.J., MÂNGIA, S \& FEIO, R.N. 2010. New record and distribution extension of Zachaenus carvalhoi Izecksohn 1983 (Anura, Cycloramphidae) in south-eastern Brazil. Herpet. Notes 3:85-86.

MYERS, N., MITTERMEIER, R.A,; MITTERMEIER, C.G., FONSECA, G.A.B. \& KENT, J. 2000. Biodiversity hotspots for conservation priorities. Nature. 430:853-858. PMid:10706275. http://dx.doi. org/10.1038/35002501

NAPOLI, M. 2005. A new species allied to Hyla circumdata (Anura: Hylidae) from Serra da Mantiqueira, Southeastern Brazil. Herpetologica. 61(1):6369. http://dx.doi.org/10.1655/03-41
NAPOLI, M., ENCARNAÇÃO, L., CUNHA, M., ABREU, R. \& HERRERA, J. 2011. Paradoxial geographic distributions, new record, and corrections of Bokermannohyla circumdata (Cope, 1870) and B. caramaschii (Napoli, 2005) (Amphibia: Anura; Hylidae). Herpet. Notes. 4:105-109.

NASCIMENTO, L.B., MIRANDA, A.C.L. \& BALSTAEDT, T.A.M.. 1994. Distribuição estacional e ocupação ambiental dos anfíbios anuros da área de proteção da captação da Mutuca (Nova Lima, MG). BIOS. 2:5-12.

NASCIMENTO, L.B., LEITE, F.S.F., ETEROVICK, P.C. \& FEIO, R.N. 2009. Anfíbios. In Biota Minas: Diagnóstico do Conhecimento sobre a Biodiversidade no Estado de Minas Gerais - Subsídio ao Programa BIOTA MINAS (G.M. Drummond, C.S. Martins, M.B. Greco \& F. Vieira, org.) Fundação Biodiversitas, Belo Horizonte, p.221-248.

NASCIMENTO, L.B., WACHLEVSKI, M. \& LEITE, F. 2005. Anuros. In Serra do espinhaço Meridional (A.C. Silva, L.C.V.F. Pedreira \& P.A.A. Abreu, eds.). O Lutador, Belo Horizonte, p.209-230.

NUSSBAUM, R.A. 1986. The Taxonomic Status of Lutkenotyphlus brasiliensis (Lütken), and Siphonops confusionis Taylor (Gymnophiona: Caeciliidae). J. Herpet. 20(3):441-444. http://dx.doi.org/10.2307/1564509

OLIVEIRA, E.F., TOLLEDO, J. \& FEIO, R.N. 2009. Amphibia, Anura, Physalaemus rupestris Caramaschi, Carcerelli and Feio, 1991: Distribution extension and Geographic distribution map. Check List. 5(4):815-818.

ORRICO, V.G.D. 2010. Amphibia, Anura, Brachycephalidae, Ischnocnema verrucosa Reinhardtand Lütken, 1862: Distribution to northeastern Brazil. Check List. 6(2):246-247.

PALMUTI, C.F.S., CASSIMIRO, J. \& BERTOLUCI, J. 2009. Food habits of snakes from the RPPN Feliciano Miguel Abdala, an Atlantic Forest fragment of southeastern Brazil. Biota Neotrop. 9(1): http://www.biotaneotropica.org.br/v9n1/en/abstract?shortcommunication+bn02209012009 (último acesso em 20/02/2010).

PASSAMANI, M. \& MENDES, S.L. 2007. Espécies da Fauna Ameaçadas de Extinção no Estado do Espírito Santo. Instituto de Pesquisas da Mata Atlântica, Vitória.

PASSOS, P. \& FERNANDES, R. 2008. Revision of the Epicrates cenchria complex (Serpentes: Boidae). Herpetol. Monogr. 22:1-30. http://dx.doi. org/10.1655/06-003.1

PEDRALLI, G.P., GUIMARÃES NETO, A.S. \& TEIXEIRA, M.D.B. 2001. Diversidade de anfíbios na região de Ouro Preto. Ciência Hoje. 30:70-73.

PERES, J., SIMON, J.E., NASCIMENTO, D.S. \& FEIO, R.N. 2010. Amphibia, Anura, Leptodactylidae, Leptodactylus cupreus Caramaschi, Feio and São-Pedro, 2008: Distribution extension. Check List. 6(4):481482.

PIRANI, R.M., MANGIA, S., SANTANA, D.J., ASSIS, B. \& FEIO, R.N. 2010. Rediscovery, distribution extention and natural history notes of Hylodes babax Heyer, 1982 (Anura, Hylodidae) with comments on the biogeographic in southeastern Brazil. South Am. J. Herpet. 5(2):83-88. http://dx.doi.org/10.2994/057.005.0202

POMBAL-JUNIOR, J.P. 1999. Oviposição e desenvolvimento de Brachycephalus ephippium (Spix) (Anura, Brachycephalidae). Rev. Bras. Zool. 16(4):967-976. http://dx.doi.org/10.1590/S010181751999000400004

POMBAL-JUNIOR, J.P., SAZIMA, I. \& HADDAD, C.F.B. 1994. Breeding Behavior of the Pumpkin Toadlet, Brachycephalus ephippium (Brachycephalidae).J. Herpet. 28(4):516-519. http://dx.doi. org/10.2307/1564972

POMBAL-JUNIOR, J.P., PRADO, G.M. \& CANEDO, C. 2003. A New Species of Giant Torrent Frog, Genus Megaelosia, from the Atlantic Rain Forest of Espírito Santo, Brazil (Amphibia: Leptodactylidae). J. Herpet. 37(3):453-460.

POUGH, F.H., JANIS, C.M. \& HEISER, J.B. 2003. A Vida dos Vertebrados. 3nd ed. Atheneu, São Paulo.

PRADO, G.M. \& POMBAL-JUNIOR, J.P. 2008. Espécies de Proceratophrys Miranda-Ribeiro, 1920 com apêndices palpebrais (Anura; Cycloramphidae). Arq. Zool. 39(1):1-85. 
PYRON, R.A., BURBRINK, F.T., COLLI, G.R., OCA, A.N.M., VITT, L.J., KUCZYNSKI, C.A. \& WIENS, J.J. 2011. The phylogeny of advanced snakes (Colubroidea), with discovery of a new subfamily and comparison of support methods for likelihood trees.Mol. Phylog. Evol. 58:329-342. PMid:21074626. http://dx.doi.org/10.1016/j.ympev.2010.11.006

ROCHA, C.F.D., VAN-SLUYS, M., PUORTO, G., FERNANDES, R., BARROS-FILHO, J.D., SILVA, R.R.E., NEO, F.A. \& MELGAREJO, A. 2000. Répteis. In A Fauna Ameaçada de Extinção do Estado do Rio de Janeiro (H.G. Bergallo, C.F.D Rocha, M.A.S. Alves \& M. Van-Sluys, eds.). Editora UERJ, Rio de Janeiro, p.79-87.

RODRIGUES, M.T. 2005. The Conservation of Brazilian Reptiles: Challenges for a Megadiverse Country. Conservation Biology 19(3):659-664. http:// dx.doi.org/10.1111/j.1523-1739.2005.00690.x

RODRIGUES, M.T., CASSIMIRO, J., PAVA, D., CURCIO, F.F., VERDADE, V.K. \& PELLEGRINO, K.C.M. 2009. A New Genus of Microteiid Lizard from the Caparaó Mountains, Southeastern Brazil, with a Discussion of Relationships among Gymnophthalminae (Squamata). American Museum Novitates 3673:1-27. http://dx.doi.org/10.1206/622.1

SABINO, J., \& PRADO, P.I. 2006. Vertebrados. In Avaliação do Estado do Conhecimento da Diversidade do Brasil (T.M. Lewinsohn, org.). Ministério do Meio Ambiente e Programa das Nações Unidas para o Desenvolvimento, Brasília, v.15, p.53-143.

SALLES, R.O.L. \& MACIEL, D.B. 2010. Amphibia, Anura, Cycloramphidae, Zachaenus carvalhoi Izecksohn, 1983: Distribution extension. Check List. 6(3):458-459.

SANTANA, D.J., SÃO-PEDRO, V.A., HOTE, P.S., ROBERTI, H.M., SANT'ANNA, A.C., FIGUEIREDO-DE-ANDRADE, C.A. \& FEIO, R.N. 2010. Anurans in the region of the High Muriaé River, state of Minas Gerais, Brazil. Herp. Notes. 3:01-10.

SANTOS, J.T., OLIVEIRA, E.F., SÃO-PEDRO, V.A., MONTEIROLEONEL, A.C. \& FEIO, R.N. 2009. Amphibia, Anura, Hypsiboas stenocephalus: Distribution extension and Geographic distribution map. Check List 5(1): 27-31.

SANTOS, P.S. 2003. Utilização de Habitats, Padrões de Atividade Reprodutiva e Fenologia Larval de uma Taxocenose de Anuros da Mata Atlântica do Sudeste do Brasil. Dissertação de Mestrado. Universidade Federal de Minas Gerais, Belo Horizonte.

SANTOS, P.S., SILVA, E.T., FELHBERG, B.H.B., SANTOS, M.T.T. \& GARCIA, P.C.A. 2011. Amphibia, Anura, Hylodidae, Megaelosia apuana Pombal, Prado and Canedo, 2003: Distribution extension, new state record and geographic distribution map. Check List7(4):394-396.

SÃO-PEDRO, V.A. \& FEIO, R.N. 2010. Distribuição espacial e sazonal de anuros em três ambientes na Serra do Ouro Branco, extremo sul da Cadeia do Espinhaço, Minas Gerais, Brasil. Biotemas. 23(1): 143-154.

SÃO-PEDRO, V.A. \& FEIO, R.N. 2011. Anuran species composition from Serra do Ouro Branco, southermost Espinhaço Mountain Range, state of Minas Gerais, Brazil. Check List. 7(5):671-680.
SÃO-PEDRO, V.A. \& PIRES, M.R.S. 2009. As Serpentes da Região de Ouro Branco, extremo sul da Cadeia do Espinhaço, Minas Gerais. Ceres. 56(20):166-171.

SILVA, E.T., COELHO, H.L., VIANA, R.S. \& SANTOS, P.S. 2011. Amphibia, Anura, Leiuperidae, Physalaemus feioi Cassini, Cruz and Caramaschi, 2010: Distribution extension. Check List. 7(3):282-284.

SILVANO, D.L. \& SEGALLA, M.V. 2005. Conservação de anfíbios no Brasil. Megadiversidae. 1(1):79-86.

SILVEIRA, A.L. 2004. Geographic distribution: Rhachidelus brazili. Herpetol. Rev. 35(4):412.

SILVEIRA, A.L. 2008. Geographic distribution: Thamnodynastes sertanejo. Herpetol. Rev. 39(2):111.

SILVEIRA, A.L., COSTA, E.R. \& SALLES, L.M. 2004a. Geographic distribution: Lystrophis nattereri. Herpetol. Rev. 35(4):412.

SILVEIRA, A.L., PIRES, M.R.S. \& COTTA, G.A. 2004b. Geographic distribution: Echinanthera melanostigma. Herpetol. Rev. 35(4):410.

SILVEIRA, A.L., PIRES, M.R.S. \& COTTA, G.A. 2004c. Geographic distribution: Leptotyphlops dimidiatus. Herpetol. Rev. 35(4):411.

SILVEIRA, A.L., PIRES, M.R.S. \& COTTA, G.A. 2010. Serpentes de uma área de transição entre o Cerrado e a Mata Atlântica no sudeste do Brasil. Arq. Mus. Nac. 68(1-2):79-110.

SIQUEIRA, C.C., VRCIBRADIC, D., DORIGO, T.A. \& ROCHA, C.F.D. 2011. Anurans from two high-elevation areas of Atlantic Forest in the state of Rio de Janeiro, Brazil. Zool. 29(4):457-464.

SOCIEDADE BRASILEIRA DE HERPETOLOGIA - SBH. 2010. Brazilian amphibians: list of species. http://www.sbherpetologia.org.br (último acesso em 05/05/2010).

TOLLEDO, J., OLIVEIRA, E.F. \& FEIO, R.N. 2009. Amphibia, Anura, Leiuperidae, Physalaemus jordanensis Bokermann, 1967: Distribution extension and Geographic distribution map. Check List. 5(3):422-424.

UETZ, P., HALLERMAN, J., BAKER, B. \& SCHMIDT, J. 2011. TIGR reptiledatabase. http://www.reptile-database.org (último acesso em 20/01/2012).

VELOSO, H.P., RANGEL FILHO, A.L. \& LIMA, J.C.A. 1991. Classificação da vegetação brasileira, adaptada a um sistema universal. IBGE, Rio de Janeiro.

VERDADE, V. \& RODRIGUES, M.T. 2008. Ontheidentity of Cycloramphus jordanensis Heyer, 1983 (Anura: Cycloramphidae). Herpetologica. 64(4):452-457. http://dx.doi.org/10.1655/08-011R2.1

VERDADE, V.K., CASSIMIRO, J. \& RODRIGUES, M.T. 2009. Amphibia, Anura, Cycloramphidae, Zachaenus carvalhoi Izecksohn, 1983 and Z. parvulus (Girard, 1853): Filling gap and geographic distribution map for the genus. Check List. 5(4):755-758.

WILKINSON, M., SAN MAURO, D., SHERRATT, E. \& GOWER, D.J. 2011. A nine-family classification of caecilians (Amphibia: Gymnophiona). Zootaxa. 2874:41-64. 
Herpetofauna da Serra do Brigadeiro

Apêndice 1. Espécies de anfíbios e répteis coletadas no Parque Estadual da Serra do Brigadeiro e entorno, municípios de Araponga, Divino, Ervália, Fervedouro, Miradouro, Muriaé, Pedra Bonita e Sericita, estado de Minas Gerais, Brasil.

Appendix 1. Specimens of amphibians and reptiles collected at the Serra do Brigadeiro State Park and surroundings, in the municipalities of Araponga, Divino, Ervália, Fervedouro, Miradouro, Muriaé, Pedra Bonita and Sericita, state of Minas Gerais, Brazil.

\section{Anfíbios}

Aplastodiscus leucopygius (Araponga: MZUFV 2740-2741, MZUFV 3019-3020, MZUFV 3602, MZUFV 3704-3707, MZUFV 5332, MZUFV 6357, MZUFV 6749, MZUFV 6786, MZUFV 7651, MZUFV 7981; Ervália: MZUFV 7111). Aplastodiscus arildae (Araponga: MZUFV 2716, MZUFV 2742-2743, MZUFV 3021, MZUFV 3063-3064, MZUFV 3285, MZUFV 3601, MZUFV 3659, MZUFV 3846, MZUFV 7111, MZUFV 7652, MZUFV 7670, MZUFV 7988, MZUFV 9873-9876; Ervália: MZUFV 11568). Bokermannohyla caramaschii (Araponga: MZUFV 3313, MZUFV 4306, MZUFV 6645-6646, MZUFV 6824-6825, MZUFV 9770-9771, MZUFV 10198-10199, MZUFV 10224, MZUFV 10333, MZUFV 10338; Ervália: MZUFV 10213, MZUFV 11724, MZUFV 11549-11550; Fervedouro: MZUFV 4834). Bokermannohyla ibitipoca (Araponga: MZUFV 4419, MZUFV 6756-6757, MZUFV 6807-6810, MZUFV 11725). Brachycephalus ephippium (Miradouro: MZUFV 6658, MZUFV 6661-6662, MZUFV 6671). Brachycephalus cf. didactylus (Araponga: MZUFV 7655). Ceratophrys aurita (Araponga: MZUFV 2279, UFMG 348). Chiasmocleis mantiqueira (Ervália: MZUFV 7312-7316 parátipos, MZUFV 10023-10027, MZUFV 10140-10143). Crossodactylus gr. gaudichaudii (Araponga: MZUFV 1866). Dendropsophus decipiens (Araponga: MZUFV 3891, MZUFV 6647-6648, MZUFV 8132, MZUFV 8380, MZUFV MZUFV 10752, MZUFV 10172-10173; Ervália: MZUFV 11695). Dendropsophus elegans (Araponga: MZUFV 2713, MZUFV 10749-10751). Dendropsophus minutus (Araponga: MZUFV 2128, MZUFV 2983, MZUFV 2984-2985, MZUFV 3023, MZUFV 3060, MZUFV 3076, MZUFV 3078, MZUFV 3079, MZUFV 3328-3330, MZUFV 3607, MZUFV 3709, MZUFV 3711, MZUFV 3841, MZUFV 3882, MZUFV 3885-3887, MZUFV 3892, MZUFV 6352, MZUFV 6652, MZUFV 7493, MZUFV 7496; MZUFV 11696; Ervália: MZUFV 11551-11552). Elachistocleis cesarii (Fervedouro: MZUFV 8279-8280). Haddadus binotatus (Araponga: MZUFV 8637, MZUFV 10765; Ervália: MZUFV 6875, MZUFV 6913, MZUFV 8023-8024, MZUFV 11686). Hylodes babax (Araponga: MZUFV 8139-8140, MZUFV 8274). Hylodes lateristrigatus (Ervália: MZUFV 10168-10171, MZUFV 10177, MZUFV 10575, MZUFV 11688). Hypsiboas albomarginatus (Araponga: MZUFV 10186). Hypsiboas albopunctatus (Araponga: MZUFV 1619, MZUFV 3315-3319, MZUFV 10410, Fervedouro: MZUFV 10761). Hypsiboas faber (Araponga: MZUFV 2982, MZUFV 3311, MZUFV 3314, MZUFV 10195). Hypsiboas pardalis (Araponga: MZUFV 3321-3325, MZUFV 3649, MZUFV 3682, MZUFV 3910, MZUFV 7674-7676, MZUFV 10649). Hypsiboas polytaenius (Araponga: MZUFV 2109, MZUFV 2112, MZUFV 2231, MZUFV 2715, MZUFV 2733-2735, MZUFV 3069, MZUFV 3288, MZUFV 3720, MZUFV 3844-3845, MZUFV 6294, MZUFV 6353, MZUFV 6651, MZUFV 6785, MZUFV 7414, MZUFV 7416-7417, MZUFV 7573, MZUFV 7578, MZUFV 7678, MZUFV 7980). Hypsiboas semilineatus (Fervedouro: MZUFV 10480, MZUFV10481-10484). Gastrotheca ernestoi (Araponga: MZUFV 10272). Ischnocnema cf. izecksohni (Araponga: MZUFV 6656, MZUFV 6670, MZUFV 6748, MZUFV 6788, MZUFV 7685-7686, MZUFV 7687, MZUFV 10493; Ervália: MZUFV 7113, MZUFV 10476). Ischnocnema parva (Araponga: MZUFV 10123-10124, MZUFV 10343, MZUFV 10345; Ervália: MUZFV 10036). Ischnocnema verrucosa (Araponga: MZUFV 10340-10341, MZUFV 10520-10521, MZUFV 11457). Ischnocnema sp. (aff. guentheri) (Araponga: MZUFV 409, MZUFV 500, MZUFV 6667, MZUFV 6789, MZUFV 7064). Leptodactylus cupreus (Ervália: MNRJ 47752, holótipo MNRJ 47753-47754 parátipos, MNRJ 50436-50438 parátipos, MZUFV 8015-8016 parátipos). Leptodactylus fuscus (Araponga: MZUFV 1865, MZUFV 3287, MZUFV 10758; Divino: MZUFV 9751; Ervália: MZUFV 11557). Leptodactylus latrans (Araponga: MZUFV 2247). Leptodactylus sp. (aff. mystaceus) (Araponga: MZUFV 1021110212; Fervedouro: MZUFV 11737). Megaelosia apuana (Araponga: MZUFV 236, lote de girino). Luetkenotyphlus brasiliensis (Araponga: MZUFV 2974, MZUFV 3941, MZUFV 10214-10215). Odontophrynus cultripes (Araponga: MZUFV 1628-1630, MZUFV 6669, MZUFV 10126). Phasmahyla sp. (Araponga: MZUFV 036 lote de girinos). Phyllomedusa burmeisteri (Araponga: MZUFV 2224, MZUFV 3332-3333, MZUFV 4308, MZUFV 4761, MZUFV 7989; Ervália: MZUFV 11566). Physalaemus cuvieri (Araponga: MZUFV 2717, MZUFV 2219, MZUFV 2254, MZUFV 3296-3297, MZUFV 3716, MZUFV 3901; Divino: 7172 9753). Physalaemus feioi (Araponga: MZUFV 2211-2212, 2214, 2215, 2217, 2489, 2541, 2724, 2726-2728, 2730, 3298, 3913-3916, 5334, 6715, 2213, 2216, 3299-3300, 3900, 5333, 5335, 6717-6720). Physalaemus maximus (Araponga: MNRJ 18810 holótipo, MNRJ 18811, MNRJ 21736-21738 parátipos, MZUFV 2723, MZUFV 3719, MZUFV 3873-3875, MZUFV 3917, MZUFV 4120-4122, MZUFV 8129, MZUFV 8272-8273, MZUFV 10125). Proceratophrys boiei (Araponga: MZUFV 3609, MZUFV 3679, MZUFV 3718, MZUFV 5310, MZUFV 6143, MZUFV 6657, MZUFV 10204-10205; Ervália: MZUFV 7109, MZUFV 8025). Proceratophrys melanopogon (Araponga: MUZFV 2201-2203, MZUFV 4302-4303, MZUFV 6795, MZUFV 6813, MZUFV 10245; Ervália: MZUFV 8931-8932, MZUFV 10043-10044, MZUFV 10244, MZUFV 10405). Rhinella pombali (Araponga: MZUFV 22452246, MZUFV 3281-3282, MZUFV 3594, MZUFV 6747, MZUFV 10210, MZUFV 10504; Ervália: MZUFV 7140; Ervália: MZUFV 11555). Scinax alter (Fervedouro: MZUFV 10754-10755, MZUFV 10757, MZUFV 10760). Scinax crospedospilus (Fervedouro: MZUFV 10753, MZUFV 10756, MZUFV 10759). Scinax eurydice (Araponga: MZUFV 2012-2013; Ervália: MZUFV 11684). Scinax flavoguttatus (Ervália: MZUFV 9124-9126; MZUFV 10671, MZUFV 10675, MZUFV 11689-11690, MZUFV 11692). Scinax flavoguttatus (Araponga: MZUFV 2115, MZUFV 2121, MZUFV 2230, MZUFV 2738, MZUFV 3289, MZUFV 6358). Scinax luizotavioi (Araponga: MZUFV 2118-2120, MZUFV 3083-3084, MZUFV 3733, MZUFV 8569-8571, MZUFV 8639-8642, MZUFV 8667-8669, MZUFV 8761, MZUFV 9825-9826, MZUFV 10557; Ervália: MZUFV 10028-10029, 10032). Scinax cf. tripui (Araponga: MZUFV 9867-9868, MZUFV 10065, MZUFV 10487; Ervália: MZUFV 8930, MZUFV 10294, MZUFV 10299-10301). Scinax sp. (aff. perereca) (Araponga: MZUFV 10406-10408, MZUFV 10411-10413; Ervália: MZUFV MZUFV 11538, 11681-11683). Scinax sp. (aff. perpusillus) (Araponga: MZUFV 4956, MZUFV 6360, MZUFV 6653, MZUFV 6826, MZUFV 7682; Ervália: MZUFV 11532-11537). Scinax sp. (aff. rizibilis) (Ervália: MZUFV 6864-6873, MZUFV 6907, MZUFV 10005-10019). Thoropa miliaris (Araponga: MZUFV 3302-3310, MZUFV 3595-3599 MZUFV 4123-4127, MZUFV 4953-4954, MZUFV 7618-7619; Ervália: MZUFV 7110, MZUFV 8929, MZUFV 11567). Vitreorana eurygnatha (Araponga: MZUFV 5336, MZUFV 6803, MZUFV 7530-7533, MZUFV 8207-8208, MZUFV 11236-11237). Vitreorana uranoscopa (Araponga: MZUFV 2744-2745, MZUFV 5337-5340, MZUFV 6636-6638). Zachaenus carvalhoi (Araponga: MZUFV 10339, MZUFV 10519, MZUFV 10642, MZUFV 11456; Ervália: MZUFV 10042). 
Moura, M.R. et al.

Apêndice 1. Continuação

Répteis

Amphisbaena microcephala (Araponga: MZUFV 668, MZUFV 800). Bothropoides jararaca (Araponga: MZUFV 1010, MZUFV 1124, MZUFV 1215, MZUFV 1489-1495, MZUFV 1499-1500, MZUFV 1504, MZUFV 1506, MZUFV 1513, MZUFV 1525, MZUFV 15581559, MZUFV 1579, MZUFV 1583-1584, MZUFV 1664, MZUFV 1669, MZUFV 1670-1671, MZUFV 1674-1675, MZUFV 1676-1677, MZUFV 1702-1706, MZUFV 1715, MZUFV 1726-1730; Ervália: MZUFV 1379). Chironius bicarinatus (Araponga: MZUFV 1557, MZUFV 1627, MZUFV 1783; Ervália: MZUFV 1731). Chironius quadricarinatus (Ervália: MZUFV 1757). Ecpleopus gaudichadii (Araponga: MZUFV 606). Echinanthera melanostigma (Araponga: MZUFV 1445, MZUFV 1658). Echinanthera undulata (Araponga: MZUFV 1839). Elapomorphus lepidus (Araponga: MZUFV 1871). Elapomorphus quinquelineatus (Muriaé: MZUFV 1432). Enyalius bilineatus (Ervália: MZUFV 918). Enyalius perditus (Araponga: MZUFV 838, MZUFV 842, MZUFV 849; Ervália: MZUFV 852). Erythrolamprus aesculapii (Ervália: MZUFV 1777). Heterodactylus imbricatus (Araponga: MZUFV 847-848, MZUFV 908). Hydromedusa maximiliani (Muriaé: MZUFV 55). Liophis jaegeri (Muriaé: MZUSP 9064). Liophis miliaris (Araponga: MZUF 989, MZUFV 1526, MZUFV 1580, MZUFV 1673). Liophis poecilogyrus (Araponga: MZUFV 1668). Mabuya dorsivittata (Ervália: MZUFV 805; Fervedouro: MZUFV 919). Micrurus corallinus (Miradouro: MCNR 053). Micrurus frontalis (Araponga: MZUFV 1582, MZUFV 1666, MZUFV 1701). Ophiodes striatus (Araponga: MZUFV 667). Oxyrhopus clathratus (Araponga: MZUFV 1563, MZUFV 1657). Oxyrhopus guibei (Miradouro: MCNR 037). Oxyrhopus petola (Araponga: MZUFV 1587; Muriaé: MZUFV 1389). Oxyrhopus trigeminus (Miradouro: MCNR 082). Philodryas olfersii (Araponga: MZUFV 1046, MZUFV 1578; Muriaé: MZUFV 1683). Sibynomorphus neuwiedi (Araponga: MZUFV 1496-1498, MZUFV 1560-1561, MZUFV 1567-1568, MZUFV 1577, MZUFV 1661-1663, MZUFV 1667, MZUFV 171, MZUFV 1517). Sibynomorphus mikanii (Muriaé: MZUFV 1395, MZUFV 1723; Ervália: MZUFV 1681). Taeniophallus affinis (Araponga: MZUFV 1294, MZUFV 1581). Thamnodynastes cf. nattereri (Araponga: MZUFV 988, MZUFV 1295, MZUFV 1444, MZUFV 1576). Tricheilostoma salgueiroi (Muriaé: MZUFV 1397, MZUFV 1519). Tropidodryas striaticeps (Araponga: MZUFV 1556, MZUFV 1730). Tropidurus torquatus (Araponga: MZUFV 851; Ervália: MZUFV 1065-1069). Urostrophus vautieri (Araponga: MZUFV 907). Xenodon merremii (Araponga: MZUFV 1501, MZUFV 1612, MZUFV 1660, MZUFV 1672, MZUFV 1697, MZUFV 1698, MZUFV 1707). Xenodon neuwiedii (Araponga: MZUFV 808, MZUFV 1122, MZUFV 1520, MZUFV 1665). 
Herpetofauna da Serra do Brigadeiro

Apêndice 2. Dados da literaturas utilizados para elaboração dos mapas de distribuição geográfica apresentados nas Figuras 10 a 12.

Appendix 2. Literature data utilized to make the geographic distributions maps presented in the Figures 10 to 12.

\begin{tabular}{ll}
\hline \multicolumn{1}{c}{ Táxon } & \multicolumn{1}{c}{ Registros de literatura } \\
\hline Amphibia, Anura & \\
Brachycephalus ephippium & Bokermann (1966), Pombal-Junior et al. (1994), Pombal-Junior (1999), \\
& Dayrell et al. (2006b), Clemente-Carvalho et al. (2008) \\
Bokermannohyla caramaschii & Napoli (2005), Napoli et al. (2011), Almeida et al. (2011), Montesinos et al. (2012) \\
Bokermannohyla ibitipoca & Caramaschi \& Feio (1990), Feio et al. (2003b), Moura et al. (2008), Montesinos et al. (2012) \\
Gastrotheca ernestoi & Caramaschi \& Rodrigues (2007), Izecksohn \& Carvalho-e-Silva (2008), Siqueira et al. (2011) \\
Hylodes babax & Heyer (1982), Canedo (2008), Assis (2009), Pirani et al. (2010) \\
Hylodes lateristrigatus & Bokermann (1966), Canedo (2008) \\
Ischnocnema verrucosa & Caramaschi \& Canedo (2006), Orrico (2010), Almeida et al. (2011), Montesinos et al. (2012) \\
Leptodactylus cupreus & Caramaschi et al. (2008), Peres et al. (2010), Almeida et al. (2011) \\
Megaelosia apuana & Pombal-Junior et al. (2003), Verdade \& Rodrigues (2008), Santos et al. (2011), \\
Physalaemus maximus & Almeida et al. (2011), Montesinos et al. (2012) \\
Proceratophrys melanopogon & Baêta et al. (2005), São-Pedro \& Feio (2010, 2011) \\
Zachaenus carvalhoi & Feio et al. (2003a), Prado \& Pombal-Junior (2008), Siqueira et al. (2011) \\
Reptilia, Squamata & Izecksohn (1983), Dayrell et al. (2006a), Verdade et al. (2009), Motta et al. (2010), \\
Echinanthera undulata & Salles \& Maciel (2010), Almeida et al. (2011) \\
Echinanthera melanostigma &
\end{tabular}

